\title{
OPIATES, CRIMINAL BEHAVIOUR, AND METHADONE TREATMENT
}

Jeremy Coid, Andrea Carvell, Zelpha Kittler, Andrew Healey, and Juliet Henderson 
This study was funded from a Grant from the Home Office. Addition support was provided by the Tower Hamlets Community Services NHS Trust.

Jeremy Coid ${ }^{1 .}$ M.D., FRCPsych, Professor of Forensic Psychiatry.

Andrea Carvell ${ }^{1 .}$, Research Fellow

Zelpha Kittler ${ }^{1 .}$, M.R.C.Psych, Clinical Research Fellow

Andrew Healey ${ }^{2}$, B.A. MSc, Research Officer

Juliet Henderson ${ }^{2}$, B.A. MSc, Research Assistant

Addresses:

1. Forensic Psychiatry Research Unit, St. Bartholomew's Hospital, William Harvey House, 61 Bartholomew Close, London EC1A 7BE

2. Personal Social Services Research Unit, Department of Social Policy, The London School of Economics and Political Science, Houghton Street, London WC2A 2AE 
Crime and Opioid Dependence: changes after entering a methadone treatment programme expenditures on illegal drugs and a fall in criminal earnings? 


\section{SUMMARY}

\section{Opiates and Crime - A Review}

This study examines the associations between opiate dependence and criminal behaviour and examines the effectiveness of methadone treatment in reducing both opiate misuse and criminal activities in a sample of treatment-seeking subjects attending NHS treatment services in a socio-economically deprived area of inner London. The report initially reviews the previous literature which confirms a strong association between opiate misuse and crime but notes that there is a continuing debate between researchers. Some argue that heroin use causes crime, in the sense that addicts can be driven to commit crimes to finance their drug habits, thereby avoiding symptoms of withdrawal. Others argue that this position is incorrect and that criminal activities more often predate use of opiates and that dependence on opiates should be construed as taking place within the context of a generally criminal and antisocial lifestyle. However, neither position is likely to be an all-embracing explanation as opiate addicts are highly heterogeneous. For some, the "causal" hypothesis is correct. However, changes in populations of opiate using-individuals over time means that most researchers will sample subjects who were engaged in delinquency prior to their opiate misuse and where their dependence occurs in the context of their antisocial lifestyle. However, the review identifies a series of studies that have managed to categorise opiate misusers on a cross-sectional basis and have indicated small subgroups where the causal hypothesis applies. Furthermore, when conceptualised on a longitudinal basis, it may not be entirely appropriate to conceptualise the criminal activity of opiate misusers as uniquely related to one or other hypothesis. Criminal addicts can shift from one pattern to another over the life course. It is argued that the debate should now move on to identifying what are the most appropriate interventions for different categories of opiate misuser and at different stages of their drugs and criminal careers.

\section{Criminal Behaviour in Treatment-seeking Opiate Addicts}

A descriptive study of 221 opiate dependent treatment-seeking subjects, revealed that the majority were male, white, and confirmed that for the majority their criminal activities had preceded their first use of opiates. Virtually all admitted to previous criminal activities, but a small subgroup had managed to support their opiate dependence in the six months before presentation to the treatment service by legal means. However, $85 \%$ obtained money to support their drug habit through various illegal means, most frequently theft (mostly 
shoplifting), followed by drug dealing, frauds and deceptions, and burglary. Of a subgroup officially in work, over half were illegally claiming unemployment benefit. A subgroup were sex workers or engaged in the sex industry, and a further small subgroup had engaged in serious crimes of robbery against the person and robberies of building societies or post offices. A "trade off" was observed in the subjects' choice between high risk criminal activities with high potential rewards but longer prison sentences if convicted, such as burglaries and muggings, and more frequent crimes with lower yields such as shoplifting. Subjects had very low annual incomes from legal sources and the average subject had spent over 10,000 a year on opiates obtained from illicit sources. However, the true cost of their criminal activities was substantially higher. The extensive criminal activities of these subjects contributed to an extensive underground criminal economy in the area where the study took place.

Subjects had multiple problems and their early histories were characterised by emotional deprivation, with high rates of criminality and drug use among family members. Many engaged in high risk activities for Hepatitis and HIV and many had a range of health problems associated with their opiate abuse and injecting. Over half had experienced co-morbid mental disorder over their lifetime, most significantly alcohol dependence and episodes of depressive illness. Over half had a co-morbid personality disorder, predominantly Antisocial Personality Disorder.

\section{Reductions in Crime and Drug Use following Methadone Treatment}

The effectiveness of a methadone treatment programme in reducing criminal activity was studied in a subgroup of 81 of the 221 subjects in the previous descriptive study. These subjects were entered into the study at a later phase of the study. Treatment consisted of substitution of illicitly obtained opiates with prescribed methadone but administered on a slow reduction basis. Comparisons were carried out between measures obtained from the 81 subjects regarding self-reported criminal activities and drug misuse in the previous one month and six months prior to presentation for treatment. Subjects were followed up at the one month and six month points after they had been prescribed methadone. The same questions regarding their self-reported activities were then administered. This study confirmed the effectiveness of the methadone treatment programme in reducing both opiate misuse and a range of criminal behaviours at 6 months. Criminal behaviour of the subjects had been 
substantially related to obtaining money for their drugs - the more crimes that they committed the more drugs they could purchase. The rate of their criminal activity was influenced, however, by previous involvement in crime, especially acquisitive offending. The criminal activities of the sample also appeared to be independently driven by both the cost of their drug habit and their previous history and experience of acquisitive crime. Overall use of heroin decreased by $50 \%$. There was a significant reduction in expenditure on drugs, injecting behaviour, and high-risk behaviours involving sharing of syringes and needles. Expenditure showed a threefold reduction. However, there were no changes in a range of other illicit drugs misused. But there were no increases in the use of other drugs and subjects had not substituted these for heroin. There was a significant increase in legally obtained income during the treatment phase, certain subjects having found work.

Burglaries and theft were reduced by a half and the impact on drug-dealing was even greater. However, there were no changes in the level of fraudulent activities, muggings, sex work, or

signing on for Department of Social Security Benefits whilst simultaneously working. Treatment appeared to have had its greatest impact on those individuals who were most heavily involved in crime. This important finding did not suggest that methadone treatment is most effective with subjects who are thought to be "easy" to treat and not engaged in crime. Retention in the treatment programme was confirmed as a highly important factor, strongly and independently associated with both reduction in illicit use of opiates and reduction in criminal activities.

\section{Economic Evaluation}

An economic evaluation was carried out on the effectiveness of methadone treatment on the sample of 81 subjects. Subjects who remained on methadone treatment for longer periods were found to have better outcomes over the six month follow-up period. If an opiate addict were to be maintained in methadone treatment for six months, statistical modelling predicted that expenditure on street drugs would fall by $£ 35$ per day on average over the period of the study. Based on the $95 \%$ confidence intervals from the regression equations, this would lead to an average fall in monthly criminal earnings of between $£ 714$ and $£ 2,626$ over the six months study period. The results support the view that, in the short-term, methadone treatment may be a viable policy tool for intervening in drug use and drug-

related crime. 


\section{OPIATES AND CRIMINAL BEHAVIOUR - A REVIEW OF THE LITERATURE}

Jeremy Coid 
It is widely accepted that there is a relationship between opioid use and crime, and many studies have found evidence for the relationship (Gandossy et al 1980, Inciardi 1981, Collins et al 1982, Hunt et al 1984, Elliott et al 1985, Johnson et al 1985, Leukefeld 1985, Nurco et al 1985, Hammersley \& Morrison 1987, Hammersley et al 1989, 1990). However, there is debate over the underlying explanations of the opioid-crime association. This has contributed to the controversial nature of prescribing opioids to addicts in the community. Two explanations for the link between addiction and crime continue to influence public and professional attitudes towards these treatment procedures: Firstly, that opioid users commit non-drug crimes for reasons entirely unrelated to their drug taking, and their criminal behaviour is usually observed to pre-date or concur with their involvement in drug use. Secondly, that addicts commit crime out of "economic necessity" in order to finance their habit. The first explanation would at first appear incompatible with the argument that prescribing opioids to addicts will reduce their criminal behaviour. (Proponents of this argument largely ignore the effectiveness of methadone treatment studies). But if addicts do commit crime as an economic necessity, it could follow that a supply of opioids on prescription will reduce their need to offend to finance their drug use. Unfortunately, differences between the proponents of these two positions on the opioid-crime association remain unresolved.

This review will examine the current literature on the associations between opiate use and criminal behaviour.

\section{Heroin Epidemics}

Some researchers have used a model of "epidemic" spread of heroin use (De Alarcon 1969, De Alarcon 1972, Hughes et al 1972, Dupont 1971, Dupont \& Greene 1973, Hughes et al 1971, Hughes \& Crawford 1972, Hughes et al 1972, Hunt 1973). This concept places heroin in the context of epidemic spread as the "disease producing" agent, incorporating the idea of drug availability, including cost and quality of heroin, as aetiological factors in facilitating spread, and offers medical interventions to control these epidemics (Hughes \& Rieche, 1995). Epidemiologists have been influenced by previous sociological theories of deviance when seeking to understand the spread of heroin. For example, early research by Finestone (1957) described the social status and subcultural role of the heroin addict as attractive to black teenagers. Other social researchers elaborated on the excitement of the heroin addicts' 
lifestyle which offered social explanations for the spread of heroin to underprivileged urban youth (Preble \& Casey 1969, Agar 1973, Sutter 1966). Cloward and Ohlin (1960) described how adolescent gangs in the USA provided social organisations through which heroin use could spread. However, by the mid 1970's, Hughes \& Rieche (1995) argued that the epidemiological concept had been replaced by an economic concept of "supply and demand" as the accepted national and international framework for substance abuse programme planning. Whilst little research was directed at the supply - demand concept itself, this framework encouraged planners to direct resources and interventions to reduce the supply side, focusing against opium poppy production, international trafficking, and local drug distribution networks. Resources and interventions to reduce demand for heroin in the USA therefore concentrated mainly on preventive education, treatment, and the incarceration of offending opiate users.

\section{Heroin Use in the USA}

In a review of the literature, Hughes \& Rieche (1995) have described the US government's epidemiologic monitoring system for substance abuse. This has multiple components, including the drug abuse warning network of reporting emergency rooms, annual surveys of high school and post-high school youth, annual national household surveys of substance abuse, drug use forecasting, community epidemiology workgroups measuring epidemiological trends in drug abuse, and a series of law enforcement systems monitoring changes in drug associated crime. The aim of these monitoring systems is to identify any major increase in the incidence of heroin use in the USA at a relatively early stage. This is considered important because early stages of heroin epidemics are often hidden and can be full-blown by the time health and other agencies become aware of the size of the affected population and are required to respond. Nevertheless, despite a surveillance system with the potential for identifying large scale heroin spread, the authors concede that treatment and law enforcement systems in the USA are not organised to respond rapidly to contain an epidemic.

Two serious epidemics were previously experienced in the USA, the first beginning after World War II, with the highest incidence occurring in the late 1940's and early 1950's (Hughes et al, 1972), and the second beginning in the late 1960's, with the highest incidence occurring between 1971 and 1977 (Gfroerer \& Brodsky, 1992). These were responded to primarily through law enforcement, although the second epidemic did bring about a 
significant expansion of community-based treatments. In both epidemics, the rate of spread of heroin began to slow when purity of heroin began to decline and cost began to increase. The observed relationship between cost, purity, availability, and tendency to spread to new users led to the adoption of the "supply-demand" marketing concept by agencies responsible for heroin control. Although there was a further epidemic of cocaine abuse in the mid 1980's, this was not associated with simultaneous spread of heroin to a large number of new users. But in 1994, the National Drug Control Strategy reported the planting of opium poppies in Columbia and Peru by well established cocaine traffickers, fuelling concerns that large quantities of low cost, high purity heroin could be introduced into North America leading to another large scale heroin epidemic.

Overall national indicators of heroin use in the USA suggested that by the mid 1990's there was an endemic pattern of use. Use appeared widespread, but the incidence of new cases appeared relatively low. It was estimated that there were 1.9 million individuals who had ever used heroin by the National Household Survey on Drug Abuse in 1985 and in 1988, and in 1992 roughly the same number were estimated. There was also evidence of a reduction in the number of casual and heavy heroin users, dropping from 1988 levels in 1991. However, there was an increase in the number of heroin-related presentations to emergency rooms. But this appeared to be accounted for by older, chronic heroin users. Between 1975 and 1993 no increases were observed amongst high school children. Trends in cost and purity of seized heroin showed considerable variability between 1987 and 1992, but with no clear evidence of increase or decrease in heroin availability. However, by late 1993 there were local indicators causing concern, for example, an increased number of young persons being introduced to heroin snorting, some to "come down" after smoking crack cocaine, with an increase in the proportion of heroin treatment admissions and increase in purity of heroin in certain cities. Nevertheless, Hughes and Rieche (1995) cautioned against generalising to the entire country from heroin trends observed in one or a few US cities or states.

\section{Heroin Use in Britain}

During the early 1950's, both drug availability and activity by official agencies was minimal, with the 1961 Brain Committee reporting that drug supply was "almost negligible" (Ministry of Health, 1961). However, the number of addicts known to the Home Office showed a modest rise from the 1960 figure of 454 to 753 by 1964. In 1967, quantities of "Chinese" 
heroin were seized by the police. It was also thought that a small minority of private medical practitioners had contributed to the changing use of drugs in London. Between 1973 and 1977, only 4,607 new addicts came to official notice and during much of the 1970's the use of opiates appeared to be relatively stable, with low rate of growth and localised concentration, predominantly in the London area. However, during the 1980's there was a profoundly different picture as a result of political shifts in the golden crescent region of South West Asia (Iran, Pakistan, and Afghanistan), and the opening of new supply routes. Cheap, high purity heroin became readily available and, with a tighter prescribing policy adopted by the new Drug Dependency Units in the UK, together with police success in dealing with the supply of Chinese heroin, these new sources of availability stimulated the market (Mott, 1991). A crucial factor in the spreading popularity of heroin over the next few years was that the new imports could be smoked ("chasing the dragon"), snorted, or sniffed. These methods overcame a deep psychological barrier that using needles posed for many individuals. For some, familiarity with sniffing amphetamine or cocaine made the move from one drug to another easier (Hartnoll et al, 1984). Over the 1980's, the purity of heroin increased in the UK and became cheaper in real terms, so that between 1981 and 1985, Home Office notifications of "new addicts" came to 21,030 (Giggs, 1991). The spatial distribution around the country represented an unanticipated spread and South (1997) observed that many commentators adopted an "epidemic" analogy at this time. It was estimated that between 74,000 and 112,000 people in the UK were dependent on opiates at sometime in 1989 and by this time "new waves" of heroin addiction were observed in areas beyond London, for example, the Glasgow metropolitan area and certain areas of Merseyside.

South observed considerable official and popular concern over "crack" as a result of alarmist warnings from visiting representatives from the USA. But by the late 1980's crack use in Britain appeared to be limited. By the early 1990's, South (1997) describes Britain as having developed a "polydrug" culture with a pattern of mixing drugs for different effects, or moving to alternatives from the preferred drug of choice in times of scarcity. A large survey of a cohort of teenagers in North West England (Parker et al, 1996) suggested a pattern of “normalisation" of drug use. By the late 1980's, and at the start of 1990's, heroin availability was still high but there were some signs that its use was in decline. However, there was then a further resurgence, with record seizures by the police in 1995 but having no discernible effect on street price. The drug now seemed to appeal to three new types of users: crack users 
who self-medicated with heroin, young socially deprived users, and individuals who had graduated to heroin from using other recreational drugs in the "dance scene" (Shapiro, 1996). However, by the late 1990's, South (1997) perceived heroin use largely within the context of widespread availability of a variety of drugs in the UK and where use was shaped by factors such as local supply, peer group pressure and influence, context of use, preferred styles of consumption, and other factors influencing purpose or intent of use.

\section{Drug Use and Crime in the USA}

What continues to remain unclear is whether there is a direct relationship between "epidemics" of heroin use and subsequent crime "waves". Although it would at first appear highly likely that a substantial rise in the number of drug users, particularly those who become addicted, would lead to an increase in the number of crimes committed to obtain money for drugs, multiple factors can intervene. Furthermore, establishing a causal link could be influenced by a time lag occurring between heroin use and increase in criminal activity.

Nevertheless, there is an undeniable statistical relationship between opiate use and crime. Nurco et al (1985) observed a high prevalence of both non-violent and violent crime amongst substance abusers in many US studies, particularly heroin and cocaine abusers. Similarly, studies of prisoners, parolees, probationers, and arrestees have all demonstrated that lifetime and recent illicit drug use were high when compared with the general population. When focusing specifically on the repetitiveness of addicts' crimes, studies by both Ball et al (1982) and Inciardi \& Chambers (1972) have indicated that narcotic addicts are frequently involved in criminal behaviour and on a daily basis. Consequently, they commit hundreds, or even thousands, of offences per individual during their addiction careers. Nurco et al (1985) concluded that the majority of addicts in the USA are habitually involved in the commission of crime and that their involvement is frequent, persistent, and widespread in scope.

Specific associations between opiates and crime would thus appear to be evident whether it is persistent offenders or chronic drug abusers who are studied. Furthermore, research in the USA suggests that arrested narcotic drug users are just as violent as other arrestees, if not more so (Chaiken \& Chaiken 1982, US Department of Justice 1983, Wish et al 1980). Studies of career criminals have also found that the majority of the most violent were heroin users and that most of these had high-cost heroin habits (Chaiken \& Chaiken 1982, Chaiken 
1983). Thus the overall magnitude of the crime problem associated with narcotic addiction is not only attributable to the frequency with which addicts commit "victimless" crimes and lesser offences, but also to the fact that many of their offences are serious and highly destructive (Nurco \& DuPont 1977, Nurco et al 1979). Within this context, a subgroup of addicts appear especially involved in crime, and amongst U.S. criminals in general, those who have abused narcotics may represent an especially recidivist subgroup. In a study of incarcerated criminals in three US states, Chaiken \& Chaiken (1982) found that serious and frequent offenders, who they described as "violent predators", had used several types of "hard" drugs, used them heavily, and had started using them as juveniles. Their use of drugs and their criminal careers usually began around the same time.

Ball et al (1983) found that the main type of crime committed by narcotic addicts was theft, including theft of goods and money from stores, burglary of homes and businesses, and other forms of theft, followed by dealing drugs or working in the drug business. Confidence tricks and forgery accounted for $8 \%$ of crimes whilst violent crimes (mostly robbery and assault) made up 2\%. An additional group of other criminal activities included pimping, fencing stolen goods, and illegal gambling. Although involved in a wide variety of offences, many individuals tended to specialise in only one or two types of crime whilst addicted. Ball et al (1983) found that over two-thirds of addicts' crimes consisted of a single type, pursued as the main or most common criminal activity, usually theft, drug dealing, or robbery. However, this was usually supplemented by additional categories of crime.

One further observation has important implications for research into the association between drugs and crime. Official records, including criminal convictions and arrest records, seriously underestimate the amount of crime committed by opiate addicts. Ball et al (1982) estimated that fewer than $1 \%$ of crimes committed by heroin addicts in a Baltimore study had resulted in arrest. Similarly, the arrest data was biased both with respect to type of offences committed and frequency of offences. Certain offences (e.g. crimes of violence) were more likely to result in arrest. However, the overall probability of arrest decreased for those addicts who had the highest crime rates. Interviewing techniques which use self-reported criminal behaviour are now considered to be more accurate. Nurco et al (1985) have recommended using a measure which includes the rate of offending per unit of time for a given population at risk. 
Besides the impact on society of acquisitive and predatory crimes, if narcotic addicts in the USA also engage in hundreds of drug sales and other drug distribution offences (Ball et al 1983, Chaiken \& Chaiken 1982, Johnson et al 1983, Moore 1977), then this has an additional and serious impact on society. This includes the establishment of an underground economy, the perpetuation of narcotic abuse by initiating use in newly recruited individuals, and allowing and encouraging the continued use of illegal drugs. Drug distribution is closely associated with homicides in the USA and other acts of violence associated with profit-taking from the distribution of drugs (Nurco et al, 1985). This phenomenon is now increasingly observed in the UK.

\section{Drug Use and Crime in the UK}

The National Treatment Outcome Research Study (NTORS) investigated treatment outcome among the largest sample of drug misusers studied so far in the UK (Gossop et al 1998). Subjects had been admitted to programmes selectively representative of the main treatment modalities available. Between March and July 1995, 1,075 subjects were recruited by 54 participating treatment programmes. These individuals presented with extensive, chronic and serious problems related to their use of drugs and alcohol. The most common drug problem was long-term opiate dependence, often in conjunction with polydrug and / or alcohol problems. High rates of criminal behaviour were reported prior to admission and a total of 70,728 separate crimes were reported by $61 \%$ of the cohort during the three months prior to study. When drug selling offences were excluded, 31,575 offences were reported, with 52\% reporting at least one such offence. The most commonly reported offence was shoplifting, with more than a third having shoplifted in the previous 90 days. Although more serious crimes such as burglary and robbery were less common, these were still reported by $12 \%$ and $5 \%$ of the cohort respectively.

These high rates of criminal behaviour were reflected in high rates of contact with the Criminal Justice System. Almost three quarters of the cohort had been arrested in the previous two years on a total of 4, 466 occasions. Although many arrests were for drug-related offences, arrests for shoplifting offences were also common, accounting for $42 \%$ of all arrests. It was concluded that this level of criminality, and the associated demands on the Criminal Justice System, represented a considerable burden on UK society (Gossop et al, 
1998).

At one year follow-up of 769 subjects (72\%), 753 successfully completed a research interview. A further $16(1.5 \%)$ had died. The high rates of criminal behaviour recorded at intake were substantially reduced at 1 year follow-up. These reductions were found both in the number of crimes committed, the number of clients engaged in criminal activities, and the improvement found both among subjects who had been treated in residential and in community settings. The most common form of continuing criminal activity at one year were crimes involving some form of theft, but there were substantial reductions. For subjects in residential services, the percentage committing any crime fell from $64 \%$ at intake to $39 \%$ at follow-up. Among the community methadone subjects, the rate fell from $62 \%$ to $40 \%$. This reduction in criminal behaviour was reflected in the reduced number of criminal acts at follow-up. Among residential clients, the total number of crimes in the previous three months fell from 13,506 to 4,827 . Among community methadone clients, the total number of criminal acts fell from 25,999 to 6,718 .

Previous research has suggested that there are local variations in British heroin use. Criminality amongst new users of heroin seems to be widespread, but there is evidence that criminality may also vary locally. Pearson (1987) interviewed heroin users in several areas of the North of England in a qualitative study which suggested that heroin users in different areas had different local drug-using traditions with respect to methods of ingestion (smoking, snorting or injection) and appropriate drug-related behaviour. He observed that heroin use with little or no crime was possible, especially if the user was willing to restrain use to within affordable limits or develop some other money-making scheme. However, some users reported being unexpectedly overtaken by heroin dependence, describing a shift (without really noticing) from heroin as a habit which they enjoyed and could control, to use which they could no longer control and which was no longer enjoyable. In this study, users beliefs, expectations, and traditions impacted both on their drug use and criminality.

A study of opioid use and crime in the Wirral, Merseyside, found a rapid rise in crime, especially burglary, mirrored in the rapid rise in the number of heroin users (Parker \& Newcombe 1987, Parker et al 1986). It was of interest that neither phenomena occurred in other neighbouring areas during the same period. Drug users in general and opioid users in 
particular were extremely prevalent in this sample of known offenders. This overrepresentation was primarily due to a substantial subgroup of opioid-using burglars. However, $35 \%$ of registered opioid users who had been convicted of non-drug crimes did not have a criminal record prior to their opioid use. Parker \& Newcombe (1987) concluded that the "economic necessity" explanation did apply to some heroin users, whereas for others (those already criminal) the "deviant career" explanation applied. They interpreted the epidemic of heroin use in the Wirral as being due to a particular set of social and historical factors which could vary in different places and at different times.

\section{The Causal Relationship between Drugs and Crime}

Nurco (1987) has been among the strongest proponents of the causal relationship between opioid use and crime, i.e. that drug users commit more crimes to finance their habit during periods of heavy drug use or "addiction", a view commonly put forward by the media. Nurco et al (1985) argued that a uniform finding in several studies has been that frequency of narcotic use is generally associated with a higher crime rate, also that the high prevalence and diversity of criminal involvement on the part of these individuals is largely for the purpose of supporting the use of drugs. Johnson et al (1983) demonstrated that the heaviest users of heroin were more likely to be classified as serious offenders. Another research group (Kruze et al, 1981) found that an "expensive" drug habit was at least a partial explanation for income-generating crime, and that using heroin and cocaine more than once a day predicted very high levels of illegal income. Further examination of these data revealed that, whereas low-use levels were generally supportable without recourse to illegal activities, frequent daily use rarely was. Similarly, after classifying a sample of prison and jail inmates into "addicted heroin users", "non-addicted heroin users", "non-heroin drug users" and "non-drug users", Chaiken \& Chaiken (1982) found that the addicted heroin users had markedly higher levels of criminal activity than the non-heroin drug users.

On the basis of longitudinal studies, Nurco et al (1985) argued that heavy drug users are not merely individuals who are innately prone to becoming involved in criminal activity. Followup studies of addicts' careers have demonstrated high rates of criminality consistently associated with their periods of addiction, but with markedly lower rates found during nonaddiction periods, suggesting a causal interpretation of the relationship between the two (Ball et al 1981, Ball et al 1982, Ball et al 1983, Shaffer et al 1984). Additional research has 
demonstrated remarkable continuity in high crime rates, measured using mean number of crime days per year, throughout addiction careers (Ball et al, 1983).

\section{Co-occurence of Opiate Use and Crime}

Desland \& Batey (1990) argued that causality models which postulate that heroin use causes crime have "proven unworkably simplistic". Several authors have proposed that heroin use and crime essentially co-occur, and for a variety of reasons, concluding that heroin addiction does not necessarily compel heroin users to commit crimes. Alternative explanations include: that heroin use and crime co-occur because individuals who become criminals are also likely to become drug users (Elliott \& Huizinga, 1984), because both activities are esteemed in local deviant subcultures (Preble \& Casey 1969, Weppner 1982, Faupel 1988), because crime and heroin use tend to occur in the same, often deprived, neighbourhoods (Nurco et al, 1984), because heroin use and associated criminality may be a local "fashion" which appears in some areas but not in other areas (Parker \& Newcombe 1987, Pearson 1987), and because the income from successful crime allows heroin users to consume large amounts of heroin (Johnson et al 1985, Collins et al 1985).

\section{Sociological Studies (“Taking care of business")}

Researchers who argue against the causal relationship between drugs and crime, tend to be influenced by earlier sociological studies of offending behaviour. In Cloward and Ohlin's (1960) "double failure" thesis, addicts are described as neither successful in the lawful or the criminal world, forming a retreatest sub-culture instead which is centred around the consumption of drugs. In contrast, Preble and Casey described addicts as engaged in "aggressively pursuing a career that is exciting, challenging, adventurous, and rewarding. They are always on the move and must be alert, flexible and resourceful." In Preble and Casey's study, addicts were preoccupied with "taking care of business" and for them, the quest for heroin was the quest for a meaningful life. This was to be fulfilled through the gratification of challenges and the excitement it provided in their life, rather than through biological gratification obtained through opiates.

Akerstrom (1985) obtained accounts of the meaning of drug use and criminal behaviour from prisoners. Most perceived crime as work, and in many cases hard work. Many had a criminal speciality, which they saw as an identity, even though they usually committed a range of 
different offences to obtain money. They attached considerable importance to developing skills, having courage, and coolness. Flirting with danger during a crime might be enhanced for some by heroin. In contrast to the notion that addicts are seduced, or sucked into drugusing circles, it became clear that many had had to work at gaining access to these drug-using circles. Furthermore, making the right connections was important in both their drug use and their criminal activities. Crime as "work" included development of practical knowledge, particularly criminal techniques, knowledge about drugs, and the process of selling drugs. Creativity and inventiveness in criminal work was highly valued by these men. Many also attached considerable importance to "beating the system", putting on a false front for professionals and those in authority, and using their criminal identity. Many reported having deliberately manipulated re-habilitation in the past, for example presenting themselves as attempting to obtain treatment when appearing in Court, pretending that their future goal was abstinence, in an attempt to obtain a less severe sentence or to receive treatment instead of imprisonment.

Akerstom observed a business orientation in his subjects. Several addicts reported that if they did not actively wish to have a business, they at least enjoyed doing business. For those heavily involved in crime, stealing was perceived as a business. Theft required considerable planning and execution, together with knowledge of what was likely to make the most money when stolen, and where to go to fence stolen goods. Drug dealing in itself was considered a small business, initially starting up with a small amount of capital obtained through crime, for example thefts and burglary, and then investing in the purchase of drugs and setting up a business as a drug dealer. Investment of time and hard work, as well as money, in their business, together with acceptance that it might be necessary to start all over again if it all went wrong, were accepted as part of the process by Akerstrom's subjects.

Conspicuous consumption and spendthrift attitudes were entirely acceptable to these men. Others who led a conventional lifestyle were looked down upon, perceived as naive, and socially "imprisoned", poorly paid for their hard work, and financially disadvantaged through having to make savings, mortgages, etc. In contrast, these addicts and thieves perceived themselves as experiencing an exciting life, with an important sense that they were "different". 
Interestingly, Akerstrom observed differences in attitude between prisoner subjects who were addicted and those who did not use drugs. Addicts believed that they had less responsibility for their criminal behaviour, together with less freedom of choice as a result of their need to obtain drugs. However, Akerstrom's interpretation of his findings were that these subjects had been confirmed in their beliefs by the general belief in society that addicts have a desperate need for drugs, and thus had been caught up in a self-fulfilling prophecy. Proponents of the heroin use causes crime hypothesis might argue that their self-perceptions were correct.

\section{The Glasgow Studies}

Two quantitative studies in Glasgow, Scotland, have posed the strongest challenge to the causal hypothesis and require detailed examination. In the first study, Hammersley et al (1989) argued that, accepting the association between opioid use and crime, and that they develop together, the picture is considerably more complex because crime and opioid use tend to influence each other. Interviews were carried out with 151 Scottish prisoners and nonprisoners, divided into five drug-using groups: (i) alcohol only, (ii) cannabis and alcohol, (iii) other drugs but not opioids, (iv) moderate consumption of opioids, and (v) heavy use of opioids. Data were obtained on drug use frequency, crime frequency and several other variables. Results demonstrated considerable rates of crime and drug use in all groups. For example, in the group using only alcohol, subjects were reported to be spending over $£ 30$ a week on alcohol and cigarettes (approximately half their mean legitimate income) and earning about the same amount from crime. Across all groups, increasing level of drugs, increased travel expenses, criminal income, drug sales income, drug expenses, theft, drug dealing, use of pills, opioids use, drug experience, and criminal experience were all correlated. Essentially, higher level drug-users committed more crimes than did lower level users. However, the relationship was not simple and when examining relationships between variables more closely, no correlations were found between the level of drugs used and delinquency or fraud. Opioid users at a moderate level did not steal significantly more or have higher criminal incomes (excluding drug-dealing) than did drug users who consumed other substances. Thus, a moderate level of opioid use was not associated with increased criminality, except drug dealing. However, heavy opioid use was associated with increased criminality. 
Legitimate incomes of opioid users were not greater than non-users' and their non-drug expenditures were also no different than other groups. Thus, the lay stereotype of the heroin user "sacrificing all to feed the addiction" was deemed inaccurate. Subjects who used larger amounts of drugs did tend to use a wider range of other categories of drug and tended to be polydrug users rather than "pure" opioid users. In addition, heavy drug users tended to have a wider variety of crime experience. Overall, they appeared more deviant in terms of both criminal activity and use of drugs. But as the opioid users appeared extreme on almost all drug and crime measures, Hammersley and colleagues argued that singling out opioid use as the cause of their criminality might be inappropriate.

To test the direction of association between drugs and crime, the researchers developed two regression models. The first was intended to explain crime with drug use. This demonstrated that opioid use was a substantial explanation for drug-dealing but only a minor explanation for theft. For theft, variables which tended to correlate with increased opioid use, especially extent of criminal experience and other drug use, were more important explanations of frequency of theft than was the use of opioids. Neither violence, delinquency, nor fraud were related to opioid use, although it was found that other drug use and alcohol use were related.

A second regression analysis sought to explain drug use with crime. The behaviour of friends of the subjects, previous drug experience, drug-dealing, and non-drug crime explained opioid use, use of pills, cannabis, and alcohol use. However, non-drug crime was a larger explanation of alcohol and pill use than it was of opioid use; non-drug crime explained opioid use better than opioid use explained theft; and pill use was more associated with non-drug crime than was opioid use.

The authors concluded that the frequency of heroin use did not determine the frequency of criminal activity. Use of all categories of drugs appeared to be associated with crime, but non-drug crime was explicable by a combination of drug use and criminal experience. Those who were currently most criminally active tended to have a wider variety of previous criminal experience. Hammersley and colleagues argued that day-to-day crime was a better explanation of drug use than drug use was of crime. In contrast, however, opioid use did seem to explain drug-dealing. Nevertheless, they concluded that their data did not support the causal hypothesis of drug use causing crime. Rather, drug use in general, opioid use in 
particular, and crime all covaried.

To Hammersley and colleagues, a major part of the explanation for opioid or polydrug use seemed to involve normal psychosocial and cultural mechanisms, rather than pathological processes. If opioid use cannot simply be explained as a matter of pharmacological need, then attempting to control crime by controlling drugs would, in the authors' opinion, be ineffective. Controlling a drug would tend to have 4 consequences: (i) if the drug is made illegal and is perceived as more dangerous, it may attain higher status, become more expensive, and more coveted. In turn, this might strengthen the association between the drug and crime. (ii) if the drug becomes unobtainable, then users and potential users may switch to another substance, which may then become associated with crime, (iii) the more a drug is perceived as illegal, desirable, and addictive, the more likely it is that seriously deviant criminals will traffic in it. This in turn encourages criminal use and promotion of the drug. (iv) the higher the penalties for drug dealing, the more likely that drug users will turn away from dealing drugs to finance their drug use and take up other forms of crime instead.

A further radical suggestion made by Hammersley and colleagues was that rather than tackling "the drugs problem" in the name of crime prevention, it might be worthwhile to deal with and focus on criminal behaviour in the name of drug-abuse prevention. As this study, and others (Collins et al 1985, Johnson et al 1985) have demonstrated that high income from crime tends to increase drug use, then, if the Scottish sample was representative of criminal drug users, it would unfortunately suggest that "crime pays". If crime pays, then adequate and lasting drug rehabilitation of criminal drug users would require nothing less than a complete change of lifestyle. However, American studies of treatment suggest this can be a difficult and lengthy process with numerous relapses (Leukefeld \& Tims, 1988). At the same time, however, the authors did concede that "treating" crime was difficult and might not be effective.

In their second study, Hammersley and colleagues examined drug use and criminal behaviour of 210 teenage licit and illicit drug users (Hammersley et al, 1990). Over 90\% of the sample, including non-users, soft drug users, opioid users and injectors, were obtained by a "snowball" method of recruiting friends and acquaintances. In this sample, none of the subjects had been injecting for more than two years. Once again, their results demonstrated 
that frequency of use of licit and illicit drugs and the frequency of all crimes were intercorrelated. Using a similar statistical method to their previous study, Hammersley and colleagues first attempted to predict five categories of crime (theft, fraud, violence, vandalism, drug dealing) from drug use and other variables. They demonstrated that drug use was a not a major and unique predictor of theft, but it did predict other crimes. At the same time, it did not appear to be a sole and sufficient explanation of any kind of crime, except possibly fraud. Instead, crime frequency was determined by a combination of the behaviour of friends of the subject, prior criminal experience, and drug use. The authors then attempted to predict drug use from crime and demonstrated that all indices of illicit drug use could be better predicted from crime than crime could be predicted from drug use. Both economic (theft and fraud) and non-economic (violence and vandalism) crimes predicted all categories of illicit drug use. Drug dealing in this sample was only predictive of the extent of soft drug use.

It was found that the behaviour of friends, as reported by the subjects, was also predictive of illicit drug use. Heavier users of soft drugs were more likely to report that a relatively high proportion of their friends used opioids. Heavier users of all illicit substances were more likely to report that a relatively high proportion of their friends injected drugs.

Two other variables were uniquely predictive of drug use. Subjects who reported less social support tended to take more illicit drugs, while subjects who had spent longer periods during childhood in local authority care, tended to take more opioids and were more likely to inject. Hammersley and colleagues concluded that their findings had broadly replicated those of their previous study (Hammersley et al, 1989) and that the pattern of association did not suggest that drug use simply caused crime. Once again, recent crime frequency appeared to be explained by drug use and previous criminal history. Drug dealing was additionally explained by lack of social support, including time spent in local authority care. In general, they concluded that drug use could be better explained by crime than crime could be explained by drug use. In both their studies, current drug use appeared to be primarily explained by crime, previous drug history, and the behaviour of the friends of the subjects. In addition, users of harder drugs tend to be the most frequency users of all other drugs.

In this second study, subjects were younger with a mean age of 15 years. Most subjects were 
not yet using drugs in a dependent fashion and both drug use and crime were intermittent, experimental behaviours at this point. Hammersley and colleagues concluded that criminal drug-using teenagers in this sample were better regarded as "delinquents" than as "drug abusers" or "drug addicts". Delinquent behaviour of all kinds appeared to be increased by prior criminal experience, having delinquent friends, and lack of conventional social support (notably including having spent time in local authority care). Having friends who are drug users and/or criminals means that an adolescent is more likely to learn about drugs and crime and to come to view them as desirable behaviours. Thus, even if the adolescent merely uses some drugs but never develops a substance dependency, they are still more likely to become criminal because, amongst their friends, criminality is relatively commonplace (see also Belsen 1975, West \& Farrington 1977). Having a prior criminal history and being criminal, independent of drug use, would make it likely that an adolescent would be able to afford to take more drugs, which in turn makes it more likely that they might become substancedependent. Lack of conventional social support can make the situation worse. Without alternative positive influences in their life, the influences of other drug users and criminals may have had greater influence.

The authors made similar points regarding intervention to their first study, arguing that any intervention which reduced their subjects' criminality would probably also reduce their drug use. Once again, the authors conceded that successful interventions in delinquency are difficult but argued that most penal sanctions against adolescent criminals seemed to make things no better, or perhaps worse, citing the views by Lipton et al (1974) and Tutt (1982). Hammersley and colleagues perceived the problems of drug abuse and criminality as deeply rooted in the culturally sanctioned use of substances, specifically tobacco use and alcohol, arguing that drug use was endemic in the population in which the research had been carried out and that drug-using rituals are built into the fabric of social life. Furthermore, laws against under age drinking and tobacco smoking are rarely enforced and a wide range of drugs were available to these Glaswegian adolescents during the study period. The authors argued that if one drug disappeared then something else might replace it. Applying the principle of "harm reduction", it was suggested that perhaps adolescents and their parents need to be educated about how to take drugs safely and without dependence, rather than promoting the message that drugs should be avoided altogether. 


\section{Crime and Categories of Opioid User}

Ethnographic studies have suggested that the development of drug use and crime varies considerably from individual to individual (Pearson 1987, Carpenter et al 1988). At one extreme can be found people who are heavy drug users, but who have always avoided crime (or are at least no more criminal than their peers whose drug use is more moderate). At the other extreme of this continuum can be found people who are extensively criminal before trying any drug harder than cannabis and who then extend their criminality after using harder drugs. Although Hammersley and colleagues have produced strong arguments against pharmacological explanations for associations between drug use and crime, the statistical methods that supported their arguments were applied across their samples as a whole. Although the weight of their evidence was indeed in favour of criminal behaviour preceding, leading to, and amplifying an already present criminal disposition, this does not necessarily mean that individuals do not exist where the simple causal relationship applies. Clinical experience reveals individuals who use opiates without recourse to crime throughout most of their addiction careers and have no prior criminal involvement, but who may at some later stage supplement their legal income by illegal methods due to pharmacological affects of opiates and a desire to avoid withdrawal symptoms and satisfy cravings, sometimes when there has been an escalation in the amount consumed on a regular basis and where the cost exceeds legal income. As there is now evidence that the pattern of opioid use in the United Kingdom has changed, and that addicts have increasingly come to resemble those in the USA, it is possible that this group of drug users may constitute a shrinking proportion. Nevertheless, statistical methods which have categorised opioids users in relation to their criminal behaviour have demonstrated that the relationship, whilst complex, may still allow for the existence of the causal association. Furthermore, attempting to argue for and against the pharmacological association between opioid addiction and crime may in itself be oversimplistic.

Several studies have attempted to delineate typologies of substances abusers and examine their drug careers as they relate to criminal behaviour. Nurco et al (1991) developed a classification scheme of narcotic addicts from structured, confidential interviews with 250 male narcotic addicts. They described ten "clusters" of types of addicts according to numbers and types of crimes involved. These clusters of types of criminal involvement, (from the least to the most serious) included: addicts uninvolved in crime (6\%); drug distributors / dealers 
(19\%); drug distributors / holders (17\%); drug distributors / tasters (7\%); thieves involved in shoplifting, fencing and property crimes (18\%); gamblers involved in numbers running, bookmaking and illegal betting (8\%); loan sharks (4\%); deceivers involved in prescription forgery and drug dealing (9\%); generalists involved in many types of non-violent crimes such as theft, burglary, and cheque forgery (5\%); and violent generalists involved in robbery and assaults (7\%). A subgroup of violent generalists, representing only $4 \%$ of the total cohort were considered especially serious as they were considered responsible for more than half of the violent crimes.

In an earlier study, Nurco and Shaffer (1982) had classified a sample of addicts according to criminality, employment, and adequacy of income to meet needs. Two of the subgroups generated by this classification were so different from one another that they suggested two distinct ways of dealing with drug activities. The first type, the "successful criminal" obtained more than enough money from illicit sources to meet his needs. The second type, the "working addict" was employed at least eight hours a day and was involved only minimally in criminal activities. Suggested implications of these differences were that the successful criminal would appear a poor candidate for recommendations that they obtain a legitimate job which paid less than their illegal income. For such individuals, the emphasis should be on monitoring in the community whether the addict was returning to drug use and crime. If reinvolvement occurred, there could be further sanctions. In contrast, the working addict might be more likely to respond to a treatment programme aimed at developing a legitimate lifestyle.

Certain authors carried out research on the premise that there is correlation between drugs and criminality, which then formed the basis of their typology. For example, Kokkevi et al (1993) and Bean (1994) have described two groups: in the first criminality, is seen as a means of financing consumption. Criminality thus becomes an economic necessity. In the second, addiction is preceded both by criminal offences and an early entry into a general career of wide ranging deviant behaviour. In many studies, the latter group is by far the largest group of subjects and this factor may have influenced through sampling procedures the representativeness of subjects when estimating the various associations between crime and drug use. 
Grapendaal et al (1992) identified a typology consisting of three groups of Dutch subjects: (i) dealing junkies who derived their income from selling drugs on a relatively small scale. Longterm, severe, multiple drug use was common and they desired to live an exciting and different kind of life; (ii) criminal junkies who obtained their income mainly from theft and burglary, using whatever drug they come across. Their deviant lifestyle began early and their subcultural life was dominated by both drugs and criminality; (iii) the normalised users with a drug-related lifestyle, but where drug abuse was mainly financed from legal sources of income. They had little connection to a deviant, criminal lifestyle.

Stimpson (1972) developed a typology in the UK based on degree of criminality and involvement in the conventional world. He described four groups very similar to the typology described by Brottman \& Freedman (1968) in the USA. These included (i) "stables" who have jobs, homes, little criminality, use drugs in a controlled manner, have limited contact with other addicts, and better family relationships, (ii) "Junkies" who are often unemployed, have high criminality, maintain close contact with other addicts, have limited family contact, a subcultural drug-orientated lifestyle, and a chaotic pattern of abuse; (iii) "Loners" who are often unemployed, less criminal than junkies, more often avail themselves of public income support, tend to take their drugs alone, and associate with other addicts only in order to obtain more drugs; and (iv) "Two-worlders" who can be placed somewhere in-between stables and junkies, more often having jobs, but also a high rate of criminality and a tendency to associate with other drug users.

Byqvist and Olsson (1998) argued that addicts who are deeply involved in the criminal underworld have played a dominating role in how the drug problem has been defined and how the drug policies came to be developed. Rather than focusing on testing causal explanations, these authors suggested that it may be possible to group drug abusers according to their relationship to the criminal sub-culture within a population and then investigate how the groups differ from each other in terms of social conditions, abuse patterns, and other factors. This approach is influenced by the general premise that a subculture of affiliation to crime is of fundamental importance both to the addicts' sense of personal identity and to how persons belonging to such a group are viewed by others in mainstream society. The authors constructed a typology according to patterns of criminal behaviour from a sample of 698 male drug abusers (not exclusive to opiates) in Sweden. They then examined the differences 
between their four types and finally tested their four categories using cluster analysis. Their four types included:

Type 1 - Addicted Criminals (25.4\%)

This group had both early drug and criminal debuts (on average in their mid teens). Progression from first use of drugs to regular use was rapid. Regular drug use coincided with age of first registered crime. Many started intravenous injection in prison or juvenile detention centre. By the time of study, this group was responsible for approximately half of all offences registered for the entire study sample. Polydrug abuse characterised this group and stimulants were the preferred substances used. They also the highest average consumption of alcohol per week. Most had experienced considerable family discord while growing up, many had alcoholic fathers, had grown up in broken homes, and had progressed through the social care system from children's homes, to juvenile detention centres, and finally prisons. They had been the object of most social interventions and had most frequently received treatment for drug abuse. They supported themselves primarily through criminal activities or social assistance. Few had been employed and very few had ever had regular employment. Social interactions were mainly with other drug users, social relations were poor, and they lived a generally deviant lifestyle. Property crimes were the most common offence during the year prior to study (70\%). Violent offences were also more common in this group and $90 \%$ had at some time served a prison sentence.

Type 2 - Criminal Addicts (24.4\%)

Onset of both crime and drug use were later in this group, 17 years and 18 years respectively. Almost twice as many subjects had drug offences as their first registered offence compared to Type 1. Juvenile delinquency was much lower than Type 1, but there had been a more rapid acceleration in their criminality after their use intensified. Although polydrug abusers, there were more opioid dependent users in this group and they more took drugs intravenously. By the time of interview, this group had very severe drug abuse problems and had become highly criminal. They had the highest number of drug-related offences. Similar to Type 1, criminal activities and social assistance were now the most common means of support and there was also extensive alcohol abuse within this group. Early experiences of coming from a broken home, being placed in institutional care during childhood, and experience of family discord did not compare to Type 1 and was similar to Types 3 and 4 . 


\section{Type 3 - Low Crime Addicts (30.2\%)}

This group had started using cannabis at a relatively young age and there had been a gradual shift to more severe abuse of drugs such as opioids or stimulants by the time of interview. Type 3 addicts contained the largest proportion of opioid abusers in the study. Average age of first offence was somewhat higher in this group (approximately 19 years), whereas first drug use was around 15 years. Byqvist and Olsson believed that drug abuse played a significant role in the development of their pattern of criminality. However, the total number of offences by interview was considerably lower than Types 1 and 2. They drank less alcohol than the Types 1 and 2 and they had had less difficult childhoods and adolescences. Most lived on their own but kept regular company with other drug abusers. During the year prior to interview, property crimes and drug offences were most common.

Type 4 - Emotionally Unstable Addicts with little or no Criminality (20\%)

This group had the best education, current job situation, and social relationships. They were the oldest by the time they were registered for their first criminal offence (mean 24 years) and the progression from first use of drugs to their first offence was the longest ( 9 years), although by that time they had been regular abusers for, on average, 7 years; $36 \%$ reported no criminal behaviour in the year leading up to the research interview and there were more subjects who had never been convicted in this group than Types 1-3, (although a subgroup admitted that they were regularly committing crimes for which they had not been caught). First substance used was most often cannabis or stimulants and the progress and development of their pattern of drug abuse was similar to Type 3. Opiates were the main substance of abuse in $15 \%$, although a further $8 \%$ used opioids as a drug of second choice. Multiple drug abuse was most extensive in this group. Alcohol consumption was also very high in this group. But frequency of drug use by injection was lower than the other groups. They had received less institutional care in childhood and fewer social interventions over their lifetime. However, experience of mental illness was most common in this group and many had attempted or considered suicide. Although Type 4 subjects had the lowest rate of criminality, those who committed crimes were most likely to commit drug offences. The authors observed that some had undoubtedly resorted to crime to finance their drug abuse, but in general they had availed themselves of legal drugs in addition to illicit drug use and their drug use was largely financed by other methods. 
Byqvist and Olsson confirmed their typology using cluster analysis, arguing that this procedure produced a grouping of subjects very similar to their original classification. As expected, they confirmed that drug users do not commit crimes only to finance their habit. Their results supported research suggesting that both criminals and addicts tend to come from the same population. Their typology further demonstrated that this was not true of all addicts and that a certain number were clearly criminal before their involvement with drugs. However, in Type 4, previously established criminal careers played a minimal role and individual factors, particularly emotional problems and in some cases mental illness, were of greater importance for the emergence and shaping of their addiction. The authors pointed out that factors other than criminality are closely associated with drug addiction and deviant behaviour, including environment, social network, peer pressure, personality, and a wide range of other cultural factors.

\section{Life histories and the Drugs-Crime Connection}

Faupel and Klockars (1987) examined whether (i) heroin addiction promoted criminal activity by placing a heavy financial burden on the addict which could not normally be met through legal means, or whether (ii) connections in the criminal sub-culture which distributed heroin had facilitated and encouraged criminal solutions to the problem of financing heroin addiction. In life history interviews with a small sample of 32 heroin addicts, it appeared that both hypotheses were, at best, true for only certain periods in addicts' careers, whilst during other periods the assumed causal dynamics were neutralised or reversed. Subjects were interviewed regarding: (1) childhood and early adolescent experiences which may have served as predisposing factors for eventual drugs/criminal involvement, (2) initial encounters with various types of drugs and criminality, (3) the evolution of their drug and criminal careers, (4) their patterns of activity during peak periods of drug use and criminality, including descriptions of typical days during these periods, (5) their preference for types of crime and drugs, (6) the structure of their understanding guiding drug use and their criminal activity, and (7) their perceptions of the nature and effectiveness of drug treatment. The authors attempted to establish a temporal sequence to their subjects' drug use and criminal behaviour. In this study, all subjects reported some criminal activity prior to their first use of heroin. However, for most subjects their criminal careers and their heroin using careers had both begun slowly. For example, there were usually several years between the first serious criminal offence and 
subsequent involvement in criminal activity on a regular basis. Similarly, all subjects reported at least occasional use of other illicit drugs prior to their first experiences with heroin. Many had spent substantial periods using heroin on an occasional basis before becoming regular users. Most importantly, the majority reported that their criminal and drug careers had begun independently of one another, although both careers had become intimately interconnected over time as each evolved. In the earliest phases of their drug and crime careers, both the decision to commit crimes and the decision to use drugs were choices which they believed they had been free to make, and which they believed that they could have discontinued before either had become a way of life in the later stages.

Two general factors shaped and influenced their drug and crime careers, not only during the early stages of each career, but as each career evolved through its different stages. The first included availability of and funds to purchase heroin, rather than the level of physical tolerance the user had developed. The second general factor included life-structure, in terms of regularly occurring patterns of daily domestic, occupational, recreational, or criminal activity. For example, most subjects spent more time engaged in conventional activities than in criminal or deviant ones. Even in the hard-core, criminal addicts' lives, their life structure involved predominantly stable forms of criminal activity. Using these two dimensions, the researchers identified four patterns of heroin use career phases: (1) the occasional user with low availability but high life structure, (2) the stabilised junkie with high availability and high life structure, (3) the free-wheeling junkie with high availability but low life structure, and (4) the street junkie with low availability and low life structure. They observed that the relationship between heroin use and crime was not necessarily consistent with phase of addiction. During the "occasional user" phase, for example, their limited level of drug use was quite affordable through a legitimate income. Any criminal activity that did take place was usually unrelated to drug use. During the "stabilised junkie" and "free-wheeling junkie" periods, the level of drug use appeared largely a function of availability, typically enhanced through criminal income. Rather than drug use causing crime, crime facilitated drug use during these periods. But the reverse relationship was observed during the "street junkie" phase, where availability through normal channels was lacking and the addict lacked the necessary structure to regulate his or her drug needs. Under these conditions, the drug habit did appear to "cause" crime in the manner commonly depicted. 
Life history data have revealed that the relationship between drugs and crime is dynamic. In addition to providing the necessary income for the purchase of heroin, criminal activity also served to structure the drug-using behaviour of the addict. Crime thus provides the addict with a daily routine which for many served to limit, or at least regulate their drug use. Whilst in any given instance it might be possible to specify a particular relationship, this study suggested that any generalisations fail to capture the complexity of the drugs-crime connection throughout an addict's career.

\section{CONCLUSION}

There is little doubt that heroin use and criminal behaviour are closely connected. Heroin users commit a considerable amount of crime and not all funds obtained from criminal activities are spent on heroin. Furthermore, a range of other drugs are likely to be used. Heroin users are disportionately represented among prison populations and there is a further over-representation of heroin use by the most serious and recidivistic subgroup of offenders. It would thus appear that heroin is just one part of a criminal and anti-social lifestyle for many offenders. In recent studies that have looked at offending and crime, the majority of subjects demonstrate that criminal behaviour preceded their heroin use. However in earlier studies, researchers tended to find little evidence of criminality before the onset of opiate addiction (Pescor 1943, Terry and Pellens 1928). It is probable that the more recent findings reflect changes in the populations of opioid users in the USA and UK, and where heroin use now tends to be concentrated among inner city youths, living in socio-economically deprived circumstances, and with a previous history of delinquency and multiple social problems. Studies such as those of Hammersley and colleagues in Glasgow have selected subjects drawn from these populations. It is therefore unsurprising that across these samples as a whole, the weight of evidence is in favour of criminal activity preceding and leading to heroin use, rather than heroin use causing crime. Nevertheless, even in the Hammersley studies, heavy use of opioids was associated with frequent and serious criminality, which appeared to be independent of early factors, and there is some additional research evidence of an intensification of criminality due to heavy use of opiates.

A direct, and causal association between heroin use and criminal behaviour would be supported by large scale epidemiological surveys showing that increase in heroin use, or 
"epidemics" of heroin use, are subsequently followed by a marked increase in criminal behaviour. However, it would in turn be necessary to demonstrate that the two were directly linked and that confounding had not occurred, also that it was the heroin users who had accounted for the subsequent rise in crime. Unfortunately, such studies have not been carried out on a large scale. Small scale studies such as those in the Wirral, Merseyside, have demonstrated an apparent direct association between increasing heroin use and a rapid rise in crime, but the phenomenon appears to be geographically localised.

Studies which have categorised populations of heroin users suggest that they are heterogeneous. Certain subgroups (albeit containing relatively small numbers) do exist where the financing of the drug habit is kept within legal limits throughout some or all of the subjects' drug careers. Some researchers have identified an additional subgroup where criminal activities began after dependence on heroin and which are carried out largely for the purpose of providing funds for heroin, in some cases for the avoidance of withdrawal symptoms. Nevertheless, these two subgroups are usually smaller than those where criminal activities preceded or now dominate addicts' lifestyles. A further question does arise, however, over the extent to which individuals with a history of delinquency preceding heroin dependence are at risk of their criminality becoming intensified as a result of increasing dependence on opioids and the need to acquire more funds to pay for more drugs. This possibility appears to have been largely rejected in the studies by Hammersley and colleagues, at least for users of moderate or low levels of heroin. Further research is required which examines the interactions between heroin use and crime in heavy users extensively involved in crime. Few longitudinal studies have been carried out in this field, but do suggest that the simplistic arguments over whether crime leads to heroin use or heroin use leads to crime are most probably redundant. All categories of heroin user can shift from one pattern of association to another over time. Even the most actively criminal individual, with the relatively early history of delinquency, and with an excess of funds derived from criminal activities to spend on goods other than heroin, can demonstrate a shift to a state where the heroin use no longer is perceived as under control and criminal activities are further accelerated to obtain more money to support an escalating drug habit.

Opponents of the "heroin causes crime" hypothesis have largely ignored the literature on treatment interventions. For example, interventions aimed directly at subjects' criminal 
activities, rather than their heroin use, would appear to be most appropriate to Hammersley and colleagues. It would follow that if heroin use does not lead to crime, then individuals whose delinquency preceded their heroin use and who are excessively involved in crime would be unlikely to respond to methadone treatment measured in terms of their criminal activity. However, the increasing evidence of the effectiveness of methadone maintenance treatment in reducing drug-related criminal behaviour, together with some evidence of an effect on combined drug- and property-related criminal behaviours, does suggest that, whilst criminal activities unrelated to drug use may be unaffected, criminal behaviour related to the procurement of funds to support drug use can be substantially reduced by methadone treatment (Marsch 1998). This would further emphasise the redundancy of the previous debate and that the debate should now shift instead to more important questions such as whether treatment interventions such as methadone maintenance are as effective in addicts who are extensively involved in crime as those who are not, which treatments are most effective for which categories of heroin user, and whether treatment interventions should involve a degree of compulsion to co-operate. Similarly, the questions of whether a rehabilitative or "casework" approach should be taken to addicts who are likely to offend whilst in the community, or whether supervision based primarily on a model of surveyance should take precedence, needs to be resolved. As the associations between heroin use and crime are so firmly established, and because heroin use is now relatively widespread within UK society, the public health implications of now shifting the debate are considerable. 


\section{CRIMINAL BEHAVIOUR IN \\ TREATMENT-SEEKING OPIATE ADDICTS}

Jeremy Coid and Zelpha Kittler 


\section{AIMS OF STUDY}

1. To describe the characteristics of a sample of opioid dependent subjects presenting at an inner city service for the treatment of drug users.

2. To describe the methods used by subjects to fund their use of opioids.

3. To examine whether opioid use causes crime, or crime causes opioid use.

\section{METHOD}

The study was conducted at a National Health Service community based clinic for drug abusers in Hackney, a socio-economically deprived, inner-city area of East London. The rate of reported drug episodes (North Thames Regional Database Figures) for the period 19961997, served by the Borough of Hackney was 492 per 100,000 population (age 15-44), compared with an overall rate of 245 per 100,000 for the North Thames region as a whole.

During the period of the study, the Community Drug Team (CDT) was an outpatient day service which acted as a primary filter for drug users of all types when accessing services. These services included a methadone detoxification programme, counselling for all forms of drug misuse, as well as onward referral for patients seeking methadone maintenance. Those individuals with three or more "failed" attempts at methadone detoxification, or those with significant psychiatric comorbidty (history of psychiatric treatment or psychosis) were referred to a hospital-based Drug Dependency Unit (DDU) nearby which was a component of the overall service in Hackney for drug users.

\section{Sampling}

All prospective clients attending the service on a walk-in basis and seeking access to the methadone programme were given a leaflet explaining the project and its aims. All clients agreeing to be interviewed signed a consent form and received a $£ 10$ supermarket voucher. Because of the intention to "catch" as many willing respondents as possible, most clients were interviewed within the first week of presentation, usually while undergoing the assessment process for the methadone programme. A total of $147(67 \%)$ were interviewed during the 
first week prior to stabilisation on methadone, with a majority of the remainder interviewed over the succeeding ten weeks.

Although subjects were primarily interviewed whilst still dependent on illicit drugs, those in a state of intoxication or in obvious withdrawal were not interviewed.

\section{Assessment Measures}

The interview included three separate questionnaires which took on average between 11/2-2 hours to complete. The first questionnaire (prepared by JC, available on request) was semistructured and designed to elicit categorical and continuous variables covering the following areas: demography and current social circumstances, lifetime and current substance misuse, drug-related physical and psychosocial problems, high-risk drug-related behaviours, family history, and experiences of childhood adversity. The interview examined in considerable detail the amount of money spent on drug misuse, methods of obtaining funds to buy drugs including criminal activities, and examined both drug- and non-drug related crimes. Subjects were asked to self-report on a range of crimes and illegal activities together with their previous involvement with the Criminal Justice System. One aim of the interview schedule was to differentiate between crimes that had been carried out before the onset of drug misuse from those which were carried out specifically to obtain money for drugs, and to differentiate those crimes that the subject did not consider to have been solely for the purpose of obtaining money for drugs.

The research interview firstly established the amount of opiates used on a daily basis (primarily heroin in the majority of subjects) followed by their daily expenditure on drugs. The interviewer then established with the subjects their average weekly expenditure followed by their current average weekly income from legal sources (e.g. work, social security benefit). This enabled an estimate of the weekly deficit to be made up from other sources. The subject was then be asked to specify which of a range of different sources had been exploited to obtain money for drugs, firstly over the lifetime, then over the last six months, and finally within the last month. This method was used to establish which criminal activities were solely involved in obtaining money for drugs. The subject was then asked about specific criminal activities including theft, burglary, fraud / deception, working and signing on for unemployment benefit, violence against the person, acquisitive violence against the person 
(primarily mugging), vandalism, drug-dealing, prostitution, and a category of "other" crimes to be specified by the subject. Self-reported criminal activities were explored in more detail as it was anticipated that not all subjects would be carrying these out solely to obtain money for drugs. By collecting this additional information, the study would then permit some qualification of drug- and non-drug related criminal behaviour. The interview was also designed to obtain a self-reported measure of the average amount of money made by a subject on an average day from each criminal activity, together with an estimate of how many days within the last week, last month, and last six months, that each criminal activity had been carried out.

Subjects were interviewed using the Schedule for Affective Disorders and Schizophrenia Lifetime version (SADS-L) (Spitzer et al, 1987). This established lifetime Axis I mental disorder for each subject over the lifetime and within the last six months. During the interview, it was important to overcome the complexities of symptom-overlap between Axis I disorders and symptoms relating to drug use by asking the respondents if the symptom occurred during changing patterns of drug use, e.g. withdrawal from stimulants or during periods of heavy alcohol abuse. A disorder was not rated positive if episodes were only related to periods of drug intoxication or withdrawal. The SADS-L category "minor depressive disorder" was also omitted as it was considered to be of low threshold for a diagnosis of depressive disorder to be comparable with most psychiatric glossaries.

The structured clinical interview for DSM-III-R personality disorders (SCID-II, Spitzer et al, 1990) was used to establish Axis II personality disorders.

The interviews were conducted by two post-membership (Royal College of Psychiatrists) medically trained clinicians who had clinical experience in the field of addictions (ZK and PK).

\section{Sample}

Between July 1995 and September 1997 (the time period of study 1), a total of 572 individuals accessed the service via the walk-in clinic. Those deemed eligible for the study fulfilled the following criteria: aged between 17 and 65 years, adequate English to understand the purpose and nature of the study, opiate dependent according to DSM-III-R criteria, 
seeking methadone treatment and then commencing on a methadone programme (dependent on satisfactory completion of the assessment procedure). A total of 247 clients were deemed to be non-eligible for inclusion for the following reasons: non-opiate dependent or seeking alternative service $(n=144)$, did not complete the assessment process $(n=84)$, inadequate standard of English $(n=20)$. Of the remaining eligible sample, 221 were interviewed, comprising $68 \%$ of the total sample. All those interviewed gave two positive urine samples for opiates; $82 \%$ of the subjects became clients at the CDT and the remainder were referred and enrolled at the DDU.

\section{Representativeness of the Sample}

As slightly less than $70 \%$ of the target population (all those engaging in a methadone programme via the Community Drug Team) was interviewed, several variables were selected from the clinic notes on the non-interviewed cases (32\%) and the two groups were compared on the following: gender $\left(\chi^{2}=0.78, \mathrm{df}=1, \mathrm{p}=0.78\right)$ ethnic group, i.e. white British or not $\left(\chi^{2}=0.78, \mathrm{df}=1, \mathrm{p}=0.37\right)$, age $(\mathrm{t}=1.18, \mathrm{p}=0.24)$, injecting status, i.e. currently injecting or not $\left(\chi^{2}=0.08, \mathrm{df}=1, \mathrm{p}=0.32\right)$, employment status $\left(\chi^{2}=3.06, \mathrm{df}=1, \mathrm{p}=0.08\right)$, and age first dependent on opiates $(\mathrm{t}=-1.66, \mathrm{p}=0.98)$. It was thus possible to conclude that the interviewed group was broadly similar to the non-interview group and hence likely to be a representative sample of opiate addicts attending these services.

\section{RESULTS}

\section{DESCRIPTION OF SUBJECTS}

\section{Demography}

Of the 221 subjects who were interviewed in the first phase of the study, 154 (70\%) were males, $67(30 \%)$ females. The majority $(168,76 \%)$ had referred themselves to the specialist services, $22(10 \%)$ had been referred by their GP, 15 (7\%) a drug counselling services, 4 (2\%) the Probation service, and $12(5 \%)$ other agencies. At interview, $174(79 \%)$ were currently of informal legal status, $20(9 \%)$ were on a probation order, $18(8 \%)$ on bail following criminal charges, $5(2 \%)$ had police warrants out for their arrest, and $4(2 \%)$ were under various other restrictions, including 1 who was serving a community service order. They were primarily of white British origin (153, 69\%), 40 (18\%) were of other European origin, 19 (8\%) AfricanCaribbean and 9 (4\%) Turkish or Turkish Cypriot; 50 (23\%) were non-British born; 89 (40\%) were cohabiting or married; 157 (71\%) were unemployed and only 64 (29\%) reported 
that they were officially in work; 8 (4\%) were at school or college. At interview, 69 (32\%) were in unstable living circumstances, for example living temporarily with friends and / or experiencing intermittent periods of homelessness.

\section{Patterns of Drug Use}

All subjects met DSM-III-R criteria for opiate dependence to be included in the study. Heroin was the primary drug of dependence in 200 (91\%), with 15 (7\%) using illegally obtained methadone, 1 subject was dependent on prescribed methadone from which he wanted to withdraw, and 5 others were dependent on other opiates such as DF118. The age at which they reported becoming dependent on opiates ranged from 15 - 48 years, with a mean of 24 years; $167(76 \%)$ had at some time injected drugs and $133(61 \%)$ were currently injecting, 17 (8\%) were currently using opiates orally, and 96 (44\%) were taking heroin by "dragonchasing". Less than half the subjects $(88,40 \%)$ had never managed to achieve any periods of abstinence after becoming dependent on opiates, 78 (35\%) having achieved abstinence on one occasion, and 55 (25\%) had achieved abstinence more than once.

Table 1 demonstrates the subjects' patterns of drug use, indicating a pattern of polydrug use. Most subjects had used most of the drugs we enquired about at some stage over their lifetime. Although they were all presenting primarily with dependence on opiates, the majority regularly used more than one opiate and additionally used cannabis, benzodiazepines, and cocaine. Table 1 also demonstrates their mean age of first use, indicating that cannabis and solvent abuse usually began in their mid-teens, followed by hallucinogens (primarily Lysergic acid), amphetamines, and then heroin, usually by their early twenties.

\section{Health and Social Difficulties}

Table 2 demonstrates the social difficulties experienced by subjects attributed to their drug use, indicating that most had got into debt with their family and friends. Most had reached the stage where their life revolved entirely around drug use prior to presentation at the specialist services, and, for many, their friends and associates were now all drug users. Table 3 demonstrates the health problems that subjects attributed to their drug use. Most had experienced pruritis, a quarter had sores and skin ulcers due to intravenous drug use, and $23 \%$ had taken accidental overdoses of opiates. 


\section{Previous Treatment for Drug Misuse}

Sixty-eight (30\%) subjects had previously received methadone for one period of treatment, 26 (12\%) for two treatments, $18(8 \%)$ three, 8 (4\%) four, 4 (2\%) five, and 1 subject (1\%) on ten occasions; 18 subjects (8\%) had previously been admitted to hospital for detoxification, and $21(10 \%)$ had received non-hospital based detoxification; $46(21 \%)$ had previously been admitted to a residential drug rehabilitation programme, and $20(9 \%)$ had at some time been admitted to psychiatric hospital for problems unrelated to drug dependence.

\section{High-Risk Behaviours}

Ninety-five (43\%) subjects had at some time used a needle after someone else and 27 (12\%) had re-used needles after another drug user within the last month; 157 (71\%) denied that they had ever re-used needles, $25(11 \%)$ claimed to clean needles before using them on every occasion, $5(2 \%)$ would clean needles some or most times, 4 (2\%) rarely, and $23(11 \%)$ were cleaning with water only. 


\begin{tabular}{||l||cc|cc|c||}
\hline \multicolumn{1}{||||}{} & \multicolumn{2}{|c|}{ Ever Used } & \multicolumn{2}{c|}{ Within Last Month } & $\begin{array}{c}\text { Mean age } \\
\text { first used }\end{array}$ \\
\hline \hline Heroin & n & \% & n & \% & \\
Cannabis & 220 & $(99)$ & 209 & $(95)$ & 21 \\
Amphetamine & 218 & $(99)$ & 140 & $(64)$ & 15 \\
Methadone & 202 & $(91)$ & 31 & $(14)$ & 18 \\
Hallucinogens & 201 & $(91)$ & 132 & $(60)$ & 25 \\
Crack cocaine & 193 & $(87)$ & 4 & $(2)$ & 17 \\
Cocaine powder & 190 & $(86)$ & 95 & $(43)$ & 25 \\
Benzodiazepine & 189 & $(86)$ & 38 & $(17)$ & 20 \\
Ecstasy & 187 & $(85)$ & 102 & $(47)$ & 21 \\
Other opiates & 167 & $(76)$ & 29 & $(13)$ & 23 \\
Other & 158 & $(72)$ & 58 & $(26)$ & 24 \\
Solvent abuse & 135 & $(61)$ & 10 & $(5)$ & 21 \\
Barbiturates & 91 & $(41)$ & 1 & $(1)$ & 15 \\
\hline
\end{tabular}

Table 1. Pattern of Drug Use $(n=221)$ 


\begin{tabular}{||l||cc|cc||}
\hline \multicolumn{1}{|c||}{} & \multicolumn{3}{|c|}{ Ever } & \multicolumn{2}{c||}{ Last 1 Month } \\
& n & \% & n & $\%$ \\
\hline \hline Friends all users & 162 & $(74)$ & 139 & $(65)$ \\
Debts family / friends & 161 & $(73)$ & 116 & $(53)$ \\
Debts bank, rent, amenities, etc. & 120 & $(54)$ & 79 & $(36)$ \\
Divorced / separated & 109 & $(49)$ & 20 & $(9)$ \\
Broken family contact & 78 & $(35)$ & 27 & $(12)$ \\
Sacked from job & 74 & $(34)$ & 8 & $(4)$ \\
Evicted & 57 & $(26)$ & 11 & $(5)$ \\
Children in care / at risk & 12 & $(13 *)$ & 9 & $(9 *)$ \\
\hline \hline
\end{tabular}

$*$ = percentage of those who had children.

Table 2. Social Difficulties attributed to Drug Use $(n=221)$ 


\begin{tabular}{||l||cc|cc||}
\hline \multicolumn{1}{||||}{} & \multicolumn{3}{|c|}{ Ever } & \multicolumn{2}{c||}{ Within Last Month } \\
& n & $\%$ & n & $\%$ \\
\hline \hline Pruritus & 172 & $(78)$ & 133 & $(61)$ \\
Sores, ulcers & 54 & $(25)$ & 29 & $(13)$ \\
Accidental overdose & 50 & $(23)$ & 2 & $(1)$ \\
Hepatitis +ve & 41 & $(19)$ & - & - \\
Falls, fractures, etc. & 36 & $(16)$ & 2 & $(1)$ \\
Road Traffic Accidents & 26 & $(12)$ & 1 & $(1)$ \\
Burns, scalds & 21 & $(10)$ & 2 & $(1)$ \\
HIV +ve & 3 & $(3 *)$ & - & - \\
\hline \hline
\end{tabular}

$*=$ percentage of subjects tested

Table 3. Health Problems attributed to Drug Use $(n=221)$ 
Forty-eight subjects $(22 \%)$ had had unprotected sex with a regular injecting partner within the last 6 months, $38(17 \%)$ within the last month; 34 (16\%) had had unprotected sex with a casual partner within the last 6 months, $18(8 \%)$ within the last month; 15 (7\%) had had anal sex within the last six month, $10(5 \%)$ within the last month; 13 subjects $(6 \%)$ had had 10 or more sexual partners within the last six months, 8 (4\%) within the last month.

\section{Funding the Drug Habit}

At interview, 200 (91\%) subjects reported that they were currently using heroin, for which they required treatment, with a mean daily consumption of 0.6 grams (range 0.1-1.75 daily). Mean daily expenditure on opiates for the entire sample was $£ 44.60$, ranging from $0-£ 280$. The mean weekly expenditure was £297.24 (range 0 - £2,000). Subjects reported that the maximum they had ever spent in one day on opiates ranged from $£ 1-£ 1,000$, with a mean of $£ 152.16$. The average weekly income for the subjects, however, amounted to $£ 102.78$, ranging from no income (in the case of 8 subjects) to $£ 750$ per week. This resulted in a deficit amounting to a mean of $£ 207.28$ per subject that had to be made up by other means. This included no deficit to be made up in the case of 40 subjects (18\%), but in the remaining $180(82 \%)$ of subjects it ranged from $£ 10-£ 1,936$ per week. There was no correlation between the mean daily amount of opiates consumed and the weekly legal income received by subjects. However, the weekly financial deficit identified at interview which had to be made up by other activities, including illegal activities, correlated with mean daily consumption $(\mathrm{r}=$ $0.53, \mathrm{p}=0.01)$.

Table 4 demonstrates the methods that had been used by subjects over their lifetime to obtain money for drugs. These include both self-reported criminal and non-criminal activities. The table represents those activities which were specifically carried out by the subjects to obtain money for drugs. The table demonstrates that $43 \%$ had at various times managed to keep their drug use within financial limits that did not necessitate criminal activity. However, less than $20 \%$ had managed to keep their drug use within limits that did not necessitate crime during the 6 months and 1 month period before presentation to the specialist services. The table also demonstrates that a wide range of different activities had been carried out by subjects to obtain money for drugs. The most common behaviour reported was the selling of personal belongings, followed by borrowing money from family 


\begin{tabular}{||l||cc|cc|cc||}
\hline \multicolumn{1}{|c||}{} & \multicolumn{2}{|c|}{ Ever } & \multicolumn{2}{c|}{ Within last 6 } & \multicolumn{2}{c|}{$\begin{array}{c}\text { Within last } \\
\text { month }\end{array}$} \\
& n & $\%$ & $\mathbf{n}$ & $\%$ & n & $\%$ \\
\hline \hline Sold possessions & 182 & $(82)$ & 117 & $(53)$ & 81 & $(37)$ \\
Borrowed from family/friends & 175 & $(80)$ & 145 & $(66)$ & 107 & $(48)$ \\
Drug dealing & 143 & $(65)$ & 62 & $(28)$ & 38 & $(17)$ \\
Theft, shoplifting & 132 & $(60)$ & 89 & $(40)$ & 63 & $(29)$ \\
Dealer's "runner" & 125 & $(57)$ & 75 & $(34)$ & 46 & $(21)$ \\
Fraud, deception & 119 & $(54)$ & 65 & $(30)$ & 41 & $(19)$ \\
Cohabited with supplier & 109 & $(49)$ & 38 & $(17)$ & 19 & $(9)$ \\
Legal financial limits & 96 & $(43)$ & 33 & $(15)$ & 42 & $(19)$ \\
Stolen from family members & 83 & $(38)$ & 28 & $(13)$ & 19 & $(9)$ \\
Burglary & 76 & $(35)$ & 24 & $(11)$ & 12 & $(6)$ \\
Begging & 55 & $(25)$ & 33 & $(15)$ & 22 & $(10)$ \\
Official loans (banks, etc.) & 39 & $(18)$ & 14 & $(6)$ & 9 & $(4)$ \\
Robbery - shop, bank, etc. & 31 & $(14)$ & 5 & $(2)$ & 3 & $(1)$ \\
Prostitution & 24 & $(11)$ & 14 & $(6)$ & 10 & $(5)$ \\
Robbery - person (mugging) & 21 & $(10)$ & 4 & $(2)$ & 2 & $(1)$ \\
Traded sex for drugs & 20 & $(9)$ & 7 & $(3)$ & 3 & $(1)$ \\
Multiple bank accounts & 17 & $(8)$ & 3 & $(1)$ & 1 & $(1)$ \\
Pimping & 13 & $(6)$ & 3 & $(1)$ & 3 & $(1)$ \\
Other & 9 & $(4)$ & 7 & $(3)$ & 7 & $(3)$ \\
\hline
\end{tabular}

Table 4. Self-reported Criminal and other Activities carried out specifically to obtain money for drugs $(n=221)$ 
and friends. This was then followed by illegal activities, including drug dealing, acting as a "runner" for a drug dealer, (supplying drugs as a middle man or otherwise running errands within the drug trade), and cohabitation with a drug supplier. Almost half the subjects had at some time lived with a supplier which enabled them to receive free drugs.

Their most frequent criminal activity included frauds and deception, followed by theft (primarily shoplifting), burglary, robberies of banks, building societies, and robbery of persons (mugging), followed by a range of other criminal activities. Theft, burglary and fraud / deception had been the most frequent criminal activities to obtain drugs within the last six months and in the one month period prior to attending the specialist service. These activities appeared to have become more frequent than drug dealing in the period leading up to their presentation for treatment.

Table 5 demonstrates the temporal relationship between criminal behaviour and opiate use reported by the subjects. Certain criminal activities tended to precede and others to follow the onset of opiate use. For example, self-reported vandalism, burglary, violence towards persons and theft / shoplifting were all reported by subjects as tending to precede their first use of opiates. However, the proportions who reported criminal activities preceding their opiate use were less than $50 \%$ for drug dealing, fraud and deception, acquisitive violence, working and signing on, other crimes, and prostitution. Only $25 \%$ of those who engaged in prostitution reported that it had preceded their dependence on opiates.

When the temporal relationship between first ever use of opiates and their age of first crime within each category was compared, these differences emerged even more strongly. For example, crimes of theft / shoplifting, burglary, violence to the person, and vandalism were significantly more likely to have preceded the age of first use of opiates. However, crimes of fraud and deception, and a range of other crimes ("other") were significantly more likely to follow their first use of opiates. There were no significant differences for working and signing on unemployment benefit, acquisitive violence, drug dealing, and prostitution. 


\begin{tabular}{|c|c|c|c|c|c|c|c|c|c|c|}
\hline & \multicolumn{2}{|c|}{ Ever } & \multicolumn{2}{|c|}{$\begin{array}{c}\text { Preceded Drug } \\
\text { Dependence }\end{array}$} & \multicolumn{2}{|c|}{ Age First Crime } & \multicolumn{2}{|c|}{ Age First Opiate Use } & \multirow[b]{2}{*}{$\begin{array}{c}\text { paired } \\
\text { t-test }\end{array}$} & \multirow[b]{2}{*}{$\mathbf{p}$} \\
\hline & $\mathbf{n}$ & $\%$ & $\mathbf{n}$ & $\% *$ & mean* & s.d. & mean* & (s.d.) & & \\
\hline "Theft / shoplifting & 183 & (83) & 133 & (73) & 15.5 & (6.16) & 20.5 & (4.59) & -9.96 & 0.000 \\
\hline Drug dealing & 170 & (77) & 84 & (49) & 21.0 & $(5.38)$ & 21.0 & $(4.73)$ & 0.79 & NS \\
\hline Fraud, deception & 106 & $(48)$ & 48 & $(45)$ & 22.0 & $(5.72)$ & 20.5 & $(4.48)$ & 2.64 & 0.010 \\
\hline Burglary & 94 & $(43)$ & 56 & $(60)$ & 17.0 & $(5.20)$ & 20.2 & $(4.71)$ & -4.74 & 0.000 \\
\hline Violence to person & 84 & $(38)$ & 66 & (79) & 17.2 & $(4.58)$ & 20.0 & $(4.50)$ & -4.31 & 0.000 \\
\hline Working and signing & 79 & $(36)$ & 31 & (39) & 23.0 & $(6.44)$ & 23.0 & $(6.44)$ & 1.67 & NS \\
\hline Vandalism & 65 & (29) & 56 & (86) & 14.5 & $(5.32)$ & 20.5 & $(4.61)$ & -8.05 & 0.000 \\
\hline Other crimes & 55 & $(25)$ & 20 & $(36)$ & 24.2 & $(6.64)$ & 20.5 & $(4.59)$ & 3.90 & 0.000 \\
\hline Acquisitive violence & 45 & (20) & 20 & (44) & 21.0 & $(5.51)$ & 20.0 & $(4.91)$ & 1.16 & NS \\
\hline Prostitution & 36 & (16) & 9 & (25) & 22.0 & $(5.13)$ & 20.0 & $(4.39)$ & 1.85 & NS \\
\hline
\end{tabular}

* = figures for those who reported each criminal activity

Table 5. Onset of self-reported criminal behaviour and opiate use (includes drug and non-drug related crimes) 
Table 6 demonstrates the self-reported criminal behaviours (both drug and non-drug related) over the subjects' lifetime, within six months of presentation to the specialist service, and within one month of presentation, together with earnings from crime. The table shows that considerably more subjects reported criminal behaviours over their lifetime when all crimes are included (drug and non drug related) than is demonstrated in Table 4 which demonstrated self-reported criminal behaviour that was solely to obtain money for drugs. Table 6 also demonstrates that the most common criminal activities were theft / shoplifting, drug dealing, working and signing on for unemployment benefit, followed by fraud / deception, violence to the person, prostitution, and "other" crimes. The pattern within the six months preceding presentation to the specialist services was generally maintained (according to subjects' self-report) in the one month preceding presentation, but with some diminution. The table also gives an indication of these criminal activities and their frequency. Obviously, individuals who were working and signing on during the preceding period could only carry out such activities during a working week. For those engaged in prostitution, theft / shoplifting, and drug dealing, approximately half the days in the preceding six months, and during the one month prior to presentation, had been spent engaged in these activities. Less time had been spent in carrying out burglary, fraud / deception, acquisitive violence (mugging), and other categories of crime. However, Table 6 also shows the mean daily earnings from these activities, indicating that the less frequent activities of acquisitive violence, burglary, and fraud / deception produced larger mean daily earnings than the more frequent criminal activities of prostitution, working and signing on, theft / shoplifting, drug dealing, and "other" categories of crime.

Fifty-five subjects (25\%) reported that there had been an increase in their illegal activities during the 6 months prior to presentation, with $34(16 \%)$ an increase in the preceding one month prior to presentation. Forty-eight $(22 \%)$ reported that this increase in their criminal activity had been the prime motivation in their seeking treatment; $148(67 \%)$ believed that there was a strong link between their criminal activities and their drug habit, with 110 (50\%) claiming at interview that their criminal activities were now carried out solely to fund their drug habit; 115 (52\%) had observed that as the amount of opiates they consumed had increased, their criminal activity had also increased. However, 64 (29\%) admitted that they derived considerable enjoyment and excitement from criminal activities; 51 subjects (23\%) reported that they would always be intoxicated before crime, 60 (27\%) sometimes, 


\begin{tabular}{|c|c|c|c|c|c|c|c|c|c|c|c|c|c|}
\hline & \multicolumn{2}{|c|}{ Ever } & \multicolumn{2}{|c|}{$\begin{array}{c}\text { With last } 6 \\
\text { months }\end{array}$} & \multicolumn{2}{|c|}{$\begin{array}{c}\text { Mean no. days } \\
\text { in } 6 \text { months } \\
\text { per offender }\end{array}$} & \multicolumn{2}{|c|}{$\begin{array}{l}\text { Within last } \\
\text { month }\end{array}$} & \multicolumn{2}{|c|}{$\begin{array}{l}\text { Mean no. days } \\
\text { in last month } \\
\text { per offender }\end{array}$} & \multirow{2}{*}{$\begin{array}{c}\text { Median } \\
\text { daily } \\
\text { earnings } \\
£\end{array}$} & \multirow{2}{*}{$\begin{array}{c}\text { Mean } \\
\text { Daily } \\
\text { earnings } \\
£\end{array}$} & \multirow{2}{*}{$\begin{array}{c}\text { Range daily } \\
\text { earnings } \\
\mathfrak{f}\end{array}$} \\
\hline & $\mathbf{n}$ & $(\%)$ & $\mathbf{n}$ & $(\%)$ & $\mathbf{n}$ & (s.d.) & $\mathbf{n}$ & $(\%)$ & $\mathbf{n}$ & (s.d.) & & & \\
\hline "Theft / shoplifting & 183 & (83) & 101 & (46) & 82 & (65.6) & 82 & (37) & 16 & (10.3) & ב50 & 84 & $1-600$ \\
\hline Drug dealing & 170 & (77) & 91 & (42) & 78 & $(69.3)$ & 65 & $(30)$ & 14 & $(10.7)$ & 60 & 209 & $5-7,000$ \\
\hline Fraud / deception & 106 & $(48)$ & 36 & (16) & 29 & $(54.9)$ & 17 & (8) & 9 & $(10.6)$ & 225 & 861 & $1-17,000$ \\
\hline Burglary & 94 & (43) & 18 & (8) & 45 & $(67.5)$ & 13 & (6) & 10 & $(10.9)$ & 250 & 537 & $10-5,000$ \\
\hline Violence to person & 84 & $(38)$ & 14 & (6) & 6 & $(10.2)$ & 9 & (4) & 13 & $(32.4)$ & - & - & - \\
\hline Working \& signing & 79 & (36) & 47 & $(21)$ & 134 & $(62.7)$ & 36 & (16) & 26 & (5.9) & 7 & 7 & $4-50$ \\
\hline Vandalism & 65 & (29) & 3 & (1) & 4 & $(3.1)$ & 2 & (1) & 1 & $(0.0)$ & - & - & - \\
\hline Other & 55 & $(25)$ & 40 & (18) & 40 & $(70.9)$ & 30 & (14) & 17 & $(10.9)$ & 25 & 43 & $2-500$ \\
\hline Acquisitive violence & 45 & (20) & 7 & (3) & 18 & $(24.4)$ & 4 & (2) & 9 & (11.4) & 400 & 2,419 & $20-25,000$ \\
\hline Prostitution & 36 & (16) & 14 & (6) & 101 & (72.9) & 12 & (5) & 17 & (11.1) & 100 & 121 & $8-700$ \\
\hline
\end{tabular}

Table 6. Self-reported Criminal Behaviours and Earnings from Crime (includes Drug and non-drug related crimes) 
but 52 (24\%) would never take drugs before carrying out crimes; 54 (25\%) claimed that they usually carry out their criminal activities when experiencing cravings for drugs, and an additional $51(23 \%)$ sometimes when experiencing withdrawal or cravings. A total of 82 (37\%) reported that their criminal behaviour was primarily due to their fear of experiencing withdrawal symptoms, an additional 52 (24\%) that crimes were sometimes carried out due to fear of withdrawal, with 115 (53\%) admitting that they would sometimes or regularly take serious risks of apprehension or detection when committing crimes due to their cravings for opiates.

\section{Previous Institutional History}

Only 35 (16\%) had never been arrested for a criminal offence; 49 (22\%) had been in approved schools or detention centres, 54 (25\%) in youth custody or borstals, 77 (35\%) had served prison sentence, and a further $22(10 \%)$ had also been in prison, but only whilst on remand. A total of $76(35 \%)$ had experienced withdrawal symptoms whilst in a prison setting and 44 $(20 \%)$ now reported that the experience of withdrawal in prison had motivated their seeking treatment.

\section{Family History}

Table 7 demonstrates the subjects' family history, indicating that a high proportion had first degree relatives who also had a history of drug or alcohol abuse. One third had a sibling who was also dependent on drugs. Almost half had a current sexual partner who was a drug user, with 49 (22\%) reporting that their relationship had started as a result of a similar drug-using lifestyle. In addition, 31 (14\%) subjects had introduced their partner to opiate use for the first time, and $17(8 \%)$ had been introduced to opiates themselves by their partner; $156(71 \%)$ subjects reported that there were current relationship difficulties, including arguments and violence, due to the subjects' drug use, and 137 (62\%) reported that they were having sexual difficulties due to their use of opiates. 


\begin{tabular}{|c|c|c|}
\hline & $\overline{\mathbf{n}}$ & $\%$ \\
\hline Mother & & \\
\hline Drug abuse & 11 & 5 \\
\hline Alcohol abuse & 25 & 11 \\
\hline Psychiatric history & 36 & 16 \\
\hline Criminal history & 14 & 6 \\
\hline Father & & \\
\hline Drug abuse & 18 & 8 \\
\hline Alcohol abuse & 66 & 30 \\
\hline Psychiatric history & 15 & 7 \\
\hline Criminal history & 43 & 19 \\
\hline Sibling drug dependent & 62 & 30 \\
\hline Current partner drug user & 109 & 49 \\
\hline
\end{tabular}

Table 7. Family History of Subjects 


\section{Early Adversity}

Table 8 demonstrates the social environment of the subjects before the age of 15, indicating that many had experienced multiple forms of social and emotional deprivation. Almost half of the subjects had been separated from their fathers before the age of 15 due to divorce or desertion, and $41 \%$ had experienced violence between their parents or parental figures. Nearly one third had experienced emotional neglect from their parents, and 29\% physical abuse or cruelty.

\section{Axis I Mental Disorders}

Table 9 demonstrates the lifetime and 6 month prevalence of mental disorders and parasuicide in the subjects. Over half (54\%) had at some stage experienced a major mental disorder, and $30 \%$ had at some stage attempted to kill themselves. The most prevalent conditions over their lifetime were alcohol dependence, followed by depression, with $13 \%$ of subjects having been depressed within the 6 months prior to presentation for treatment.

\section{Axis II DSM-III-R Personality Disorders}

Table 10 demonstrates that almost two thirds of subjects had a personality disorder according to the DSM-III-R Axis II classification. Antisocial personality disorder was the most prevalent in $49 \%$, followed by avoidant, borderline, and paranoid personality disorders. 


\begin{tabular}{||l||cc||}
\hline \multicolumn{1}{||}{} & n & $\%$ \\
\hline \hline Peers encouraged crime & 111 & 51 \\
Separated from father & 99 & 45 \\
Violence between parents & 89 & 41 \\
Emotional neglect from parents & 71 & 32 \\
Reared in poverty & 67 & 31 \\
Physical abuse / cruelty from parents & 63 & 29 \\
Separated from mother & 33 & 15 \\
Local authority care & 31 & 14 \\
Sexual abuse before 15 yrs & 30 & 14 \\
Family encouraged drug use & 29 & 13 \\
Reared by relatives & 20 & 9 \\
Sexual abuse (non-family) & 18 & 8 \\
Adopted / fostered & 17 & 8 \\
Family encouraged crime & 17 & 8 \\
Sexual abuse (family member) & 16 & 7 \\
\hline \hline
\end{tabular}

Table 8. Early Social Environment of Subjects (before 15 years) $(n=221)$ 


\begin{tabular}{||l||cc|cc||}
\hline & Lifetime Prevalence & \multicolumn{2}{|c||}{ m ms Prevalence } \\
& $\mathbf{n}$ & $\mathbf{( \% )}$ & $\mathbf{n}$ & $\mathbf{( \% )}$ \\
\hline \hline Alcohol dependence & 101 & $(47)$ & 15 & $(7)$ \\
Depression & 86 & $(39)$ & 28 & $(13)$ \\
Parasuicide & 64 & $(30)$ & 4 & $(2)$ \\
Phobic disorder & 39 & $(18)$ & 28 & $(13)$ \\
Anxiety disorder & 22 & $(10)$ & 4 & $(2)$ \\
Dysthymia & 19 & $(9)$ & 4 & $(2)$ \\
Panic disorder & 17 & $(8)$ & 4 & $(2)$ \\
Drug-induced psychosis & 15 & $(7)$ & - & - \\
Obsessive-compulsive disorder & 6 & $(3)$ & 2 & $(1)$ \\
Schizophrenia & 3 & $(1)$ & 2 & $(1)$ \\
Mania / hypomania & 2 & $(1)$ & 1 & $(1)$ \\
Schizoaffective disorder & 1 & $(1)$ & 1 & $(1)$ \\
Somatization & 1 & $(1)$ & 1 & $(1)$ \\
No Axis I disorder & 100 & $(46)$ & - & - \\
\hline \hline
\end{tabular}

Table 9. Lifetime and 6 month prevalence of Axis I Mental Disorders and Parasuicide $(n=220)$ 


\begin{tabular}{||l||cc||}
\hline & $\mathbf{n}$ & $(\mathbf{\%})$ \\
\hline \hline Antisocial & 102 & $(49)$ \\
Avoidant & 31 & $(15)$ \\
Borderline & 28 & $(14)$ \\
Paranoid & 27 & $(13)$ \\
Passive-aggressive & 16 & $(8)$ \\
Obsessive-compulsive & 14 & $(7)$ \\
Narcissistic & 9 & $(4)$ \\
Dependent & 7 & $(3)$ \\
Self-defeating & 7 & $(3)$ \\
Schizoid & 5 & $(2)$ \\
Histrionic & 4 & $(2)$ \\
Schizotypal & 2 & $(1)$ \\
None & 75 & $(36)$ \\
\hline \hline
\end{tabular}

Table 10. DSM-III-R Axis II Personality Disorders $(n=206)$ 


\section{CONCLUSION}

Although the sample of subjects interviewed in the study were representative of opiate addicts attending drug dependency services in East London, they may not be typical of opiate users in the general population. They were predominantly male, white, of British or other European origin, unemployed, and with a history of abusing a wide range of drugs over the lifetime. Most had injected at some stage in their drug careers, but nearly half were now using heroin by "dragon chasing". Their early histories were characterised by emotional deprivation and there were high rates of criminality and drug use among family members. A significant subgroup were at risk for Hepatitis and HIV as a result of their high risk behaviours and many had a range of health problems associated with opiate abuse and injecting. Over half had experienced co-morbid mental disorder over their lifetime, most significantly alcohol dependence, and episodes of depressive illness. Over half had a co-morbid personality disorder predominantly Antisocial Personality Disorder.

The subjects demonstrated a wide range of activities, legal and illegal, to obtain money for drugs. Most had at some time sold their possessions and borrowed from family and friends. Only $15 \%$ had kept their expenditure on opiates within legal financial limits over the six month period prior to presentation at the services so that the remaining $85 \%$ subjects obtained money to support their drug habit through various illegal means, most frequently theft (including shop-lifting), followed by drug-dealing, fraud and deceptions, and burglary. Of the sub-group who were officially in work, over half were illegally claiming unemployment benefit. A sub-group were sex workers or were engaged in the sex industry and a further subgroup had engaged in serious crimes of robbery against the person and robberies of building societies or post offices.

More frequent criminal activities such as thefts and drug-dealing yielded less money on a daily basis than infrequent activities such as frauds and burglaries. But offences such as burglary carried much higher risks of a longer sentence of imprisonment if the subject was apprehended and subsequently convicted. This suggested a trade-off for subjects in their choice between high-risk criminal activities with high potential rewards and more frequent crimes with lower yields.

Subjects had a very low annual income from legal sources. But the average subject spent over 
$£ 10,000$ per year on opiates obtained from illicit sources. The true cost of their criminal activities was substantially higher. For example, the subjects reported that when stealing new items from shops (often stolen to order) they would typically receive around one third of the retail price for the goods when they sold them on. Similarly, money obtained through burglaries did not include the cost of damage to property whilst breaking in, replacement of stolen items, involvement of the police, etc. However, this annual expenditure by the average subject reflects a considerable investment of time and energy engaged in illegal activities, together with a steady source of income, and with guaranteed high profits, for those who supplied them with opiates and those who fenced their stolen goods. Overall, this illegal activity represented a considerable underground criminal economy in the area studied, where crime by heroin addicts constituted a significant component of the overall level of crime within the community.

Virtually all subjects admitted to previous criminal offences even if they had not been arrested and most subjects had been engaged in delinquency which had preceded their first use of opioids. This sample is not dissimilar to that of Hammersley et al (1989) and there was a strong correlation between the level of their opiate consumption and the amount of money obtained through criminal activities. This could mean that subjects who were heavily involved in criminal activities had an excess of funds available to finance the use of drugs, as well as funds for other goods and amenities. Thus, the opiate use could be construed as just one facet of an overall deviant lifestyle in a substantial number of these subjects. However, more than half subjectively believed that there was a strong link between their criminal activities and their drug habit and half claimed at interview that their crimes were carried out solely to fund their dependence on drugs. It is probable, however, that the choice of a treatment-seeking sample had lead to these findings and the considerably different impression to that obtained from the studies of Hammersley and colleagues which had included prisoners and later youths from the community. A significant group of these treatment-seeking subjects had described an escalation in both their drug taking and criminal activities prior to their presentation at these NHS services and that this had also determined their realisation that they needed treatment. It is possible that subgroups of the subjects included in the studies by Hammersley might at some stage reach a similar phase in their drug and criminal careers where they identify the need for treatment and at a time when their use of heroin and other opiates would be no longer under their control, as with many of the subjects in this present study. At this point their criminality was partly "driven" by the need to obtain money for 
drugs. The contrast in findings between these different samples is probably explained by the fact that the subjects included in them had entered very different phases in their lifetime drug and crime careers. These should not be considered fixed and inflexible. The direction of the drugs - crime connection can be in different directions for different individuals at different times over their life course. 


\section{CRIME AND OPIOID DEPENDENCE: \\ CHANGES AFTER ENTERING A METHDADONE TREATMENT PROGRAMME}

Andrea Carvell, Jeremy Coid, Zelpha Kittler 


\section{AIMS OF STUDY}

1. To identify whether methadone treatment reduces opiate and other drug misuse.

2. To identify whether methadone treatment reduces self-reported criminal activity and earnings from crime.

3. To identify which criminal activities are reduced by methadone treatment and which are not.

4. To identify whether opioid use causes crime or crime causes opioid use.

5. To identify subgroups of opioid users based on their history of drug use and criminal careers.

\section{REVIEW OF THE LITERATURE}

There is increasing interest in the effectiveness of methadone treatment in reducing the criminal activity of opioid misusers. To some extent this reflects the growing public concern over rising crime rates in many westernised countries and the consequent politicisation of "law and order". Two major reviews of the literature and a meta-analysis of studies have recently concluded that methadone maintenance treatment is successful in not only in reducing the illicit use of opiates, its associated mortality and morbidity, improving social rehabilitation, lowering the risk of HIV infection, but that it also reduces criminal activity (Bertschy 1995, Farrell et al 1994, Marsch 1998).

Not all studies have demonstrated that methadone treatment reduces frequency of criminal activity, but the majority do demonstrate significant reductions amongst those who are in treatment (McGlothin \& Anglin 1981, Nolimal \& Crowley 1990, Anglin \& Powers 1991, Mavis et al 1991, Longshore et al 1994). However, wide variations in the level of efficacy have been observed. For example, methadone successfully reduced illicit opioid use in 36$73 \%$ of patients (McGlothin \& Anglin 1981, Strain et al 1993), and crime rates in 20-90\% of patients (Dole et al 1968, Maddux \& McDonald 1973, Anglin \& McGlothin 1984, Nurco et al 1984), whilst a small number of studies reported absence of an effect (Anderson \& Nutter 
1975, Paxton et al 1978, Bale et al 1980).

More recently, Marsch (1998) carried out a metanalysis of 24 studies which have investigated the effect of methadone maintenance treatment in reducing criminal behaviour. There was considerable heterogeneity between sample sizes and methods used. Some studies included only drug-related crimes in their outcome measurements, others addressed both drug and property crimes, whilst others included drug and non-drug related crimes such as traffic violations, vagrancy, and misdemeanours. The studies with significant positive findings tended to have measured either drug-related crimes or combinations of drug- and propertyrelated crimes. When analyses were made of the effectiveness of methadone maintenance treatment in reducing all criminal behaviours by subjects in treatment, the studies demonstrated an overall small to medium effect size. However, when studies were analysed in accordance with crime typology, and when homogenous studies were independently assessed, the nature of the relationship between methadone maintenance interventions and criminal behaviours was clarified further. There appeared to be a significant, overall large effect of treatment in those which investigated the effectiveness in reducing specifically drugrelated criminal behaviours. A significant, but overall small to moderate effect, was obtained when examining interventions in reducing both drug-and property-related criminal activities combined. Only a small effect was demonstrated on combined drug-and non-drug related criminal behaviours.

The results indicated that the effectiveness of methadone maintenance treatment is most apparent in its reduction in drug-related criminal behaviours, although a substantial effect on drug-and property-related criminal behaviours was also evident in the studies. Marsch concluded that this latter finding was probably an indirect result of the intervention's direct effect on reducing illicit opiate use, in that as drug use decreases, criminal behaviours related to the procurement of funds to support drug use also decrease. The inability of methadone maintenance intervention to produce a consistent and substantial effect on combined drug-and non-drug related crimes suggested that treatment effects are restricted only to those crimes that are associated with drug use. Some opiate-dependent individuals appeared to have a propensity to engage in certain criminal behaviours, not directly related to drug use. Several studies specifically reported a negligible effect on non-drug related crimes, whilst reporting a significant effect on drug-related crimes (Cushman 1971, Jacobs et al 1978, Bale et al 1980), and with one study even observing an increase in non-drug related crimes after admission to 
treatment (Boudoris, 1976).

These findings largely correspond to arguments that previous criminality is a much better statistical explanation of the extent of opioid use than opioid use is of crime (Hammersley et al 1989, Hammersley et al 1990). In a study of incarcerated drug users and attenders at Scottish drug clinics, the best predictor of crime frequency during periods of drug use was the breadth of previous criminal experience (Hammersley et al 1989). In a second study of teenage community-based drug users, Hammersley et al 1990 confirmed that criminal drugusing teenagers were better regarded as "delinquents" than "drug abusers". Delinquent behaviour of all kinds appeared to be increased by prior criminal experience, having delinquent friends, and lack of conventional social support (notably having spent time in local authority care). Thus, the notion that many criminal activities are not directly related to opioid use and tend to precede the use of opioids, is reflected in findings suggesting that methadone maintenance treatment is less effective for certain crimes. Nevertheless, the results of Marsch's meta-analysis do not entirely support the arguments made by Hammersley and colleagues and tend to promote a more positive message that treatment interventions can lead to reduction in a range of crimes in individuals who enrol in treatment programmes.

Whilst considerable study has been devoted to examining the association between crime and opioid use, one under-utilised approach has been the examination of the additional relationship of these two variables upon the outcome of treatment with methadone. However, this requires a modified view of treatment effectiveness. Hall (1993) has argued that appraising treatment effectiveness in the addictions field has been made unnecessarily difficult by refusing to settle for less than perfection. Insistence on abstinence as the only acceptable outcome of treatment has lead some practitioners and policy-makers to seriously underestimate the therapeutic benefits of methadone maintenance treatment. Within this context, Hall argued that importance should be attached to the indisputable fact that most studies have convincingly demonstrated that methadone maintenance not only reduces illicit drug use but also criminality. It does appear, however, that certain drug maintenance programmes are more effective than others in reducing criminal activity and that certain addicts, particularly those with extensive prior criminality, are more resistant to the effects of treatment. Nevertheless, two studies in Australia and the USA (Sechrest 1979, Bell et al 1992), have demonstrated that retention in treatment programme (rather than drop-out) is the most important variable in reducing subsequent criminal involvement. The two most 
important variables which influence retention appear to be the philosophy of the treatment approach taken by the clinic to which the subject is referred and the dose of methadone which is prescribed (Capelhorn \& Bell, 1991). Nevertheless, in a USA study (Sechrest, 1979), drug offence rates dropped only after a year in treatment and the rates of other offences did not fall until 2-3 years of treatment, indicating that additional important factors may have been operating once the drug-user had been retained within the programme. Thus, whilst a client's willingness and ability to change are important, treatment factors are additionally important in retaining clients.

It has been argued by Bell et al (1992) that remaining in treatment can simply be attributed to motivation. A highly controlled programme, which did not tolerate additional drug use, was not found to be more effective in reducing criminal activity than a tolerant programme. Rather, the more regimented programme was less effective as those expelled from treatment then continued to offend. Additional factors of a chosen criminal lifestyle and marked antisocial or psychopathic personality traits were not measured in these subjects. These factors could independently influence both attendance and the likelihood of committing further crimes in a subgroup of clients. This subgroup may also be especially prone to drop out of a treatment programme, however effective or tolerant, a possibility which requires further examination. One additional important factor which must be taken into account is the finding that in certain clinics the period just before entry into a methadone programme (or whilst on the waiting list for entry) is associated with an escalation in criminal activity populations (Newman et al 1984, Bell et al 1992), possibly motivating entry into the programme in the first place as the addict progressively fails to cope with the increasing economic demand of supporting a drug habit. This phenomenon would appear to give some support to the argument for the "simple" or direct relationship between opioid use and crime and has important methodological implications in the need to control for escalating criminal activity in the early stages of treatment and the risk that such individuals may drop out of studies due to their increased risk of arrest.

In conclusion, the literature on methadone maintenance provides convincing evidence that treatment can reduce the criminal activities of individuals who have become dependent on opioids. However, the evidence is less convincing for criminal activities that are not directly drug-related and questions still remain over the effectiveness for subjects who have extensive criminal histories pre-dating their dependence on opioids and who are committed to a 
criminal lifestyle. A more detailed study of response to and compliance with methadone maintenance treatment may help further clarify (i) the associations between crime and opioid use, (ii) whether previous patterns of criminality have a major effect on outcome, and (iii) whether there are more complex interactions between these two sets of variables leading to final outcome, measured both in terms of continuing opioid abuse and criminal activity.

\section{METHOD}

The study was conducted at a community-based service for drug abusers in Hackney, a socioeconomically deprived, inner city of East London. During the period of study, a Community Drug Team (CDT) operated as an outpatient day service. This acted as a primary filter for drug users of all types when accessing services. These services included a methadone detoxification programme, counselling for all forms of drug misuse, as well as onward referral for patients seeking methadone maintenance. Those individuals with three or more failed attempts at methadone detoxification, or those with significant psychiatric comorbidity (history of psychiatric treatment or psychosis) were referred to a hospital-based Drug Dependency Unit (DDU) nearby which was a component of the overall service in Hackney for drug users.

The criteria for entry into the study were (i) untreated opiate dependence according to DSMIII-R criteria for a minimum of six months and (ii) that they should have resided in the community for a six-month period prior to entry into the study to enable them to be at liberty to commit crimes should they wish to do so. All prospective clients attending the service on a walk-in basis and seeking access to the methadone programme were given a leaflet explaining the project and its aims. All clients agreeing to be interviewed signed a consent form and received a $£ 10$ supermarket voucher. The majority of clients were interviewed within the first week of presentation, usually while undergoing the assessment process for the methadone programme and prior to being accepted into the programme and given a prescription of methadone. During this first interview, data were collected on their self-reported criminal activities in the one month prior and six months period prior to their presentation at the CDT. The majority of subjects, if they did not drop out of attendance at the CDT prior to being enrolled into methadone treatment, received a prescription for methadone within two weeks. A sample of 116 patients who had initially been interviewed at presentation at the CDT were recruited into the study at the point at which they started the treatment programme and 
received a prescription of methadone. Each subject consented to a follow-up interview at the one month stage after starting treatment and at six months after starting treatment for which they were paid a $£ 10$ supermarket voucher on each occasion. Of these subjects, a subgroup of $81(70 \%)$ completed all three stages of interviewing and were successfully followed-up at the one month and six month points. Interviewing from first presentation and to the six month follow-up for the treated cohort took place from July 1996 to April 1998. Subjects were given a choice of location for the interview, either in the treatment setting (the CDT or DDU) or in the community, usually their homes.

A subgroup of 35 subjects (30\%) dropped out of the study, the majority of whom could not be traced and/or who persistently failed to attend appointments to be interviewed. Their characteristics are compared with the treated sample in Table 1. This demonstrated that, as was expected, the majority of the sample were male, though slightly more females were interviewed as a result of male drop-outs. The average age of the sample was 31.5 years, with a range of 20-48 years. There were no significant differences between drop-outs and the treated sample according to ethnicity, accommodation, employment, and marital status. There were no significant differences between the drop-outs and treated sample in their history of drug misuse.

\section{Data Analysis}

The data were analysed at three levels. Firstly, examinations were made of the relationship between patterns of drug use and patterns of criminal behaviour, and whether there was a correlation between the level of consumption of illicit drugs and the monetory gain from criminal activity carried out to obtain them. Secondly, the study examined whether the treatment received by the subjects influenced their drug use and their criminal behaviour by examining whether there were differences between the level of drug consumption and the level of criminal behaviour over six months prior to entry to the treatment and at six months after receiving treatment.

The second stage of the analysis examined the impact of intervening variables on the relationships which had been examined in the first level of analysis. The variables employed in this second level included: 
Table 1: Demographic Characteristics of the Total sample (N-116), the Treated Cohort $(n=81)$, and the Drop-out Group $(n=35)$

\begin{tabular}{|c|c|c|c|c|}
\hline Characteristics & & $\begin{array}{c}\text { Total Sample } \\
\text { N=116 } \\
\text { n }(\%)\end{array}$ & $\begin{array}{c}\text { Cohort } \\
\text { Sample } \\
n=81 \\
n(\%) \\
\end{array}$ & $\begin{array}{c}\text { Cohort Drop- } \\
\text { outs } \\
\text { n=35 } \\
\text { n }(\%) \\
\end{array}$ \\
\hline Sex & $\begin{array}{l}\text { Male } \\
\text { Female }\end{array}$ & $\begin{array}{ll}83 & (72) \\
32 & (28)\end{array}$ & $\begin{array}{ll}55 & (68) \\
26 & (32)\end{array}$ & $\begin{array}{rr}28 & (80) \\
7 & (22)\end{array}$ \\
\hline Age & Mean & $30.4 \mathrm{yrs}$ & $29.0 \mathrm{yrs}$ & $33.6 \mathrm{yrs}$ \\
\hline Ethnicity & $\begin{array}{l}\text { White British } \\
\text { Black/mixed race } \\
\text { European } \\
\text { Other }\end{array}$ & $\begin{array}{rr}82 & (71) \\
10 & (9) \\
22 & (19) \\
2 & (2)\end{array}$ & $\begin{array}{r}58(72) \\
5(6) \\
17(21) \\
1(1)\end{array}$ & $\begin{array}{rc}24 & (69) \\
5 & (14) \\
5 & (14) \\
1 & (3)\end{array}$ \\
\hline Accommodation & $\begin{array}{l}\text { Council/H.A. } \\
\text { Private Rent } \\
\text { N.F.A. } \\
\text { Squat } \\
\text { Hostel } \\
\text { With family } \\
\text { Other }\end{array}$ & $\begin{aligned} 23 & (28) \\
29 & (25) \\
20 & (17) \\
16 & (14) \\
9 & (8) \\
9 & (8) \\
1 & (1)\end{aligned}$ & $\begin{array}{cc}21 & (26) \\
18 & (22) \\
15 & (19) \\
11 & (14) \\
7 & (9) \\
8 & (10) \\
1 & (1)\end{array}$ & $\begin{array}{cc}11 & (31) \\
11 & (31) \\
5 & (14) \\
5 & (14) \\
2 & (6) \\
1 & (3) \\
& -\end{array}$ \\
\hline Employment & $\begin{array}{l}\text { Unemployed/ } \\
\text { Sickness benefit } \\
\text { Employed } \\
\text { F/t Education }\end{array}$ & $\begin{array}{r}81(77) \\
25(22) \\
2(2)\end{array}$ & $\begin{array}{r}71(88) \\
8(10) \\
2(3)\end{array}$ & $\begin{array}{r}27(77) \\
8(23) \\
0(0) \\
\end{array}$ \\
\hline Marital Status & $\begin{array}{l}\text { Single } \\
\text { Co-habiting } \\
\text { Married } \\
\text { Divorced }\end{array}$ & $\begin{array}{c}63(54) \\
35(30) \\
7(6) \\
11(10)\end{array}$ & $\begin{array}{c}46(57) \\
26(32) \\
4(5) \\
5(6)\end{array}$ & $\begin{array}{l}17(49) \\
9(26) \\
3(9) \\
6(17)\end{array}$ \\
\hline
\end{tabular}


Table 2: Comparison of Drug Misuse History in Treated Group and Drop-outs

\begin{tabular}{|c|c|c|c|c|}
\hline \multicolumn{2}{|l|}{ Characteristics } & $\begin{array}{c}\text { Total Sample } \\
\mathrm{N}=116\end{array}$ & $\begin{array}{c}\text { Cohort Sample } \\
n=81\end{array}$ & $\begin{array}{c}\text { Cohort Drop- } \\
\text { outs } \\
n=35\end{array}$ \\
\hline \multicolumn{2}{|c|}{ Age of onset of opiate dependency $\quad$ Mean } & $24.6 \mathrm{yrs}$ & 23.8 yrs & $26.6 \mathrm{yrs}$ \\
\hline \multicolumn{2}{|c|}{ Period of Dependency $\quad$ Mean } & $5.2 \mathrm{yrs}$ & $5.0 \mathrm{yrs}$ & \\
\hline Heroin & $\begin{array}{l}\text { No. and (\%) using drug } \\
\text { Mean use in last month } \\
\text { Mean daily cost in last month }\end{array}$ & $\begin{array}{c}111(96) \\
24.2 \text { days } \\
£ 41.13 \\
\end{array}$ & $\begin{array}{c}80(99) \\
24.9 \text { days } \\
£ 40.49 \\
\end{array}$ & $\begin{array}{l}31(89) \\
6.1 \text { days } \\
£ 3.18 \\
\end{array}$ \\
\hline $\begin{array}{l}\text { Methadone } \\
\text { (illicit) }\end{array}$ & $\begin{array}{l}\text { No. and (\%) using drug } \\
\text { Mean use in last month } \\
\text { Mean daily cost in last month }\end{array}$ & $\begin{array}{l}68(59) \\
5.6 \text { days } \\
£ 3.09\end{array}$ & $\begin{array}{l}47(58) \\
5.3 \text { days } \\
£ 3.05\end{array}$ & $\begin{array}{l}21(60) \\
6.1 \text { days } \\
£ 3.18\end{array}$ \\
\hline $\begin{array}{l}\text { Other } \\
\text { Opiates }\end{array}$ & $\begin{array}{l}\text { No. and (\%) using drug } \\
\text { Mean use in last month } \\
\text { Mean daily cost in last month }\end{array}$ & $\begin{array}{l}22(19) \\
2.3 \text { days } \\
£ 0.29\end{array}$ & $\begin{array}{l}18(22) \\
1.6 \text { days } \\
£ 0.33\end{array}$ & $\begin{array}{c}4(11) \\
1.4 \text { days } \\
£ 0.20\end{array}$ \\
\hline Amphetamines & $\begin{array}{l}\text { No. and (\%) using drug } \\
\text { Mean use in last month } \\
\text { Mean daily cost in last month }\end{array}$ & $\begin{array}{c}16(14) \\
0.7 \text { days } \\
£ 0.40 \\
\end{array}$ & $\begin{array}{l}10(12) \\
0.4 \text { days } \\
£ 0.32 \\
\end{array}$ & $\begin{array}{c}6(17) \\
1.4 \text { days } \\
£ 0.57 \\
\end{array}$ \\
\hline Barbiturates & $\begin{array}{l}\text { No. and (\%) using drug } \\
\text { Mean use in last month } \\
\text { Mean daily cost in last month }\end{array}$ & $0(0.0)$ & $0(0.0)$ & $0(0.0)$ \\
\hline Crack & $\begin{array}{l}\text { No. and (\%) using drug } \\
\text { Mean use in last month } \\
\text { Mean daily cost in last month }\end{array}$ & $\begin{array}{l}45(39) \\
2.3 \text { days } \\
£ 12.00\end{array}$ & $\begin{array}{l}32(40) \\
1.7 \text { days } \\
£ 11.97 \\
\end{array}$ & $\begin{array}{l}13(37) \\
3.8 \text { days } \\
£ 12.07\end{array}$ \\
\hline LSD & $\begin{array}{l}\text { No. and (\%) using drug } \\
\text { Mean use in last month } \\
\text { Mean daily cost in last month }\end{array}$ & $\begin{array}{l}1(1) \\
4 \text { days } \\
£ 2.00\end{array}$ & $\begin{array}{l}1(1) \\
4 \text { days } \\
£ 2.00\end{array}$ & $0(0.0)$ \\
\hline Cannabis & $\begin{array}{l}\text { No. and (\%) using drug } \\
\text { Mean use in last month } \\
\text { Mean daily cost in last month }\end{array}$ & $\begin{array}{l}77(66) \\
9.9 \text { days } \\
£ 2.46 \\
\end{array}$ & $\begin{array}{c}54(67) \\
9.9 \text { days } \\
£ 2.58 \\
\end{array}$ & $\begin{array}{l}23(66) \\
9.7 \text { days } \\
£ 2.20 \\
\end{array}$ \\
\hline $\begin{array}{l}\text { Benzo- } \\
\text { diazepines }\end{array}$ & $\begin{array}{l}\text { No. and (\%) using drug } \\
\text { Mean use in last month } \\
\text { Mean daily cost in last month }\end{array}$ & $\begin{array}{c}56(48) \\
3.96 \text { days } \\
£ 0.54 \\
\end{array}$ & $\begin{array}{l}38(47) \\
3.31 \text { days } \\
£ 0.46 \\
\end{array}$ & $\begin{array}{l}18(51) \\
5.5 \text { days } \\
£ 0.73 \\
\end{array}$ \\
\hline Sovlvents & $\begin{array}{l}\text { No. and (\%) using drug } \\
\text { Mean use in last month } \\
\text { Mean daily cost in last month }\end{array}$ & $\begin{array}{l}1(1) \\
4 \text { days } \\
£ 2.00 \\
\end{array}$ & $\begin{array}{l}1(1) \\
4 \text { days } \\
£ 2.00 \\
\end{array}$ & $0(0.0)$ \\
\hline Ecstasy & $\begin{array}{l}\text { No. and (\%) using drug } \\
\text { Mean use in last month } \\
\text { Mean daily cost in last month }\end{array}$ & $\begin{array}{c}13(12) \\
0.29 \text { days } \\
£ 0.72\end{array}$ & $\begin{array}{l}8(10) \\
0.22 \text { days } \\
£ 0.78\end{array}$ & $\begin{array}{c}5(14) \\
0.46 \text { days } \\
£ 0.86\end{array}$ \\
\hline
\end{tabular}

Patterns of drug use - temporal patterns, poly-drug use, recreational use, etc. 
Patterns of criminal behaviour - acquisitive crimes, violent crimes, drug offences

Treatment programme, attendance profile - a measure of the length of time since leaving the programme in the case of subjects who had dropped out but who were subsequently traced.

Structural characteristics of the sample - age, gender, employment, accommodation status, family, and environmental background.

A third level of exploratory analysis was then carried out which attempted to identify exemplars, or typical profiles, of drug and criminal behaviour within the sample, and then to examine these profiles in relation to the treatment outcomes.

In the first stage, assessment of the relationship between drug use and criminal behaviours was carried out using correlation analysis and regression analysis. In the second stage, the exploration of intervening variables was carried out using analysis of variance and analysis of co-variance. In the third stage of analysis, the initial exploratory examination of behavioural profiles for drug use and criminal behaviour used Factor Analysis.

In the first level of analysis, the effects of participating in the treatment programme involved the computation of indicators which measured behavioural change, using a six month period prior to treatment and comparing this with a six month period post-entry to treatment. Measures of drug use and criminal activity were compared for the two time periods using Students t-test and Wilcoxon's matched pairs test. Additional variables were then computed to obtain the difference in the monthly cost of all drugs consumed by subjects, the difference in average daily expenditure on drugs, the differences in weekly income from legal sources, and the differences in total value of criminal activity over each six month period. A further variable was computed to assess the influence of family and environmental background on drug use and criminal behaviour. This was constructed from a simple aggregate measure intended to reflect exposure to family and early environmental problems. These included parental/family drug and alcohol use, parental/family criminal behaviour, being placed with non-familiar carers during childhood (fostering, adoption, state care), adverse home environment (exposure to poverty, emotional, physical and sexual abuse), and exposure to 
peer groups during childhood who encouraged drug use and criminal activity.

A fourth stage of data analysis was then carried out which assessed the intervening variables which had lead to measures of outcome using analysis of variance of both drug and criminal behaviour variables, measures of attendance for treatment during the six month period, and demographic data.

A fifth stage of analysis finally examined behaviour profiles of previous drug and criminal activities on behavioural change using cluster analysis, discriminant function analysis, and regression analysis.

\section{Results}

1. Relationship Between Drug Use and Criminal Behaviour:

The association between levels of drug use and criminal activity was examined using data from the full sample of 116 subjects who were interviewed prior to their entry into the treatment programme. Pearsons correlation analysis was used to assess whether there was a statistically significant correlation between the total cost of all drugs used and a range of independent variables, including income level and the difference between income and drug expenditure, the total spent on drugs derived from criminal activity over the second six month period, the total number of previous arrests and previous convictions for acquisitive offences and drug-related offences. The analysis was repeated using non-parametric correlation analysis in order to check for variations in the distribution of data. This analysis revealed highly significant correlations between the total cost of all drugs used and money obtained from criminal activity $(\mathrm{r}=0.968, \mathrm{p}=0.000)$, and the total cost of all drugs used by subjects and the overall level of criminal activity measured on a daily basis according to the days involved in crime $(\mathrm{r}=0.288, \mathrm{p}=0.011)$. However, no significant associations were identified between the total cost of drugs used and subjects' previous histories of criminal behaviour.

To test for the influence of intervening variables, an additional analysis of variance was undertaken using demographic characteristics including age, gender, accommodation status, employment status, and family history as a covariate. No significant effects were found. 
On the basis of preliminary correlation analysis, a regression analysis was then implemented. The analysis used the total financial gain from the criminal activity in the six months prior to treatment as the dependent variable and a step-wise equation which included the total cost of drugs consumed, the difference between subjects legal income and their expenditure on drugs, the age at which they first became dependent on opiates, the total period of their drug dependence, and their past criminal history in terms of both acquisitive convictions and drugrelated convictions. This equation yielded a multiple $\mathrm{R}$ of $0.402, \mathrm{R}^{2}=0.162$ and $\mathrm{F}=10.41, \mathrm{p}$ $=0.0001$. The most significant variables included deficit between income and drug expenditure $(\mathrm{T}=3.18)$ and previous convictions for acquisitive crime $(\mathrm{T}=3.01)$.

\section{Preliminary Modelling of Drug and Criminal Behaviour Profiles:}

The broad pattern of drug use and criminal activity outlined above is likely to be under-pinned by variations in multiple behaviours. In order to identify patterns within these behaviours, factor analysis of the key variables was undertaken next. This analysis identified ten factors of which the first five contributed to over $50 \%$ of the variance as demonstrated in Table 3 . The first two factors shown are broad configurations where factor one defines the economic situation deriving patterns of both drug and criminal activity and which is reflected by high factor loadings associated with the total cost of drug use, length of dependency, and income expenditure deficits. The second factor defines the criminal profile of the drug user, reflecting the high loadings associated with age, previous convictions (particularly for acquisitive violence), and monetary gain from burglary and theft. The three remaining factors denote particular patterns of drug use and include a heroin - focused profile primarily associated with high levels of theft activity, a 
Table 3: Factor Analysis of Drugs and Criminal Behaviour

\begin{tabular}{|c|c|l|l||}
\hline Factor & $\begin{array}{c}\text { \% of } \\
\text { variance }\end{array}$ & \multicolumn{1}{|c||}{ Main Variables } & \multicolumn{1}{|c||}{ Description } \\
\hline 1 & 18 & $\begin{array}{l}\text { drugs expenditure deficit, } \\
\text { total cost of drugs, } \\
\text { total value of crime } \\
\text { age first became dependent }\end{array}$ & Economic situation \\
\hline 2 & 11 & $\begin{array}{l}\text { value of theft, } \\
\text { value of burglary, } \\
\text { age, } \\
\text { previous acquisitive conviction/s, } \\
\text { previous arrests }\end{array}$ & Criminal profile \\
\hline 3 & 9 & $\begin{array}{l}\text { period of dependence, } \\
\text { daily amount of heroin, } \\
\text { value of theft }\end{array}$ & $\begin{array}{l}\text { Drugs profile 1: } \\
\text { Heroin focused }\end{array}$ \\
\hline 4 & 7 & $\begin{array}{l}\text { daily amount of benzodiazepines, } \\
\text { value of work in addition to benefits, } \\
\text { previous acquisitive conviction/s }\end{array}$ & $\begin{array}{l}\text { Drugs Profile 2: } \\
\text { Benzodiazepine } \\
\text { focused }\end{array}$ \\
\hline 5 & 6 & $\begin{array}{l}\text { frequency of solvent use, } \\
\text { value of burglary } \\
\text { no of sexual partners in past month }\end{array}$ & $\begin{array}{l}\text { Drugs Profile 3: } \\
\text { Solvents focused }\end{array}$ \\
\hline
\end{tabular}


Benzodiazepine-focused profile is primarily associated with high levels of benefit fraud, and a solvents-focused profile primarily associated with high levels of burglary.

3. The Effects of Participation in the Treatment Programme:

The effects on patterns of drug use and criminal behaviour of entering into the Methadone Treatment Programme were next examined by comparing the responses of subjects on a range of key indicators. A total of 81 subjects provided comparative data on drug use and criminal activity measured at first presentation at the clinic (reported retrospectively over the previous 6 months), and similarly reported at six months follow-up.

Table 4-6 show matched-pair comparisons of subjects' mean scores using both Students t-test and then Wilcoxon's Test to allow for nonparametric distribution in the data.

Table 4 compares number of days that drugs were used, the daily amount consumed, and the daily cost of drugs over the six months prior to treatment and six months after follow-up. Programme attendance demonstrates a significant impact on the level of heroin use which was reduced on average by half over the six month treatment period. There appeared to be some reduction in the number of days on which subjects used illicit Methadone and other opiates, but this was not reflected in the amount of these drugs consumed or their mean daily cost. Treatment did not appear to impact on the use of other drugs such as amphetamines, barbiturates, crack cocaine, powdered cocaine, hallucinogens, cannabis, benzodiazapines, or solvents. 
Table 4: Comparison of patterns of drug use and expenditure on drugs during 6 months pre- and post-treatment

\begin{tabular}{|c|c|c|c|c|c|}
\hline Drugs & Indicator & $\begin{array}{c}\text { Mean score } \\
\text { pre-treatment }\end{array}$ & $\begin{array}{c}\text { Mean score } \\
\text { post-treatment }\end{array}$ & t-test/sig & Wilcox $\mathrm{z} /$ sig \\
\hline \multirow[t]{3}{*}{ Heroin } & Days used & 24.89 & 11.0 & $\begin{array}{l}10.78 \\
0.000\end{array}$ & $\begin{array}{l}-6.7931 \\
0.0000\end{array}$ \\
\hline & Daily amount & 0.54 & 0.24 & $\begin{array}{l}7.04 \\
0.000\end{array}$ & $\begin{array}{l}-5.7545 \\
0.000\end{array}$ \\
\hline & Daily cost & 42.02 & 19.40 & $\begin{array}{l}7.65 \\
0.000 \\
\end{array}$ & $\begin{array}{l}-5.7764 \\
0.0000 \\
\end{array}$ \\
\hline \multirow[t]{3}{*}{ Methadone (illicit) } & Days used & 5.34 & 1.70 & $\begin{array}{l}3.85 \\
0.000 \\
\end{array}$ & $\begin{array}{l}-3.9391 \\
0.0001 \\
\end{array}$ \\
\hline & Daily amount & 52.85 & 51.77 & $\begin{array}{l}0.13 \\
0.903\end{array}$ & $\begin{array}{l}-0.1185 \\
0.9057\end{array}$ \\
\hline & Daily cost & 7.13 & 6.66 & $\begin{array}{l}0.93 \\
0.705 \\
\end{array}$ & $\begin{array}{l}-0.3568 \\
0.7213 \\
\end{array}$ \\
\hline \multirow[t]{2}{*}{ Other Opiates } & Days used & 2.83 & 0.42 & $\begin{array}{l}1.82 \\
0.72\end{array}$ & $\begin{array}{l}-2.4640 \\
0.0137\end{array}$ \\
\hline & Daily cost & 15.00 & 6.00 & $\begin{array}{l}2.40 \\
0.139 \\
\end{array}$ & $\begin{array}{l}-1.6036 \\
0.1088 \\
\end{array}$ \\
\hline \multirow[t]{2}{*}{ Amphetamines } & Days used & 0.39 & 0.31 & $\begin{array}{l}0.36 \\
0.719 \\
\end{array}$ & $\begin{array}{l}-1.0669 \\
0.2860 \\
\end{array}$ \\
\hline & Daily amount & 0.67 & 0.67 & $\begin{array}{l}0.00 \\
1.000 \\
\end{array}$ & $\begin{array}{l}0.0000 \\
1.0000 \\
\end{array}$ \\
\hline Barbiturates & Days used & 2.45 & 0.12 & $\begin{array}{l}1.42 \\
0.161\end{array}$ & $\begin{array}{l}-1.0690 \\
0.2850\end{array}$ \\
\hline \multirow[t]{3}{*}{ Crack } & Days used & 1.86 & 2.39 & $\begin{array}{l}-0.78 \\
0.439 \\
\end{array}$ & $\begin{array}{l}-0.8811 \\
0.3783 \\
\end{array}$ \\
\hline & Daily amount & 0.23 & 0.32 & $\begin{array}{l}-0.90 \\
0.383 \\
\end{array}$ & $\begin{array}{l}-1.0223 \\
0.3066 \\
\end{array}$ \\
\hline & Daily cost & 49.54 & 47.27 & $\begin{array}{l}0.50 \\
0.629 \\
\end{array}$ & $\begin{array}{l}-0.5601 \\
0.5754 \\
\end{array}$ \\
\hline Cocaine & Days used & 0.49 & 0.44 & $\begin{array}{l}0.12 \\
0.901 \\
\end{array}$ & $\begin{array}{l}-14589 \\
0.1446 \\
\end{array}$ \\
\hline LSD & Days used & 0.05 & 0.04 & 0.44 & -0.4472 \\
\hline \multirow[t]{3}{*}{ Cannabis } & Days used & 10.25 & 10.80 & $\begin{array}{l}-0.48 \\
0.631 \\
\end{array}$ & $\begin{array}{l}-0.7964 \\
0.4258 \\
\end{array}$ \\
\hline & Daily amount & 0.24 & 0.51 & $\begin{array}{l}1.03 \\
0.308 \\
\end{array}$ & $\begin{array}{l}-0.467 \\
0.9627 \\
\end{array}$ \\
\hline & Daily cost & 7.19 & 5.15 & $\begin{array}{l}2.19 \\
0.40 \\
\end{array}$ & $\begin{array}{l}-1.7856 \\
0.0742 \\
\end{array}$ \\
\hline \multirow[t]{3}{*}{ Benzodiazepines } & Days used & 3.27 & 2.43 & $\begin{array}{l}0.93 \\
0.357 \\
\end{array}$ & $\begin{array}{l}-2.4331 \\
0.0150 \\
\end{array}$ \\
\hline & Daily amount & 2.00 & 2.39 & $\begin{array}{l}-0.48 \\
0.646 \\
\end{array}$ & $\begin{array}{l}-0.5071 \\
0.6121 \\
\end{array}$ \\
\hline & Daily cost & 0.64 & 1.55 & $\begin{array}{l}-1.27 \\
0.273 \\
\end{array}$ & $\begin{array}{l}-0.7303 \\
0.4652 \\
\end{array}$ \\
\hline Solvents & Days used & 2.46 & 0.11 & $\begin{array}{l}1.36 \\
0.177 \\
\end{array}$ & $\begin{array}{l}-1.09 \\
0.273 \\
\end{array}$ \\
\hline
\end{tabular}


Table 5: Comparison of criminal activities and financial gain during 6 months pre- and cost-treatment

\begin{tabular}{|c|c|c|c|c|c|}
\hline $\begin{array}{l}\text { Criminal } \\
\text { Activity }\end{array}$ & Indicator & $\begin{array}{c}\text { Mean score } \\
\text { pre- } \\
\text { treatment }\end{array}$ & $\begin{array}{c}\text { Mean score } \\
\text { post- } \\
\text { treatment }\end{array}$ & t-test/sig & $\begin{array}{c}\text { Wilcox/ } \\
\text { sig }\end{array}$ \\
\hline \multirow[t]{2}{*}{ Theft } & $\begin{array}{l}\text { Days last } 6 \\
\text { months }\end{array}$ & 44.04 & 20.56 & $\begin{array}{l}2.76 \\
0.008 \\
\end{array}$ & $\begin{array}{l}-2.372 \\
0.017 \\
\end{array}$ \\
\hline & Value $(\mathfrak{f})$ & 3542.92 & 1239.63 & $\begin{array}{l}2.15 \\
0.035\end{array}$ & $\begin{array}{l}-2.801 \\
0.005\end{array}$ \\
\hline \multirow[t]{2}{*}{ Burglary } & $\begin{array}{l}\text { Days last } 6 \\
\text { months }\end{array}$ & 3.36 & 1.20 & $\begin{array}{l}1.71 \\
0.101\end{array}$ & $\begin{array}{l}-2.201 \\
0.028\end{array}$ \\
\hline & Value $(\mathfrak{f})$ & 427.16 & 74.07 & $\begin{array}{l}2.02 \\
0.046\end{array}$ & $\begin{array}{l}-2.201 \\
0.028\end{array}$ \\
\hline \multirow[t]{2}{*}{ Fraud } & $\begin{array}{l}\text { Days last } 6 \\
\text { months }\end{array}$ & 2.43 & 7.66 & $\begin{array}{l}-1.09 \\
0.283 \\
\end{array}$ & $\begin{array}{l}-0.314 \\
0.753 \\
\end{array}$ \\
\hline & Value $(\mathfrak{f})$ & 548.12 & 200.62 & $\begin{array}{l}0.92 \\
0.358\end{array}$ & $\begin{array}{l}-1.448 \\
0.148\end{array}$ \\
\hline \multirow{2}{*}{$\begin{array}{l}\text { Working + } \\
\text { Claiming } \\
\text { Benefits }\end{array}$} & $\begin{array}{l}\text { Days last } 6 \\
\text { months }\end{array}$ & 27.02 & 31.86 & $\begin{array}{l}-0.48 \\
0.634 \\
\end{array}$ & $\begin{array}{l}-1.009 \\
0.313 \\
\end{array}$ \\
\hline & Value $(\mathfrak{f})$ & 869.52 & 544.62 & $\begin{array}{l}1.12 \\
0.266\end{array}$ & $\begin{array}{l}-0.039 \\
0.969\end{array}$ \\
\hline \multirow[t]{2}{*}{$\begin{array}{l}\text { Acquisitive } \\
\text { Violence }\end{array}$} & $\begin{array}{l}\text { Days last } 6 \\
\text { months }\end{array}$ & 3.69 & 1.15 & $\begin{array}{l}1.11 \\
0.290\end{array}$ & $\begin{array}{l}-1.604 \\
0.109\end{array}$ \\
\hline & Value $(\mathfrak{f})$ & 253.58 & 9.26 & $\begin{array}{l}1.10 \\
0.275\end{array}$ & $\begin{array}{l}-1.826 \\
0.068\end{array}$ \\
\hline \multirow[t]{2}{*}{$\begin{array}{l}\text { Drug- } \\
\text { Dealing }\end{array}$} & $\begin{array}{l}\text { Days last } 6 \\
\text { months }\end{array}$ & 56.38 & 19.82 & $\begin{array}{l}3.33 \\
0.002\end{array}$ & $\begin{array}{l}-2.904 \\
0.004\end{array}$ \\
\hline & Value $(\mathfrak{f})$ & 6031.73 & 486.23 & $\begin{array}{l}2.58 \\
0.012 \\
\end{array}$ & $\begin{array}{l}-3.825 \\
0.0001\end{array}$ \\
\hline \multirow[t]{2}{*}{ Sex Work } & $\begin{array}{l}\text { Days last } 6 \\
\text { months }\end{array}$ & 17.40 & 19.10 & $\begin{array}{l}-0.08 \\
0.938\end{array}$ & $\begin{array}{l}-0.365 \\
0.715\end{array}$ \\
\hline & Value $(\mathfrak{f})$ & 175.31 & 158.76 & $\begin{array}{l}0.100 \\
0.917 \\
\end{array}$ & $\begin{array}{l}0.000 \\
1.000\end{array}$ \\
\hline \multirow[t]{2}{*}{$\begin{array}{l}\text { Other } \\
\text { Crime }\end{array}$} & $\begin{array}{l}\text { Days last } 6 \\
\text { months }\end{array}$ & 13.90 & 0.09 & $\begin{array}{l}2.89 \\
0.005 \\
\end{array}$ & $\begin{array}{l}-1.125 \\
0.260\end{array}$ \\
\hline & Value $(\mathfrak{f})$ & 451.83 & 205.62 & $\begin{array}{l}1.91 \\
0.060\end{array}$ & $\begin{array}{l}-2.556 \\
0.011\end{array}$ \\
\hline
\end{tabular}


Table 6: Comparison of aggregated scores of drug use and criminal behaviours during 6 months pre- and post-treatment

\begin{tabular}{|c|c|c|c|c|}
\hline$\overline{\text { Dimensions }}$ & $\begin{array}{l}\text { Mean scores } \\
\text { pre-treatment }\end{array}$ & $\begin{array}{c}\text { Mean scores } \\
\text { post- } \\
\text { treatment }\end{array}$ & $\begin{array}{l}\text { test value/ } \\
\text { sig }\end{array}$ & $\begin{array}{l}\text { Wilcoxon/ } \\
\text { sig }\end{array}$ \\
\hline \multicolumn{5}{|c|}{ drug expenditure and behaviour } \\
\hline $\begin{array}{l}\text { Monthly drug use } \\
\text { expenditure }(£)\end{array}$ & 1252 & 339 & $\begin{array}{l}-8.85 \\
0.000 \\
\end{array}$ & $\begin{array}{l}-7.078 \\
0.000 \\
\end{array}$ \\
\hline Level of IV drug use & 2.95 & 2.03 & $\begin{array}{l}2.43 \\
0.017\end{array}$ & \\
\hline $\begin{array}{l}\text { Level of shared inj } \\
\text { equipment }\end{array}$ & 3.04 & 0.27 & $\begin{array}{l}-6.65 \\
0.000\end{array}$ & $\begin{array}{l}-5.49 \\
0.000 \\
\end{array}$ \\
\hline $\begin{array}{l}\text { Daily expenditure on } \\
\text { drugs }(\mathfrak{E})\end{array}$ & 153.6 & 52.16 & $\begin{array}{l}8.19 \\
0.000\end{array}$ & $\begin{array}{l}-5.831 \\
0.000\end{array}$ \\
\hline $\begin{array}{l}\text { Maximum expenditure in } \\
1 \text { day }(\mathfrak{f})\end{array}$ & 153.6 & 52.16 & $\begin{array}{l}5.16 \\
0.000\end{array}$ & $\begin{array}{l}-5.831 \\
0.000\end{array}$ \\
\hline 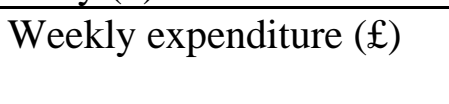 & 312.4 & 83.5 & -8.91 & $\begin{array}{l}-7.083 \\
0.000\end{array}$ \\
\hline \multicolumn{5}{|c|}{ income and criminal activity } \\
\hline $\begin{array}{l}\text { Gain from monthly } \\
\text { criminal activity }(\mathfrak{E})\end{array}$ & 1590 & 366 & $\begin{array}{l}2.97 \\
0.004\end{array}$ & \\
\hline $\begin{array}{l}\text { Gain from 6-monthly } \\
\text { criminal activity }(£)\end{array}$ & 10984 & 2930 & $\begin{array}{l}3.21 \\
0.002\end{array}$ & \\
\hline $\begin{array}{l}\text { Average weekly income } \\
(\mathfrak{f})\end{array}$ & 70.45 & 104.86 & $\begin{array}{l}-2.03 \\
0.046\end{array}$ & $\begin{array}{l}-2.576 \\
0.010\end{array}$ \\
\hline $\begin{array}{l}\text { Average weekly deficit } \\
\text { (£) }\end{array}$ & 245.8 & 43.13 & $\begin{array}{l}8.14 \\
0.000\end{array}$ & $\begin{array}{l}-6695 \\
0.000\end{array}$ \\
\hline $\begin{array}{l}\text { Mean no. of arrests in } 6 \\
\text { months }\end{array}$ & 0.691 & 0.345 & $\begin{array}{l}2.65 \\
0.010\end{array}$ & $\begin{array}{l}-2.769 \\
0.005\end{array}$ \\
\hline
\end{tabular}


Table 5 compares criminal activity over the six months prior to treatment and at six months follow-up. Treatment was associated with a significant reduction in thefts, burglary, and drug-dealing, but was not associated with any reduction in the level of frauds and deception, working whilst signing on for social security benefits, acquisitive violence, or sex work.

Table 6 compares the aggregated scores of drug use and criminal behaviour between the two time periods. This demonstrates a highly significant fall in expenditure on a monthly basis, level of intraveneous drug use, frequency with which injecting equipment was shared, daily expenditure on drugs, the largest expenditure in any single day compared to the largest expenditure on a single day in the previous six month period, and their overall weekly expenditure on drugs. There was a significant fall in illegal income on a monthly, six monthly, and six monthly basis, a fall in overall (legal and illegal) weekly income, the deficit between their legal income and total expenditure on drugs, and the mean number of arrests between the two six month periods. In general, the mean monthly expenditure on drugs demonstrated a three-fold reduction. The same trend was found for level of criminal activity, with an average reduction in the overall financial gain from crime falling from $£ 1,590$ when first interviewed to $£ 366$ at six month follow-up. The average deficit (difference between legal income and drug expenditure) reduced by a factor of 6 over the same period.

\section{Examination of Intervening Variables:}

The next part of the analysis examined whether the findings in 3. above were mediated through intervening variables such as attendance at the clinic for treatment, demographic factors, and the environmental context. But the study did not measure exact of periods of each subject's attendance within the treatment programme. Of the treated sample $(\mathrm{N}=81), 38 \%$ remained in treatment at six month follow-up, with the remainder varying from between 1 and 20 weeks within the treatment programme over the follow-up period. To assess the effect of discontinuity in attendance for treatment, an analysis of variance was carried out with "continuing treatment - discontinued treatment" as the grouping variables and with the following dependent variables:

Differences in total monthly expenditure on drugs at six month follow-up compared with pretreatment. 
Difference in monetary gain from criminal activity over the period.

Difference in total income over the period.

Number of weeks heroin free in last six months.

Number of weeks drug free in the last six months.

Monthly expenditure on all drug use.

Total monetary gain from criminal activity in last six months.

No significant differences were found between the group still in treatment and those who were no longer attending on any key indicators, with the exception of the number of weeks heroin free $(\mathrm{F}=10.63, \mathrm{p}=0.0001)$. There was thus no strong evidence to support the operation of a "time decay" effect in relation to attendance patterns. A chi-square test which cross-tabulated programme status with increase/decrease in drug and criminal activity indicated similar results. Analysis of variance was also carried out on these variables using age, sex, accommodation status, employment status, and nationality as dependent variables. No significant differences in pattern of drug use and criminal activity were found.

The effects of two "historical" sets of factors were examined on changes in patterns of drug use in criminal behaviour following entry to the Methadone Programme. These included an aggregate measure of environmental and family history (see above), and previous history of drug use and criminal activity. Using Pearson's correlation analysis, Behavioural change indicators, including differences between monthly expenditure on all drugs over the six months follow-up and six months pre-treatment difference in financial gain from criminal activity and difference in total income over the same period, were correlated with the following variables:

Environmental and family problems score. 
Total cost of all drug use at entry to treatment.

Total monetary gain from all criminal activity at entry to treatment.

The deficit between legal income and drug expenditure.

The analysis demonstrated that changes in drug use patterns were highly correlated with changes in criminal activity patterns. The relationship indicated that the greater the reduction in drug use, the greater reduction in criminal activity $(\mathrm{R}=0.304, \mathrm{p}=0.006)$. Significant changes in drug consumption were also associated with previously high levels of drug use. The higher the previous level of drug consumption, the greater the reduction in drug usage over the treatment period $(\mathrm{R}=0.906, \mathrm{p}=0.000)$. The pattern also held true for criminal activity where the higher the previous level of criminal activity, the greater the reduction in crime over the treatment period $(\mathrm{R}=0.962, \mathrm{p}=0.000)$. Although aggregate scores of family and environmental history were significantly associated with previous history of arrest $(\mathrm{R}=$ $0.252, \mathrm{p}=0.02)$ and also convictions for acquisitive crime $(\mathrm{R}=0.342, \mathrm{p}=0.002)$, there were no significant correlations with changes observed in criminal activity or drug use during the treatment period.

\section{Factors Affecting Behavioural Change:}

Two regression analyses were undertaken to investigate in more detail the relationship between changes in patterns of drug use and criminal behaviour and several potential contributory variables. In the first equation, a step-wise analysis was performed using the differential in total cost of drug use prior to entry into treatment and after the six month treatment period as the dependent variable and with the following independent variables:

Aggregate score of early family and environment factors.

Number of weeks since treatment ended.

Total expenditure on drugs prior to treatment.

This equation yielded a multiple $\mathrm{R}$ of $0.901, \mathrm{R} 2$ value of 0.811 . The main contributory 
variables were the total cost of drug use prior to treatment $(\mathrm{T}=16.59)$ and the number of weeks since treatment ended $(T=-3.04)$. This suggested that reductions in levels of drug use are strongly influenced by the level of drug use prior to entry to treatment and that there is a time - decay effect with drug consumption increasing in direct proportion to the length of time since dropping out of treament.

The second regression analysis involved a measure of change in financial gain from criminal activity over the treatment period as the dependent variable and the following independent variables:

Aggregate score of family and early environment factors.

Number of weeks since treatment ended.

Total cost of drug use prior to treatment.

Total financial gain from all criminal activity at entry into treatment.

The difference between total monthly expenditure on all drugs at six month follow-up and six months prior to treatment.

A step-wise solution yielded a multiple $\mathrm{R}$ of $0.962, \mathrm{R} 2$ value of $0.926, \mathrm{~F}=970.33, \mathrm{p}=$ 0.0000. Previous levels of criminal activity in the six months before treatment were by far the greatest contributing factors to changes observed in criminal activity during participation in the Methadone Treatment Programme.

\section{Drug and Criminal Profiles:}

Building on the results of the multi-variate analyses described above, the final analyses focused on exploring the patterns of drug use and criminal activity within the treated sample $(\mathrm{N}=81)$. An initial hierarchical cluster analysis was firstly carried out using Ward's method on a range of key variables which included: 
Previous patterns of drug use.

Previous patterns of criminal activity.

Changes in drug use and criminal behaviour following treatment.

Attendance status within Methadone Treatment Programme.

Length of dependence on opiates.

Total income.

Change in total income.

This analysis identified 10 clusters within the sample, with a high proportion (77\%) concentrated in one cluster suggesting a homogeneous drug-using population. A residual group formed $7 \%$ of the population sample, with the remaining cluster consisting of single out-lying cases. This small residual cluster was distinguished from the main cluster because it constituted a group of long-term opiate-dependent individuals. The remaining outlying groups included specific drug-use profiles such as amphetamine abusers, crack-cocaine abusers, etc.

The descriminant analysis supported these patterns, with $96 \%$ of cases correctly classified. 


\section{CONCLUSION}

The study has confirmed the effectiveness of a Methadone Treatment Programme on a relatively homogenous sample of opiate dependent subjects attending an inner city drug dependency service. The study also revealed complex interactions between the subject's previous criminal histories, their criminal activities in the six months prior to entry into the treatment programme, their expenditure on drugs, and the financial gain from their criminal activities. As expected, there was a direct relationship between their financial gain from crime and the amount they spend on drugs. The more involved in crime in the six months prior to treatment, the more they had spent on drugs. Although previous criminal history contributed independently to their current level of criminal activities, in that those with previous convictions committed more crimes, previous criminal history did not determine the amount they spent on drugs. Current level of criminal activity was also independently related to the deficit between their legal earnings and the amount they spent on drugs. Overall, these findings are not supportive of Hammersley and Hammersley's (1990) contention that heroin use is largely determined by previous criminality and that criminality is not determined by heroin use in this sample. It would appear that the criminal behaviour of these subjects was directly related to obtaining money for their drugs, and that the more crimes they committed the more drugs they could purchase. The rate of their criminal activity was influenced, however, by their previous involvement in crime, especially acquisitive offending, and reflecting their level of criminal sophistication. The criminal activities of the sample would thus appear to be independently driven both by the cost of their drug habit and their previous history and experience of acquisitive crime.

The study conclusively demonstrated that, on the basis of self-report, the Methadone Treatment Programme had contributed to a significant decrease in both illicit drug consumption and the criminal activities that were associated with supporting their drug consumption. Overall expenditure on drugs, injecting behaviour, and high risk behaviours involving sharing of syringes and needles all decreased during treatment, with expenditure showing a three-fold reduction. Use of heroin decreased by $50 \%$. But there were no changes in the levels of illicit methadone, amphetamines, barbiturates, crack cocaine, powder cocaine, cannabis, or benzodiazepine misuse at the end of the six month treatment period. At the same time, it is nevertheless important to point out that there were no significant increases in the levels of misuse of these other drugs by these polydrug-abusing subjects, or that they had 
substituted these for heroin. Similarly, treatment was accompanied by a fall in the level of financial gain from criminal activities, which was further supported by the fall in the number of reported arrests by the police during the treatment period. There was also a significant overall increase in income obtained by legal means, certain subjects having found work during the treatment period.

Important differences were observed in the impact that treatment had had on different categories of crime. Burglaries and theft were reduced by a half and the impact on drug dealing was even greater. However, there were no changes in the level of their fraudulent activities, acquisitive violence (mugging), sex work, or signing on for Department of Social Security benefits whilst simultaneously working. This would partly suggest that certain criminal activities may be more closely linked to obtaining money for drugs than others but also that once engaged in certain patterns of crime, that subjects tended to persist in these after treatment. Reducing the need to obtain money for drugs by substituting methadone did not necessarily render opiate-dependent individuals any less likely to engage in sex work, carry out frauds and deceptions, desist from mugging, or more likely to inform the DSS that they were now employed. However, as thefts and drug-dealing were the most common criminal activities carried out by the sample, it is highly important from a crime prevention perspective that these were the categories of crime on which the treatment appeared to have the greatest impact.

Treatment also appeared to have had its greatest impact on those individuals who were most heavily involved in crime. This was an important finding which did not support the expectation that subjects who were most criminally active (and who had the most extensive previous criminal histories) would be least likely to benefit from the treatment programme. It also did not suggest that methadone treatment is most effective with the "easy" subjects, minimally engaged in crime, and is the opposite of what would be expected if Hammersley and Hammersley's (1990) thesis were correct. The overall benefits achieved by this treatment programme were substantially contributed to by the dramatic reductions in crimes committed by those who had been most criminally active. 
In conclusion, retention in the treatment programme was a highly important factor and strongly and independently associated with both reduction in illicit use of opiates and reduction in criminal activities, which were closely correlated with each other. 


\title{
ECONOMIC EVALUATION:
}

\section{DOES METHADONE TREATMENT LEAD}

\author{
TO REDUCED EXPENDITURES ON \\ ILLEGAL DRUGS AND A FALL IN
}

CRIMINAL EARNINGS?

Andrew Healey, Jeremy Coid, Juliet Henderson, Andrea Carvell, and Zelpha Kittler 


\section{SUMMARY}

This report describes the results from a longitudinal study of a sample of 81 referrals to a methadone treatment programme based at Hackney, East London.

The primary aims of the analysis were to assess:

- Whether time spent in methadone treatment reduces expenditures on illegal drugs

- Whether increasing expenditures on drugs leads to higher levels of earnings generated from crime

ـ The reduction in illegal earnings resulting from reduced spending on drugs brought about by time spent on methadone

\section{MAIN FINDINGS}

Treatment clients who stay on methadone treatment for longer periods are predicted to have better outcomes measured over a 6 month follow-up period.

* If a drug addict was to be maintained in methadone treatment for 6 months the statistical modelling predicts that expenditure on street drugs would fall by $£ 35$ per day on average over the period of the study. Based on the $95 \%$ confidence intervals from the regression equations, this would lead to an average fall in monthly criminal earnings of between $£ 714$ and $£ 2626$ over the 6 month study period.

The results support the view that, in the short term, methadone treatment may be a viable policy tool for tackling drug use and drug related crime. 


\section{INTRODUCTION}

Methadone treatment is seen as a viable means of diverting drug addicts away from the use of heroin and other illegal substances. If successful such a policy could offer benefits to addicts in terms of more stable lives and reduced exposure to health risks, and the wider society who are seen to pay the price for drug addiction via current levels of property crime.

Maintaining a drug addict on a methadone treatment programme is comparatively inexpensive to other forms of residential-based drug dependency treatment. A recent Department of Health study (Healey et al, 1999) has estimated that the weekly cost of delivering methadone would be in the region of $£ 40$ which, given what are viewed to be the potential gains from pursuing such a policy, seems like a worthwhile resource commitment. However, there can be little justification for spending scarce public resources on policies without reliable evidence of their effectiveness and added value in terms of improvements in the welfare addicts and society in general.

In this report we contribute to the existing body of evidence using data from a longitudinal survey of addicts referred to a methadone programme provided by the Hackney Community Drugs Team in East London. The primary focus of our analysis is on illegal drug expenditures and its relationship to methadone treatment, and whether methadone treatment can indirectly reduce earnings generated from criminal activity. More specifically, we employ statistical modelling procedures to test two hypotheses:

1. Access to prescribed methadone is an effective means of reducing levels of illegal drug expenditures

and,

2. Any reductions in drug expenditures will reduce the amount of earnings that drug addicts generate through crime

After providing a background to the design of the study and a description of the characteristics of those individuals included in the analysis, we present details of the patterns of drug expenditure and illegal earnings over the period of the study. This serves as a backdrop for the more rigorous econometric modeling of the data. We estimate two behavioural models: the first assesses, other things equal, the extent to which time spent in 
methadone treatment impacts on levels of drug expenditure; the second model seeks to estimate whether, other things equal, levels of expenditure on drugs is related to the amount of earnings problem drug users generate from crime. If these relationships are found to exist then it should be possible to estimate with some degree of certainty the indirect effect that methadone treatment has on earnings generated through crime.

\section{STUDY DESIGN AND CHARACTERISTICS OF DRUG USERS}

\section{Study design}

116 referrals to the Hackney Community Drugs Team were initially recruited to the study and followed over a 6 month period after their entry on to a programme of methadone treatment. All subjects satisfied the DSM III diagnostic requirement for substance dependency, and each was required to have been resident in the community for the six months previous to treatment entry thus giving them equal opportunity to have committed offences. Every study participant was interviewed at the start of their treatment programme (or as close to this as possible), at 1 month and at 6 months. A structured face-to-face interview schedule was administered by a project researcher at each phase. The instrument comprised of questions designed specifically for the purposes of this project and existing research instruments. Participants were asked to reveal amongst other things socio-demographic details, information on how much they spent on illegal drugs on a daily basis and details of how much income they generated from illegal sources. All data is subsequently self-report. For the analysis in this paper we have used data from the first and 6 month interviews only, due to incomplete information on criminal earnings at 1 month.

\section{Sample characteristics}

Of the original 116 subjects who were recruited, 81 had completed all three stages of assessment and had useable data for analysis. The average age of these 81 subjects was 31.51 years, $74 \%$ were male and over two-thirds reported being out of a job at the first assessment. The primary substance of misuse with the sample was heroin. Study participants were asked to provide details of how much on average they spent on drugs on daily basis with reference to a one month period prior to interview. The mean value given at the first interview was $£ 44.7$, although there was some degree of dispersion around this mean as indicated by the standard deviation of £30.0. Some addicts reported spending on average as little as $£ 10$ or less per day on drugs, with others reporting that their current usage level was 
costing them in excess of $£ 100$ per day.

The mean weekly source of legitimate income gained from employment and/or state benefits was is in the region of $£ 70$. There was obvious anomaly between stated daily expenditure patterns on drugs and how much money subjects declared that they had at their disposal from legitimate sources. The mean weekly deficit between the stated value drug purchases and legitimate earnings was considerable- $£ 217$ per week.

Beyond undeclared legitimate sources of cash (e.g.savings) the most likely source of this deficit was income generated via criminal activity. Table 1 reports descriptive statistics of earnings from specific types of offence and for total earnings from all illegal sources. In this instance we have excluded two outliers whose total criminal earnings were by far in excess of what was though to be feasible. The average monthly income generated through crime was $£ 1224.17$ over 1 month with a standard deviation of $£ 1821.70$ indicating considerable variability around the average. By no means all of the subjects reported generating income from crime. A sizeable minority of the sample (around two thirds) declared that they did not generate income via illegal means.

For those who were engaged in crime, a variety of activities were pursued. The types of offence with the highest average earnings were theft and drug dealing. Mean earnings were lowest for prostitution and for theft involving violence (including muggings). However, these average values tend to hide the nature of the distribution of criminal earnings across the sample. The percentiles given in table 1 indicate that for specific types of offence, the data is right skewed, which is more extreme for some offence types compared with others. Burglary, fraud, theft with violence and prostitution were all rarely reported sources of income with the more frequently reported offences included drug dealing, theft and the illegitimate claiming of state benefits. 
Table 1: Criminal earnings over one month prior to start of treatment (£s): Descriptive statistics

\begin{tabular}{|c|c|c|c|c|c|c|c|c|c|}
\hline & & Burglary & $\begin{array}{c}\text { Theft with } \\
\text { Violence }\end{array}$ & $\begin{array}{c}\text { Drug } \\
\text { Dealing }\end{array}$ & Fraud & Theft & $\begin{array}{c}\text { Benefits } \\
\text { Fraud } \\
\end{array}$ & Prostitution & $\begin{array}{c}\text { Total illegal } \\
\text { earnings }\end{array}$ \\
\hline Number of Subjects & & 79 & 79 & 79 & 79 & 79 & 79 & 79 & 78 \\
\hline Mean & & 121.52 & 5.06 & 570.38 & 159.03 & 411.96 & 143.76 & 29.37 & 1224.18 \\
\hline Median & & .00 & .00 & .00 & .00 & 157.00 & .00 & .00 & .00 \\
\hline Standard Deviation & & 637.64 & 34.11 & 2113.84 & 757.58 & 1062.68 & 398.79 & 252.07 & 1821.70 \\
\hline \multirow[t]{9}{*}{ Percentiles } & 60 & .00 & .00 & .00 & .00 & .00 & .00 & .00 & 748.00 \\
\hline & 75 & .00 & .00 & 180.00 & .00 & 100.00 & .00 & .00 & 2005.00 \\
\hline & 80 & .00 & .00 & 320.00 & .00 & 360.00 & 15.00 & .00 & 2568.00 \\
\hline & 90 & .00 & .00 & 1400.00 & .00 & 1500.00 & 600.00 & .00 & 4353.50 \\
\hline & 95 & 800.00 & .00 & 2800.00 & 650.00 & 2800.00 & 1440.00 & .00 & 5545.00 \\
\hline & 96 & 1600.00 & .00 & 3920.00 & 3020.00 & 3360.00 & 1440.00 & .00 & 6256.00 \\
\hline & 97 & 1920.00 & 72.00 & 5880.00 & 3815.00 & 4550.00 & 1483.20 & 48.00 & 6463.00 \\
\hline & 98 & 3200.00 & 184.00 & 10920.00 & 4084.00 & 5390.00 & 1627.20 & 944.00 & 6710.00 \\
\hline & 99 & 5000.00 & 280.00 & 16800.00 & 4200.00 & 5600.00 & 1800.00 & 2240.00 & 7000.00 \\
\hline
\end{tabular}




\section{LONGITUDINAL CHANGES IN EXPENDITURE ON DRUGS AND CRIMINAL EARNINGS}

\section{Drug expenditures}

Not surprisingly, at the start of their programme of methadone treatment all subjects reported a positive level of expenditure on drugs. By the time of the 6 month follow up interview, only 9 individuals declared that they had not made any daily purchases of illegal substances over the previous 1 month reference period. However, there was evidence to suggest that overall levels of drug use had fallen over the 6 month study period. The mean reported daily expenditure on drugs fell from $£ 44.74$ at the start of treatment to $£ 13.21$ as measured 6 months later: In order to determine whether this difference was systematic on merely down to chance, a t-test was conducted on the difference in mean expenditures at the two time points: the differences were in fact shown to be statistically significant at the 5\% level ( $t=-8.06$; $\mathrm{p}=0.00)$.

Whilst t-tests are a conventional approach to comparing means in this way, they should only be strictly used in instances where the data are shown to be normally distributed. This was not the case with the drug expenditure data. Therefore we also carried out a Wilcoxon signed ranks test which makes no distributional assumptions. Table 2 reports the results from this analysis. Between the start of treatment and 6 months later 68 subjects reported a fall in the daily amount they spent on illegal drugs compared to 11 who reported an increase. Nobody in the study reported no change in drug spending over the period. This leftward shift in the distribution of drug expenditures was statistically significant.

\section{Criminal earnings}

Criminal earnings showed a similar pattern of change over the 6 month study period. Mean illegal earnings over one month fell from $£ 1224.12$ at the beginning of treatment to $£ 322.87$ at 6 months. Using a t-test this was again shown to be a statistically significant reduction $(\mathrm{t}=-$ 3.93; $\mathrm{p}=0.00$ ). Table 3 reports the results from the Wilcoxon test. Forty-six subjects declared a reduction in monthly illegal earnings compared with 14 subjects who reported an increase. A sizeable number of individuals, 18 , reported no change in the amount of earnings generated through crime. As with drug expenditures, this reduction in criminal earnings was found to be statistically significant.

Table 2: Wilcoxon signed ranks test for daily drug expenditures 


\begin{tabular}{lccc}
\multicolumn{1}{l}{} & N & $\begin{array}{c}\text { Mean } \\
\text { Rank }\end{array}$ & $\begin{array}{c}\text { Sum of } \\
\text { Ranks }\end{array}$ \\
\hline $\begin{array}{l}\text { Negative } \\
\text { Ranks }^{\mathrm{a}} \\
\text { Positive Ranks }^{\mathrm{b}}\end{array}$ & 68 & 43.31 & 2945.00 \\
Ties $^{\mathrm{c}}$ & 0 & 19.55 & 215.00 \\
Total & 79 & & \\
\hline
\end{tabular}

a daily expenditure at 6 months <daily expenditure at start of treatment

b daily expenditure at 6 months $>$ daily expenditure at start of treatment

c No change in expenditure

Test Statistics ${ }^{\mathrm{b}}$

Z -6.671

Asymp. Sig. ${ }^{\mathrm{a}}(2-\quad .000$

tailed)
a Based on positive ranks.
b Wilcoxon Signed Ranks Test 
Table 3: Wilcoxon signed ranks test criminal earnings for one month

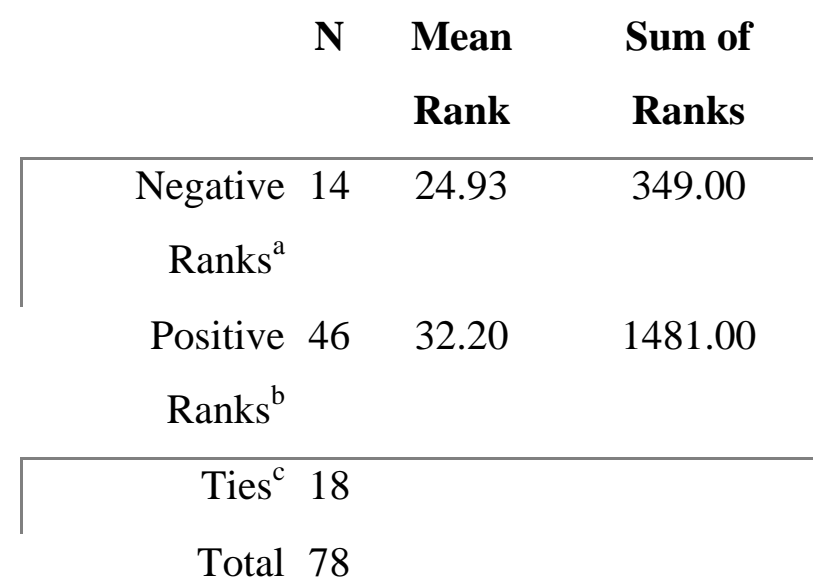

a Criminal earnings before treatment $<$ criminal earnings at 6 months

b Criminal earnings at start treatment> criminal earnings at 6 months

c No change in criminal earnings

Test Statistics $^{b}$

$$
\mathrm{Z}-4.167
$$

Asymp. Sig. (2- $\quad .000$

tailed)

a Based on negative ranks.

b Wilcoxon Signed Ranks Test 
Taken together, these observed reductions in drug spending and illegal earnings are encouraging. However, simple bi-variate comparisons between time points do not provide any insight into the extent to which the observed reductions in drug expenditure were due to the effects of methadone treatment, nor whether the fall in reported income from crime was either fully or partly a result of the observed reduction in drug expenditures. Whilst we would hope that such inter-connecting relationships do exist, there may be a host of other behavioural factors responsible for the patterns observed. A more rigorous test for treatment effects and the relationship between drug expenditures and earnings from crime requires more detailed multivariate research.

\section{STATISTICAL MODELLING}

\section{Methods and hypotheses}

Multivariate panel (or longitudinal) data methods were used to employ more stringent tests of the key hypotheses we were interested in. We estimate two regression equations to determine which factors have a statistically important impact on drug expenditures and earnings from crime over the time period covered by the study. To reiterate, our to main hypotheses are: 1) Increasing time spent in methadone treatment will reduce expenditures and illegal drugs; 2) Increasing drug expenditures will lead to an increase in income generated illegally. Moreover, if methadone treatment is effective in changes patterns of illegal drug use it will indirectly reduce drug users incentives to generate income via crime.

To test for these effects we employed a random-effects regression procedure (Greene, 1993). Drug expenditures and criminal earnings are taken to be dependent on a set of randomly distributed variables. Each variable can either measure subject characteristics that are timeinvariant (e.g. gender, age at treatment intake, previous contact with treatment services) or time-variable individual effects (e.g. employment status, methods of drug use, exposure to treatment). Unobserved variables which account for unexplained variation in crime and heroin use can also be distinguished as such and are assumed to be normally distributed with a zero mean and constant variance. Zero covariance between any unobserved determinants of crime and heroin use and observed explanatory variables in the estimated models is also assumed. 
The data generated on illegal earnings and drug expenditures introduced two statistical problems threatening the reliability of the results. Firstly, a substantial proportion subjects reported zero criminal earnings at their first interview and at follow-up This amounts to what is known in the literature as censoring of the dependent variable (Maddala, 1983) and is a common feature in data of this type. Suffice to say that if left uncorrected it can lead to a substantial underestimate of the effect of drug expenditures on the level of criminal earnings generated by drug users. Exploratory analyses revealed that this was in fact the case. The chosen method of correcting for his problem was the widely used tobit method (Maddala, 1983) which makes an adjustment for the fact that a random-effects regression can only be estimated on positive criminal earnings.

A second problem arose from the potentially endogenous relationship between drug expenditures and criminal earnings which were both measured with reference to the same period: Whilst we might expect the demand for street drugs as expressed through expenditures to positively impact on incentives to commit crime, it is equally plausible that the amount of money generated from illegal activities will drive how much income individuals spend on drugs. Statistically this type of relationship can be problematic because it leads to covariance between key explanatory variables (in this case drug expenditures) and the unexplained variance in criminal earnings. This violates a key assumption of the random effects regression model. To correct for this problem a two-stage least squares approach using instrumental variables was combined with the tobit random-effects specification. The problem of censoring and endogeneity were not thought to be a major issue of concern in the drug expenditure regression model with respect to estimating the effect of time in methadone treatment on heroin expenditures. The random effects regression was estimated using generalised least squares (GLS). The heroin expenditures regression was subjected to a statistical specification test recommended by Hausman (1978) to assess whether there was evidence of bias arising from any confounding effects from unobserved variables. Unfortunately the same test is not applicable to a tobit random-effects specification and could not therefore be applied to the criminal earnings regression model. 


\section{Variables used in statistical modelling}

Table 4 provides some descriptive details of the variables (with labels and definitions) used in the panel data regressions. In the first equation the log of average reported daily expenditures on drugs over a one month reference period is the dependent variable. Logged values were employed to obtain a more favourable distribution of residual variation in drug expenditures given the assumption of normality underpinning the random effects approach. Estimated regression coefficients should therefore be interpreted as proportional rather than absolute effects. The dependent variable in the second estimated equation is reported average monthly illegal earnings earnings (including theft, theft with violence, drug dealing, prostitution, burglary, fraud, and benefits fraud). Drug expenditures and criminal earnings were also utilised as explanatory variables in the regression models.

A host of other explanatory variables were also derived from study interviews with subjects kept at the community drugs team. Time spent in methadone treatment was measured in weeks, with three categorical (zero-one) variables identifying whether a subject had been in contact with treatment programmes in the past. These included hospital drug dependency (detox) units, residential rehabilitation programmes and methadone treatment. Previous imprisonment and time spent in a borstal were also included as a categorical variables.

The number of times arrested over a 6 month period prior to the start of treatment and over the 6 month follow-up period was also included as an explanatory variable. Two variables identified aspects of a subject's drug use: the number of months over which a subject considered themselves to be addicted to drugs was entered as a continuous variable; and whether a subject reported injecting drugs was included as a categorical variable. Standard socio-demographic measures were entered into both equations including subject gender, age, marital status and number of years in full time education. Subjects were also asked to indicate the amount of financial debt they were in at the start of treatment and at 6 months. This was also included in the analyses. Finally, two variables were included in an attempt to measure any effect of childhood living circumstances on current drug using and criminal behaviour. The first was a continuous variable constructed from an existing scale measuring severity of problems within a subject's family as a child. A second related categorical variable identified whether family members activity encouraged a subject to engage in crime as a child.

More exact representations of the equations we wished to estimate are: 
Equation 1: Determinants of drug expenditures

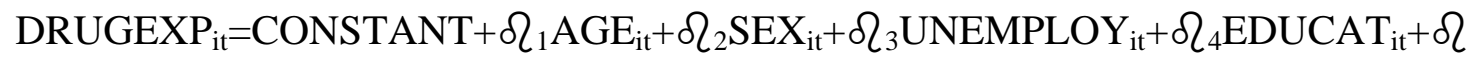
${ }_{5} \mathrm{FAMPROB}_{\mathrm{it}}+$

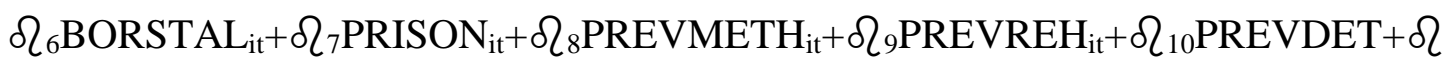

${ }_{11} \mathrm{MARITAL}+\Omega_{12} \mathrm{DEBT}+\Omega_{13} \mathrm{ARREST}+\Omega_{14} \mathrm{INJECT}+\Omega_{15} \mathrm{METHWEEKS}+\Omega_{16} \mathrm{CRIMEARN}$ $+\mathrm{U}_{\mathrm{i}}+\mathrm{E}_{\mathrm{it}}$

Equation 2: Determinants of criminal earnings

CRIMEARN $_{\mathrm{it}}=\mathrm{CONSTANT} \quad \lambda_{1}$ DRUGEXP $_{\mathrm{it}} \quad+\lambda_{2} \mathrm{AGE}_{\mathrm{it}}+\lambda_{3} \mathrm{SEX}_{\mathrm{it}}+\lambda_{4} \mathrm{UNEMPLOY}_{\mathrm{it}}+\lambda$ ${ }_{5}$ EDUCAT $_{\mathrm{it}}+\lambda_{6}$ FAMCRIM $_{\mathrm{it}} \lambda_{7}$ FAMPROB $_{\mathrm{it}}+\lambda_{8}$ PRISON $_{\mathrm{it}}+\lambda_{8}$ BORSTAL $_{\mathrm{it}}+\lambda_{10}$ PREVREH $_{\mathrm{it}}+\lambda$ ${ }_{11}$ PREVMETH $_{\mathrm{it}}{ }^{+}$

$\lambda_{12} \mathrm{PREVDET}+\lambda_{13} \mathrm{MARITAL}+\lambda_{14} \mathrm{DEBT}+\lambda_{15} \mathrm{ARREST}+\mathrm{W}_{\mathrm{i}}+\mathrm{Z}_{\mathrm{it}}$

The $\beta s$ and $\lambda s$ are the model coefficients to be estimated (measuring the unit effect of each variable on drug expenditures and illegal earnings), $E_{i t}$ and $Z_{i t}$ are the time- variant individual effects components of the random effects regression and $\mathrm{Wi}$ and $\mathrm{Ui}$ are the fixed individual effects error term components. The subscripts "i" and " $\mathrm{t}$ " indicate that the equation is to be estimated using longitudinal data such that drug expenditures and criminal earnings for a study subject $\mathrm{i}$ at time $\mathrm{t}$ are hypothesized to be dependent on the each right hand side variable for the ith subject measured at time $t$.

For equation 1 preliminary regressions revealed that the errors were non-normally distributed which violates an assumption of classical linear regression. To attempt to rectify this problem DRUGEXP was log transformed which produced a more favourable distribution of model residuals. The log transformation does not affect our ability to test the specific relationships we were interested in, although the estimated coefficients should be interpreted as proportional rather an absolute unit effects. 
Table 4: Variables used in economic analyses

\begin{tabular}{|c|c|c|c|c|c|}
\hline \multirow[t]{2}{*}{ VARIABLE } & \multirow[t]{2}{*}{ LABEL } & START OF & \multicolumn{3}{|c|}{6 MONTHS } \\
\hline & & Mean & $\begin{array}{l}\text { Standard } \\
\text { Deviation }\end{array}$ & Mean & $\begin{array}{l}\text { Standard } \\
\text { Deviation }\end{array}$ \\
\hline $\begin{array}{l}\text { Criminal earnings over } 1 \\
\text { months before start of } \\
\text { treatment } / 6 \text { month interview }\end{array}$ & CRIMEARN & 1224.18 & 1821.70 & 330.00 & 874.02 \\
\hline $\begin{array}{l}\text { Average daily expenditure on } \\
\text { drugs over } 1 \text { month before } \\
\text { start of treatment/before } 6 \\
\text { months }\end{array}$ & DRUGEXP & 44.28 & 30.40 & 13.02 & 16.67 \\
\hline Age at start of treatment & AGE & 31.45 & 6.52 & 31.45 & 6.52 \\
\hline Gender $0=$ male, $1=$ female) & SEX & 0.27 & 0.45 & 0.27 & 0.45 \\
\hline 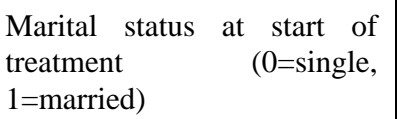 & MARITAL & 0.50 & 0.50 & 0.50 & 0.50 \\
\hline $\begin{array}{l}\text { Unemployed at start of } \\
\text { treatment/at } 6 \text { months }(0=\text { no, } \\
1=\text { yes })\end{array}$ & UNEMPLOY & 0.67 & 0.47 & 0.64 & 0.48 \\
\hline $\begin{array}{l}\text { Amount of debt at start of } \\
\text { treatment/at } 6 \text { months }\end{array}$ & DEBT & 719.00 & 1161.90 & 615.40 & 1530.25 \\
\hline $\begin{array}{l}\text { Number of years in full time } \\
\text { education at start of } \\
\text { treatment }\end{array}$ & EDUCAT & 11.78 & 2.44 & 11.78 & 2.44 \\
\hline $\begin{array}{l}\text { Months addicted to drugs at } \\
\text { start of treatment }\end{array}$ & PERIOD & 64.31 & 65.23 & 64.31 & 65.23 \\
\hline $\begin{array}{l}\text { Injecting drugs at start of } \\
\text { treatment/at } 6 \text { months }(0=\text { no, } \\
1=\text { yes })\end{array}$ & INJECT & 0.72 & 0.45 & 0.70 & 0.46 \\
\hline $\begin{array}{l}\text { Family encouraged criminal } \\
\text { behaviour when subject was } \\
\text { a child ( } 0=\text { no, } 1=\text { yes) }\end{array}$ & FAMCRIM & 0.28 & 1.12 & 0.28 & 1.12 \\
\hline $\begin{array}{l}\text { Severity of familial problems } \\
\text { when subject was a child }\end{array}$ & FAMPROBS & 5.19 & 3.05 & 5.19 & 3.05 \\
\hline $\begin{array}{l}\text { Spent time in Methadone } \\
\text { treatment before current } \\
\text { treatment episode } \quad(0=\text { no, } \\
1=\text { yes })\end{array}$ & PREVMETH & 0.55 & 0.50 & 0.55 & 0.50 \\
\hline $\begin{array}{l}\text { Spent time in residential } \\
\text { rehab before } \\
\text { current } \\
\text { treatment episode } \quad(0=\text { no, } \\
1=\text { yes })\end{array}$ & REVREH & 0.19 & 0.40 & 0.79 & 0.409 \\
\hline $\begin{array}{l}\text { Use of inpatient detox before } \\
\text { current treatment episode } \\
(0=\text { no, } 1=y e s)\end{array}$ & PREVDET & 0.12 & 0.32 & 0.12 & 0.32 \\
\hline $\begin{array}{l}\text { Spent time in prison before } \\
\text { current treatment episode } \\
(0=\text { no, } 1=\text { yes })\end{array}$ & PRISON & 0.38 & 0.50 & 0.38 & 0.50 \\
\hline $\begin{array}{l}\text { Spent time in borstal before } \\
\text { current treatment episode } \\
(0=\text { no, } 1=\text { yes })\end{array}$ & BORSTAL & 0.28 & 0.45 & 0.28 & 0.45 \\
\hline $\begin{array}{l}\text { Number of arrests over } 6 \\
\text { months before start of } \\
\text { treatment } / 6 \text { month interview } \\
(0=\text { no, } 1=\text { yes })\end{array}$ & ARREST & 0.71 & 1.34 & 0.35 & 0.59 \\
\hline $\begin{array}{l}\text { Number of weeks in current } \\
\text { episode of methadone } \\
\text { treatment }\end{array}$ & METHWEEKS & $0.62 *$ & 1.46 & 17.93 & 7.68 \\
\hline
\end{tabular}

* Some subjects had started treatment at the time of the first interview 


\section{RESULTS}

Tables 5 gives details of the results from our estimation of equation 1 . We only report variables obtaining statistical significance at the 5\% level. The number of subjects included in this instance was reduced from a possible maximum of 162 (i.e. 81 subjects measured at two points in time) to 147 due to missing data relating to specific variables and the exclusion of an outlier who reported what were thought to be infeasibly high values of criminal earnings. The estimated equations were sensitive to their inclusion which is unsurprising given the modest sample size that was analysed. Moreover, its inclusion yielded results that were completely counter to prior expectations.

The Hausman specification test carried out for the drug spending regression revealed no evidence of bias resulting from unobservable factors in the random-effects specification $(\chi$ $\left.{ }^{2}=2.82 ; \mathrm{p}=0.88\right)$. The number of weeks spent on a methadone programme is a statistically significant determinant of average daily expenditures on drugs. According with our expectations, the METHWEEKS variable had a negative coefficient: a week spent in methadone treatment predicted to reduce daily expenditures by $6.3 \%$. The $95 \%$ confidence interval around the coefficient on METHWEEKS was $-7.8 \%$ to $-4.8 \%$ suggesting that this estimated effect is reasonably precise.

The other significant determinants of drug expenditures were the subject's age, whether they injected drugs and the amount of earnings generated through illegal activities. Older individuals were predicted to report spending less each day on drugs whilst those who injecting drugs were estimated to spend $56 \%$ more each day on illegal substances than noninjecting individuals. The variables measuring criminal earnings over one month has the expected positive effect on daily drug expenditures, although we would we would add that the its estimated effect could be bias due to the endogeneity problem discussed earlier. This is also likely to be a problem with the injecting status variable given that the method of drug use may be partly determined by how much of a given drug an individual is using. 


\section{Table 5}

Random-effects GLS regression model of log of daily drug expenditures

Number of observations $=147$

Number of subjects $=80$

$\operatorname{chi}^{2}(16)=174.95$

Prob $\mathrm{chi}^{2}=0.0000$

\begin{tabular}{lc}
\hline Variable & Coefficient* (95\% CI) \\
\hline Age (years) & $-0.04(-0.07$ to -0.02$)$ \\
Previous detainment in youth custody & $0.53(0.04$ to 1.03$)$ \\
Injects drugs & $0.56(0.18$ to 0.94$)$ \\
Weeks in methadone treatment & $-0.63(-0.08$ to -0.05$)$ \\
Amount of criminal earnings over 1 month $(\mathfrak{s})$ & $0.2 \times 10^{-3}\left(0.1 \times 10^{-3}\right.$ to $\left.0.3 \times 10^{-3}\right)$ \\
\hline
\end{tabular}

*Natural log of daily drug expenditures used as dependent variable. Coefficients should be interpreted as proportional effects 
Table 6 describes the results for equation 2. Again we only report statistically significant variables. The number of subjects included in the modelling exercise was reduced from a possible maximum of 162 to 148. Again this was due to missing data and the exclusion of the outliers. As already explained, the estimation of this equation involved the employment of the two-stage least squares method combined with a tobit regression. A crucial element of this procedure is the selection of a set of what are termed "instrumental variables" (IVs). IVs should be variables that are determinants of the endogenous variable in question (in this case DRUGEXP in equation 2) but independent of, in this case, the level of reported criminal earnings. The two prime candidates for IVs in this instance were the injecting status of subjects and the number of weeks spent on a methadone the programme. Both were shown to be significant predictors of drug expenditures and preliminary analyses supported the assumption that they were not direct determinants of levels of illegal earnings.

Having conducted the 2-stage least squares censored regression, higher levels of daily expenditure on drugs were found, as expected, to be a significant predictor of higher levels of income generated through crime. An additional pound spent on drugs each day was estimated to increase earnings over one month by $£ 44$. The $95 \%$ confidence interval for the DRUGEXP variables revealed that this was not a particularly precise estimate, ranging from $£ 21$ to $£ 67$.

The only other significant variables in equation 2 were whether a subject had previously been imprisoned and whether in the past they had spent time on a residential rehabilitation programme. Both these variables had coefficients with positive signs and in both cases the estimated effects are large: subjects reporting imprisonment in the past were predicted to have reported criminal earnings over a month that were $£ 865$ higher than subjects with no previous contact with the prison service. Subjects reporting time spent previously on a rehabilitation programme were predicted to monthly criminal earnings that were $£ 1075$ more than subjects with no previous contact with this type of treatment. It is possible that these variables may have been picking up the effects of an unobservable confounding influence, such as latent criminality, although in this instance were unable to specifically test whether this was the case. Whilst this is more obviously a possibility with the PRSION variable, it may also have been the case subjects with more serious anti-social problems have in the past selected themselves for residential rehabilitation.

\section{Table 6}


Two-stage least squares random-effects tobit regression model of criminal earnings over one month

Number of observations $=148$

Number of subjects $=76$

Wald $\operatorname{chi}^{2}(16)=79.23$

Prob $\mathrm{chi}^{2}=0.0000$

79 uncensored observations

69 left-censored observations

Variable

Daily drug expenditure (£s)

Previous imprisonment

Previous treatment in residential rehab programme

\section{Coefficient (95\% CI)}

$44.22(21.12$ to 67.31$)$

864.80 (24.67 to 1704.92$)$

1075.38 (288.21 to 1862.55$)$ 


\section{DISCUSSION}

\section{Study limitations}

Hackney is largely a deprived inner city borough of East London, and to this extent the sample analysed may have been broadly representative of problem drug users attending treatment services in other inner city areas. However, given the non-random nature of the sample and the fact that treatment regimes offered in Hackney may differ from those delivered in other localities it seem unlikely that the results will be wholly applicable treatment populations nationally. The regression models were also based on a relatively small sample of subjects when compared to numbers recruited in other prospective cohort studies, although the treatment of the data as a panel, thereby increasing the number of observations for analysis, to some extent counteracts this problem. Multiple regression analyses on bigger samples may have yielded more precise regression coefficient estimates.

All data is self-report and open to reporting bias, although the use self-report methods is to some extent unavoidable in instances where measures of actual levels of criminal involvement are required. The use of official records will only yield data based on crime detected by the police. Drug expenditure data may also be subject to similar problems although we note that in other studies a close correlation has been found between urine testing and self-reported levels of drug usage (Gossop et al, 1997).

Subjects were only followed up over a 6 month period thus limiting the study to an assessment of how short-term outcomes are linked to variable periods of time spent in treatment. The relationship between time spent on methadone and primary measures of outcome over more extended periods may differ to those reported here. It should also be noted that the regression model of treatment effects assumes that the proportional impact of a week in treatment in linear. An important issue for future research would be to, for example, to determine whether and to what extent treatment effects diminish with time spent in a programme.

\section{Descriptive analyses and model predictions}

Descriptive analyses and simple bi-variate comparisons revealed that over 6 months average reported daily expenditures on drugs and the level of illegal earnings over 1 month both fell substantially. These changes were statistically significant. Statistical modelling of the data 
provided a more rigorous test of whether time spent on a programme of methadone treatment could be linked to there observed reductions in spending on drugs, and to what extent any reductions resulted in the reported fall in earnings from crime.

The results offer encouragement. Lengthier periods in methadone treatment were shown to reduce levels of daily expenditure on drugs, and drug spending was shown to be determinant of higher levels of earnings generated through crime. The coefficient on weeks in treatment from the drug expenditure regression and the coefficient on daily drug expenditure in the criminal earnings regression can be used to predict the indirect effect of time in treatment on monthly criminal earnings. The absolute reduction in daily drug spending arising from the proportional effect of an additional week spent in treatment can be derived using the sample mean level of daily drug spending at intake to treatment ( $£ 45$ per day) as a base. Whilst the proportional effect of treatment in the estimated model is assumed to remain constant over time, the absolute reduction in weekly drug spending per additional treatment will decline given that mean daily expenditures will also fall with increasing time spent in treatment.

If a client remained on methadone for this period, daily drug expenditures are predicted to fall from $£ 45$ to $£ 10$ per day over the follow-up period of the study. Combining this estimated fall of $£ 35$ per day with the coefficient on the drug expenditure variable from the regression model in table 2 yields a predicted reduction in monthly criminal earnings over a 6 month follow-up of $£ 1568$. Building in the statistical uncertainty to these estimates using the $95 \%$ confidence intervals from both regression models, the fall in monthly criminal earnings could range from $£ 714$ to $£ 2626$.

\section{Policy implications}

Time spent in methadone treatment was found to have an important contribution towards reducing daily expenditures on illegal drugs in both statistical and absolute terms. Even if expenditure on street drugs is not completely prevented by access to methadone, the results from the criminal earnings regression model imply that modest reductions in expenditures could still lead to a sizable reduction in income generated through criminal activity. This is consistent with existing evidence on treatment effectiveness with respect to criminal behaviour (Hubbard et al, 1989; Farrell et al, 1994; Gerstein et al, 1994; Powers et al, 1991; Parker and Kirby, 1996, Healey et al, 1999). Thus from a broader social perspective, methadone treatment services appear to offer a potentially viable policy option. 
A recent national outcomes study of drug dependency treatment services has estimated that a week in methadone treatment would cost, on average, in the region of $£ 40$ (1995/96 prices; Healey et al, 1999). Cost is a crucial consideration in service planning where "value for money" takes precedence in decisions over how to allocate limited public resources . Based on this weekly figure, the cost of maintaining someone on methadone for 6 months would be, on average, $£ 960$. Using the predicted range of uncertainty regarding the decrease in monthly criminal earnings over the 6 month study period arising from maintenance on methadone for 6 months ( $£ 714$ to $£ 2626$ ), the accumulated reduction in illegal earnings over the study period is crudely estimated to lie between $£ 2142$ and $£ 7878$. Whilst it should be stressed that criminal earnings are far from an ideal measure of the benefits of crime prevention, this estimate compares favourably with cost. 


\section{REFERENCES}

Agar, M.H. (1973). Ripping and running: a formal ethnography of urban heroin addicts. New York, NY: Seminar Press.

Akerstrom, M. (1985). Crooks and Squares. Lifestyles of Thieves and Addicts in Comparison to Conventional People. New Brunswick. Transaction Books.

Anderson, G.S. \& Nutter, R.W. (1975). Clients and outcomes of a methadone treatment program. International Journal of the Addictions, 10, 937-948.

Anglin, M.D. \& McGlothin, W.H. (1984). Outcome of narcotic addict treatment in California, in: Tims, F.M. \& Ludford, J.P. (Eds) Drug Abuse Treatment Evaluation: strategies, progress \& prospects. NIDA Research Monograph Series No. 51, pp. 106-128 (Rockville, MD, National Institute on Drug Abuse).

Anglin, M.D., \& Speckart, G. (1988). Narcotics use and crime: A multisample, multimethod analysis. Criminology, 26, 197-233.

Anglin, M.D. \& Powers, K.I. (1991). Methadone treatment and legal supervision: individual and joint effect on the behaviour of narcotics addicts. Journal of Applied Behavioural Science, 27, 515-531.

Bale, R.N., Van Stone, W.V., Kuldau, J.M., Engelsing, T.M.J., Elashoff, R.M. \& Zarcone, V.P. (1980). Therapeutic communities vs methadone maintenance: a prospective controlled study of narcotic addiction treatment: design and one-year follow-up. Archives of General Psychiatry, 37, 179-193.

Ball, J.C. \& Corty, E. (1988). Basic issues pertaining to the effectiveness of methadone maintenance treatment. In C.G. Leukefeld, \& F.M. Tims (Eds.), Compulsory treatment of drug abuse: Research and clinical practice (pp. 178-191). (NIDA Research Monograph 86). Rockville, MD: National Institute on Drug Abuse. 
Ball, J.C., Rosen, L., Flueck, J.A. \& Nurco, D.N. (1981). The criminality of heroin addicts: When addicted and when off opiates. In J.A. Inciardi (Ed.), The drugs-crime connection (pp. 39-65). (Sage Annual Reviews of Drug and Alcohol Abuse, Vol. 5). Beverly Hills: Sage.

Ball, J.C., Rosen, L., Flueck, J.A. \& Nurco, D.N. (1982). Lifetime criminality of heroin addicts in the United States. Journal of Drug Issues, 12, 225-239.

Ball, J.C., Shaffer, J.W. \& Nurco, D.N. (1983). The day-to-day criminality of heroin addicts in Baltimore - A study in the continuity of offence rates. Drug and Alcohol Dependence, 12, 119-142.

Bean, P. (1994). Drugs and Crime in Britain: An Overview. Drugs, Education, Prevention and Policy, 1, 93-99.

Bell, J. Digiusto, E., Byth, K. (1992). Who should receive methadone maintenance? British Journal of Addiction, 87, 689-694.

Belsen, W.A. (1975). Juvenile Theft: The Causal Factors (London, Harper \& Row).

Bertschy, G. (1995). Methadone maintenance treatment: an update. European Archives of Psychiatry and Clinical Neuro-science, 245, 114-24.

The Big Issue (1999) Drugs at the sharp end. The Big Issue in the North Trust.

Boudoris, J. (1976). Criminality and addiction. International Journal of the Addictions, 11, 951-966.

Byquist, S. \& Olsson, B. (1998). Male Drug Abuse, Criminality, and Subcultural Affiliation in a Career Perspective. Journal of Psychoactive Drugs, 30, 53-68.

Caplehorn, J.R.M., Bell, J. (1991). Methadone dosage and retention of patients in maintenance treatment. Medical Journal of Australia, 154, 195-199.

Carpenter, C., Glassner, B., Johnson, B.D \& Loughlin, J. (1988). Kids, Drugs, and Crime 
(Lexington, MA, Lexington Books).

Chaiken, J.M. \& Chaiken, M.R. (1982). Varieties of criminal behaviour. Santa Monica: Rand.

Chaiken, M.R. (1983). Crime Rates and Substance Abuse Among Types of Offenders. Interdisciplinary Research Center, Santa Monica, CA.

Cloward, R. \& Ohlin, L. (1960). Delinquency and Opportunity. Glencoe. The Free Press.

Collins, J.J., Hubbard, R.L., Rachal, J.V., Cavanaugh, E.R., Craddock, S.G. \& Kristiansen, P.L. (1982). Criminality in a Drug Treatment Sample: measurement issues and initial findings (Research Triangle Institute, PO Box 12194, NC 27709, U.S.A.).

Collins, J.J., Hubbard, R.L. \& Rachal, J.V. (1985). Expensive drug use and illegal income: A test of explanatory hypotheses. Criminology, 23, 743-764.

Cushman, P. (1971). Methadone maintenance in hard-core criminal addicts: economic effects. New York State Journal of Medicine, 71, 1768-1774.

De Alarcon, R. (1969). The spread of heroin abuse in a community. United Nations Bulletin Narcotics, 21, 17-22.

De Alarcon, R. (1972). An epidemiological evaluation of a public health measure aimed at reducing the availability of methylamphetamine. Psychological Medicine, 2, 293-300.

Desland, M. \& Batey, R. (1990). Criminality of heroin users presenting to an Australian hospital-based drug and alcohol unit. British Journal of Addiction, 85, 795-801.

Dole, V.P., Nyswander, M.E. \& Warner, A. (1968). Successful treatment of 750 criminal addicts. Journal of the American Medical Association, 12, 2708-2711.

DuPont, R.L. (1971). Profile of a heroin addiction epidemic. New England Journal of Medicine, 285, 320-4. 
DuPont, R.L., Greene, M.H. (1973). The dynamics of a heroin addiction epidemic. Science, 181, 716-22.

Elliott, D.S., Huizinga, D. \& Ageton, S.S. (1985). Explaining Delinquency and Drug Use London, Sage.

Farrell, M., Ward, J., Mattick, R., Hall, W., Stimson, G.V., des Jarlais, D., Gossop, M. and Strang, J. (1994) Methadone maintenance treatment in opiate dependence: a review. British Medical Journal ; 30: 997-1001.

Finestone, H. (1957). Cats, kicks and color. Social Problems, 5, 3-13.

Gandossy, R.P., Williams, J.R., Cohen, J. \& Harwood, H.J. (1980). Drugs and Crime: a survey and analysis of the literature (Washington, DC, U.S. Department of Justice) [British Library Ref GP-US/5511].

Gerstein, D.R., Johnson, R.A., Harwood, H.J., Fountain, D., Suter, N. and Malloy, K. (1994) Evaluating Recovery Services: The California Drug and Alcohol Treatment Assessment (CALDATA), general report submitted to the state of California Department of Alcohol and Drug Programs.

Gfroerer, J., Brodsky, M. (1992). The incidence of illicit drug use in the United States, 19621989. British Journal of Addiction, 87, 1345-51.

Giggs, J. (1991). The Epidemiology of Contemporary Drug Abuse, in D. Whynes and P. Bean, eds.; Policing and Prescribing: The British System of Drug Control. London: Macmillan. 
Gossop, M., Marsden, J., Stewart, D., Edwards, C., Lehmann, P., Wilson, A. and Segar, G. (1997). The National Treatment Outcome Research Study in the United Kingdom: sixmonth follow-up outcomes. Psychology of Addictive Behaviours, 11, 324-37.

Gossop, M., Marsden, J., Stewart, D. (1998). NTORS at One Year. The National Treatment Outcome Research Study. Changes in Substance Use, Health and Criminal Behaviour at One Year after Intake. Department of Health.

Grapendall, M. (1992). Cutting their coat according to their cloth: economic behaviour of Amsterdam opiate users. International Journal of the Addictions, 27, 487-501.

Greene, W.H. (1993) Econometric Analysis, McMillan, New York.

Hall, W., Bell, J., Carless, J. (1993). Crime and drug use among applicants for methadone maintenance. Drug and Alcohol Dependence, 31, 123-129.

Hammersley, R.H. \& Morrison, V.L. (1987). Effects of poly-drug use on the criminal activities of heroin users. British Journal of Addiction, 82, pp. 899-906.

Hammersley, R.H., Forsyth, A., Morrison, V. \& Davies, J.B. (1989). The relationship between crime and opioid use. British Journal of Addiction, 84, pp. 1029-1043.

Hammersley, R.H., Forsyth, A, Lavelle, T. (1990). The criminality of new drug users in Glasgow. British Journal of Addiction, 85, 1583-1594.

Hanlon, T.E., Nurco, D.N., Kinlock, T.W. \& Duszynski, K.R. (1990). Trends in criminal activity and drug use over an addiction career. American Journal of Drug and Alcohol Abuse, 16, 223-238.

Hartnoll, R., Lewis, R., \& Bryer, S. (1984). Recent Trends in Drug Use in Britain. Druglink, 19, 22-4.

Hausman, J. (1978). Specification tests in econometrics, Econometrica, 46, 1251-1271. 
Healey, A., Knapp, M., Pacelli, L., Astin, J., Gossop, M., and Marsden, J. (1999). Do Drug Dependency Treatments Prevent Crime? Econometric Evidence from the National Treatment Outcome Research Study (NTORS). Report submitted to the Department of Health.

Hubbard, R.L., Rachal, J.V., Craddock, S.G. \& Cavanaugh, E.R. (1984). Treatment outcome prospective study (TOPS): Client characteristics and behaviours before, during and after treatment. In F.M. Tims, \& J.P. Ludford (Eds.), Drug abuse treatment evaluation: Strategies, progress, and prospects (pp. 42-68). (NIDA Research Monograph 51). Rockville, MD: National Institute on Drug Abuse.

Hubbard, R.L., Marsden, M.E., Rachal, J.V., Harwood, H.J., Cavanaugh, E.R. and Ginzburg, H.M. (1989) Drug Abuse Treatment: A National study of Effectiveness, The University of North Carolina Press.

Hughes, P.H., Crawford, G.A., Barker, N.W. (1971). Developing an epidemiologic field team for drug dependence. Archives of General Psychiatry, 24, 389-93.

Hughes, P.H., Crawford, G.A. (1972). A contagious disease model for researching and intervening in heroin epidemics. Archives of General Psychiatry, 27, 149-55.

Hughes, P.H., Senay, E.C., Parker, R. (1972). The medical management of a heroin epidemic. Archives of General Psychiatry, 27, 585-91.

Hughes, P.H. \& Rieche, O. (1995). Heroin Epidemics Revisited. Epidemiologic Reviews, 17, 66-73.

Hunt, L.G. (1973). Heroin epidemics: a quantitative study of current empirical data. Washington, DC: Drug Abuse Council.

Hunt, D., Lipton, D.S. \& Spunt, B. (1984). Patterns of criminal activity among methadone maintenance clients and current narcotics users not in treatment. Journal of Drug Issues, 14, 687-702.

Inciardi, J. \& Chambers, C.D. (1972). Unreported criminal involvement of narcotic addicts. 
Journal of Drug Issues, 2, 57-64.

Inciardi, J.A. [Ed.] (1981). The Drugs-crime Connection (New York, Sage).

Jacobs, P.E., Doft, E.B. \& Koger, J. (1978). Methadone and criminality: a suburban perspective. American Journal of Drug and Alcohol Abuse, 5, 51-58.

Johnson, B.D., Goldstein, P., Preble, E., et al. Economic Behaviour of Street Opiate Users: Final Report. Narcotic and Drug Research, Inc., New York, 1983.

Johnson, B.D., Goldstein, P.J., Preble, E., Schmeidler, J., Lipton, D.S., Spunt, B. \& Miller, T. (1985). Taking care of Business. The Economics of Crime by Heroin Abusers (Lexington, MA, Lexington Books).

Kaul, B. \& Davidow, B. (1981). Drug use patterns of patients on methadone maintenance treatment in New York City. American Journal of Drug and Alcohol Abuse, 8, 17-25.

Kleber, H.D. (1989). Treatment of drug dependence: What works. International Review of Psychiatry, 1, 81-100.

Kokkevi, A., Ciappas, J., Boukouvala, V., Alevizou, V., Anastassopoulou, E., Stefanis, C. (1993). Criminality in a sample of drug abusers in Greece. Drug and Alcohol Dependence, 31, 111-121.

Kruze, A.M., Harwood, H.J., Kristiansen, P.L., et al (1981). Economic Costs to Society of Alcohol and Drug Abuse and Mental Illness - 1977, Vol. 1, Report. Research Triangle Institute, Research Triangle Park, NC.

Leukefeld, C.G. (1985). The clinical connection: drugs and crime. International Journal of the Addictions, 20, pp. 1049-1064. 
Lipton, D., Martinson, R. \& Wilks, J. (1975). The Effectiveness of Correctional Treatment: A Survey of Treatment Evaluation Studies (New York, Praeger).

Longshore, D., Hsieh, S. \& Anglin, M.D. (1994). Reducing HIV risk behaviour among injection drug users: effect of methadone maintenance treatment on number of sex partners. International Journal of the Addictions, 29, 741-757.

Maddala, G.S. (1983) Limited Dependent and Qualitative Variables in Econometrics, Econometric Society Monographs, Cambridge University Press, Cambridge.

Maddux, J.F. \& McDonald, L.K. (1973). Status of 100 San Antonio addicts one year after admission to methadone maintenance. Drug Forum, 2, 239-252.

Marlatt, G.A. \& George, W.H. (1984). Relapse prevention: Introduction and overview of the model. British Journal of Addiction, 79, 261-273.

Marsch, L.A. (1998). The efficacy of methadone maintenance interventions in reducing illicit opiate use, HIV risk behaviour, and criminality: a meta-analysis. Addiction, 93, 515-532.

Mavis, B.E., DeVoss, G.H. \& Stoffelmayr, B.E. (1991). The perceptions of program directors and clients regarding the efficacy of methadone treatment. International Journal of the Addictions, 26, 769-776.

McGlothin, W.H. \& Anglin, M.D. (1981). Shutting off methadone: costs and benefits. Archives of General Psychiatry, 38, 885-892.

McGlothin, W.H. \& Anglin, M.D. (1981). Long-term follow-up of clients of high- and lowdose methadone programs. Archives of General Psychiatry, 38, 1055-63.

Ministry of Health (1961). Drug Addiction: Report of the Interdepartmental Committee. London: HMSO.

Moore, M.H. (1977). Buy and Bust. Lexington Books, Lexington, MA. 
Mott, J. (1991). Crime and Heroin Use, in D. Whynes and P. Bean, P, eds., Policing and Prescribing: The British System of Drug Control. London: Macmillan.

Nolimal, D. \& Crowley, T.J. (1990). Difficulties in a clinical application of methadone-dose contingency contracting. Journal of Substance Abuse Treatment, 7, 219-224.

Nurco \& Dupont (1977). A preliminary report on crime and addiction within a communitywide population of narcotic addicts. Drug and Alcohol Dependence, 2, 109-121.

Nurco, D.N., Wegner, N., Baum, H., Makofsky, A. (1979). A Case Study: Narcotic Addiction over a Quarter of a Century in a Major American City. U.S. Government Printing Office, Washington, DC.

Nurco, D.N. \& Shaffer, J.W. (1982). Types and characteristics of addicts in the community. Drug and Alcohol Dependence, 9, 43-78.

Nurco, D.N., Shaffer, J.W. \& Ball, J.C. (1984). Trends in the commission of crime among narcotic addicts over successive trends of addiction and non-addiction. American Journal of Drug and Alcohol Abuse, 10, 481-489.

Nurco, D.N., Ball, J.C., Shaffer, J.W. \& Hanlon, T.E. (1985). The criminality of narcotics addicts. Journal of Nervous and Mental Disease, 173, pp. 94-102.

Nurco, D.N. (1987). Drug addiction and crime: a complicated issue. British Journal of Addiction, 82, 7-9.

Nurco, D.N., Hanlon, T.E., Balter, M.B. et al (1991). A classification of narcotic addicts based on type, amount and severity of crime. Journal of Drug Issues, 21, 429-448. 
Parker, H., \& Kirby, P. (1996). Methadone Maintenance and Crime Reduction on Merseyside, Crime Prevention and Protection Series Paper 72, Police Research Group, Home Office.

Parker, H. \& Aldridge, J. (1996). Drugs Futures: Changing Patterns of Drug Use Amongst English Youth. London: Institute for the Study of Drug Dependence.

Parker, H. \& Newcombe, R. (1987). Heroin Use and Acquisitive Crime in an English Community. British Journal of Sociology, 3, 331-50.

Paxton, R., Mullin, P. \& Beattie, J. (1978). The effects of methadone maintenance with opioid takers: a review of some findings from one British city. British Journal of Psychiatry, 132, 473-481.

Pearson, G. (1987). The New Heroin Users. Oxford: Basil Blackwell.

Pescor, M.J. (1943). A statistical analysis of the clinical records of hospitalised drug addicts. Public Health Reports Supplement. 143.

Powers, K., Hanssens, D.M., Hser, Y. and Anglin, M.D. (1991). Measuring the long-term effects of public policy: the case of narcotics use and crime. Management Science, 37, 627644.

Preble, E. \& Casey, J. (1969). Taking care of business - the Heroin User's Life on the Streets. International Journal of the Addictions, 4, 1-24.

Preble, E. \& Casey, J.J. (1969). Taking care of business: the heroin user's life on the streets. International Journal of the Addictions, pp. 1-24.

Sechrest, D.K. (1979). Methadone programmes and crime reduction: a comparison of New York and California addicts. International Journal of Addictions, 14, 377-400. 
Sells, S.B., Demaree, R. \& Hornick, C. (1980). Comparative effectiveness of drug abuse treatment modalities. (NIDA Services Research Report). Rockville, MD: National Institute on Drug Abuse.

Shaffer, J.W., Nurco, D.N., Kinlock, T.W. (1984). A new classification of narcotic addicts based on type and extent of criminal activity. Comprehensive Psychiatry, 25, 315-328.

Shapiro, H. (1996). Heroin in the '90's: From A to B. Druglink, 11, 3: 8-9.

Simpson, D.D., Joe, G.W., Lehman, W.E.K. \& Sells, S.B. (1986). Addiction careers: Etiology, treatment, and 12-year follow-up outcomes. Journal of Drug Issues, 16, 107-121.

Simpson, D.D. \& Sells, S.B. (1982). Evaluation of drug abuse treatment effectiveness: Summary of the DARP followup research. (NIDA Treatment Research Report). Rockville, MD: National Institute on Drug Abuse.

Stimpson, G.V. (1973). Heroin and Behaviour. New York. John Wiley.

Strain, E.C., Stitzer, M.L., Liebson, I.A. \& Bigelow, G.E. (1993). Methadone dose and treatment outcome. Drug and Alcohol Dependence, 33, 105-117.

Strain, E.C., Stitzer, M.L., Liebson, I.A. \& Bigelow, G.E. (1993). Dose-response effects of methadone in the treatment of opioid dependence. Annals of Internal Medicine, 119:23.

Sutter, A.G. (1966). The world of the righteous dope fiend. Issues in Criminology, 2, 177222.

Terry, C.E. and Pellens, M. (1928). The Opium Problem. New York. The Haddon Craftsman. 
Tutt, N. (1982). An overview of intervention with young offenders: The political and legal contexts, in: P. Feldman (Ed.) Development in the Study of Criminal Behaviour, Volume 1: The prevention and Control of Offending (London, Wiley).

U.S. Department of Justice (1983). Report to the Nation on Crime and Justice: The Data. National Criminal Justice Reference Service, Rockville, MD.

Weppner, R.S. (1982). Status and role among narcotic addicts: Implications for treatment personnel. International Journal of Offender Therapy and Comparative Criminology, 25, 233-247.

West, D.J. \& Farrington, D.P. (1977). The Delinquent Way of Life (London, Heinemann).

Wish, E. (1982). Are Heroin Users Really Nonviolent? Paper presented at the Meeting of the Academy of Criminal Justice Sciences, Louisville, March.

Wish, E., Klumpp, K.A., Moorer, A.H., et al (1980). An Analysis of Drugs and Crime Among Arrestees in the District of Columbia. National Technical Information Service, Springfield, VA. 